\title{
X-Ray Scattering and Coarse-Grained Simulations for Clustering and Interactions of Monoclonal Antibodies at High Concentrations
}

Barton J. Dear ${ }^{\mathrm{a}}$, Jonathan A. Bollinger ${ }^{\mathrm{a}, \mathrm{b}}$, Amjad Chowdhury ${ }^{\mathrm{a}}$, Jessica J. Hung ${ }^{\mathrm{a}}$, Logan R.

Wilks ${ }^{\mathrm{a}}$, Carl A. Karouta ${ }^{\mathrm{a}}$, Kishan Ramachandran ${ }^{\mathrm{a}}$, Tony Y. Shay ${ }^{\mathrm{a}}$, Maria P. Nieto ${ }^{\mathrm{a}}$, Ayush

Sharma $^{\mathrm{a}}$, Jason K. Cheung ${ }^{\mathrm{c}}$, Dmytro Nykypanchuk ${ }^{\mathrm{d}}$, P. Douglas Godfrin ${ }^{\mathrm{e}}$, Keith P.

Johnston $^{* a}$ and Thomas M. Truskett*a,f

a. McKetta Department of Chemical Engineering, The University of Texas at Austin, Austin, TX 78712, United States

b. Center for Integrated Nanotechnologies, Sandia National Laboratories, Albuquerque, NM 87185, United States

c. Biophysical and Biochemical Characterization, Sterile Formulation Sciences, Merck \& Co., Inc., Kenilworth, NJ 07033 USA

d. Center for Functional Nanomaterials, Brookhaven National Laboratory, Upton, NY 11973, United States

e. Department of Chemical Engineering, Massachusetts Institute of Technology, Cambridge, MA 02139, United States

f. Department of Physics, The University of Texas at Austin, Austin, TX 78712, United States

*Corresponding authors:

Keith P. Johnston - Phone: (512) 471-4617_email: johnston@ che.utexas.edu

Thomas M. Truskett - Phone: (512) 471-6308 email: truskett@ che.utexas.edu 
Table of Contents

Section S1: Additional Details on mAb Sample Preparation and SAXS

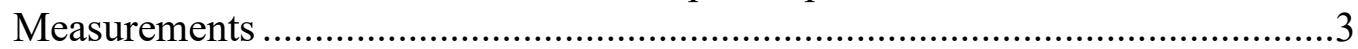

Section S2: Low Concentration SAXS Measurements and Fits .................................

Section S3: Comparison of SAXS and SLS Results for mAb2 ...............................11

section S4: S(Q) for both mabs in additional co-solute systems ..............................12

Section S5: High Concentration SAXS with Hard Sphere Yukawa Fits....................14

Section S6: Simulations with a Different P(q): $\mathrm{mAb} 4: \mathrm{NaCl}(\mathrm{B})$ instead of

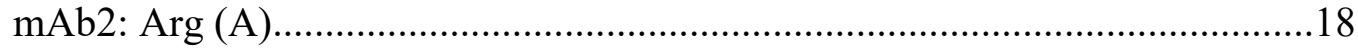

Section S7: Comparison of Interaction Potentials with those from Studies of other 12 Bead Models .................................................................................. 19

Section S8: Real Space Visualizations of Bead Model Simulations .........................21

Section S9: Results For All Bead Models at $125 \mathrm{mg} / \mathrm{ml}$ with Additional K

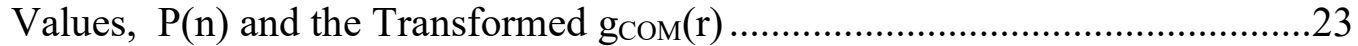

Section S10: FabFab1 Model Discussion .............................................................30

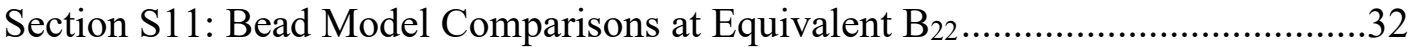

Section S12: Effect of mAb Concentration on Simulations ......................................36

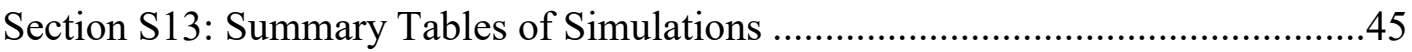

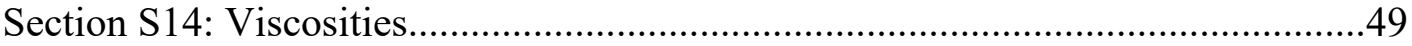

Section S14.1: Viscosity Experimental Details ………….............................49

Section S14.2 Modeling Viscosities by Ross-Minton Equation....................52

Section S14.3 Modeling Viscosities by Entanglement Model .......................55

Section S14.4 Modelling Viscosities by Kastelic Model .............................58

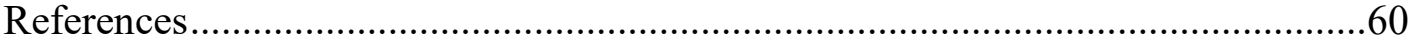




\section{Section S1: Additional Details on mab Sample Preparation and SAXS Measurements}

The mAb2 solutions were prepared by centrifugal diafiltration into $30 \mathrm{mM}(\mathrm{Na})$ Ace buffer at $\mathrm{pH} 5.5$ followed by centrifugal ultrafiltration as described in previous work. ${ }^{1}$ After ultrafiltration $2.5 \mathrm{M}$ solutions of cosolute were mixed with $500 \mathrm{mM}(\mathrm{Na})$ Ace at $\mathrm{pH} 5.5$ and DI water to achieve a solution that was added directly to small aliquots of the mAb solution to achieve the target final co-solute concentration (typically $250 \mathrm{mM}$ ) while maintaining $30 \mathrm{mM} \mathrm{Na}$ (Ace) buffer and simultaneously achieving the target $\mathrm{mAb}$ concentration. The mAb4 samples were made by the same process, except that prior to the diafiltration the samples were concentrated via centrifugal ultrafiltration to $\sim 50 \mathrm{mg} / \mathrm{ml}$, the diafiltration buffer was $30 \mathrm{mM} \mathrm{His}(\mathrm{HCl})$ at $\mathrm{pH} 6$ and the co-solutes were added to mAb4 solutions during diafiltration, as in previous work, ${ }^{1-2}$ to improve permeation and stability during filtration ${ }^{3}$ as mAb4 was known to be highly viscous and unstable. The mAb solution concentrations were measured by UV-vis spectroscopy identically to the procedure in previous work, using Beer's law at $280 \mathrm{~nm}$ with a path length of $1 \mathrm{~cm}$, and respective extinction coefficients of 1.42 and 1.44 $\mathrm{ml} / \mathrm{mg} / \mathrm{cm}$ for $\mathrm{mAb} 2$ and $\mathrm{mAb} 4 .^{2-3}$ Note the mAb4 solutions are not concentrated to as high concentration as those for mAb2 as the samples stopped permeating during filtration. 

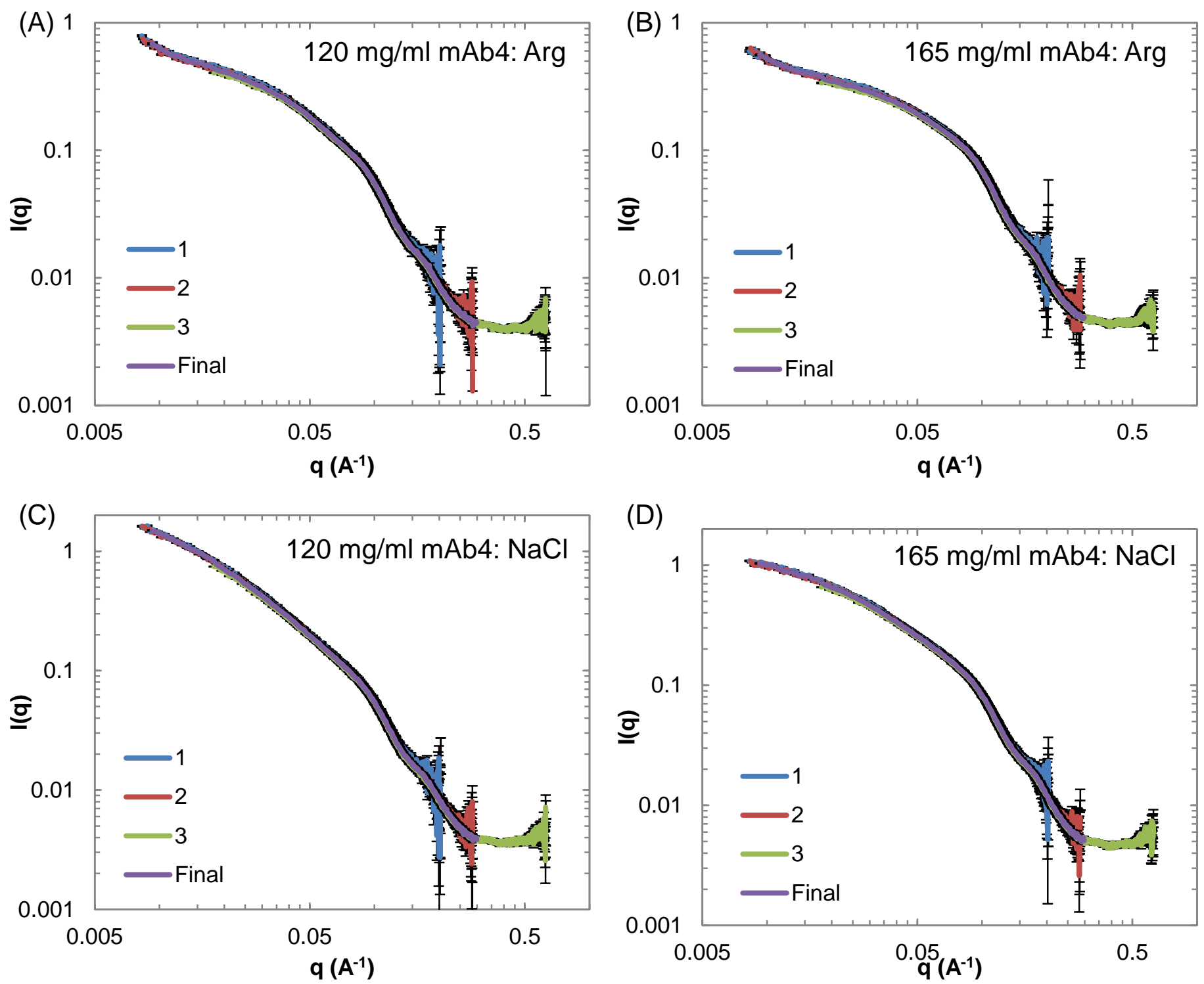

Figure S1.1. Measured intensity versus $q$ (before solvent subtraction) of all $\mathrm{mAb} 4$ solutions $>5 \mathrm{mg} / \mathrm{ml}$ for each of three $q$-ranges tested (1,2 and 3) as well as for the weighted average of the three ranges, which was used for all subsequent data (Final). The $I(q)$ values are for (A) mAb4: Arg at $120 \mathrm{mg} / \mathrm{ml},(\mathrm{B}) \mathrm{mAb} 4:$ Arg at $165 \mathrm{mg} / \mathrm{ml}$, (C) $\mathrm{mAb} 4: \mathrm{NaCl}$ at $120 \mathrm{mg} / \mathrm{ml}$, and (D) $\mathrm{mAb} 4: \mathrm{NaCl}$ at $165 \mathrm{mg} / \mathrm{ml}$. The Final $I(q)$ for a given $q$ value was calculated by the following formula: $I(q)_{\text {Final }}=I(q)_{1} w_{1}+I(q)_{2} w_{2}+I(q)_{3} w_{3}$, where $\mathrm{W}_{\mathrm{i}}$ are the weight factors that equal 0 if $I(q)$ was not measured for that $q$ in $q$-range $i$, and are otherwise calculated by $w_{i}=\frac{\sum_{i=1}^{3} e_{i}}{e_{i}}$ with $e_{i}$ is the instrumental error of measurement as calculated by the SAXSLab software and represented visually by the error bars. 


\section{SECTION S2: Low CONCENTRATION SAXS MEASUREMENTS ANd Fits}

The following section contains the size measurements of the different low concentration SAXS measurements from Guinier analysis as mentioned in the text, as well as the actual form factor, P(q), data and best fit bead model fits. Visualizations of each bead model fit are also shown, along with the calculated decoupling function, $\beta(q)$, from the bead model fit. Finally, the dimensions and actual bead positions are presented for each bead model fit of $\mathrm{P}(\mathrm{q})$.

Table S2.1. Radius of gyration, $\mathrm{R}_{\mathrm{g}}$, from Guinier Analysis and Maximum dimension, $\mathrm{D}_{\max }$, from real space form factor, $\mathrm{p}(\mathrm{r})$, calculated from the measured frequency space form factor, $\mathrm{P}(\mathrm{q})$, of $\mathrm{mAb}$ samples at $5 \mathrm{mg} / \mathrm{ml}$. The $\mathrm{B}_{22}$ is also reported from SLS measurements and for $\mathrm{mAb} 2$ solutions are identical to values in previously published, ${ }^{4}$ while for mAb4 solutions were measured by the same procedure as the mAb2 solutions. The $\mathrm{B}_{22} / \mathrm{B}_{22, \mathrm{St}}$ is the measured value of $\mathrm{B}_{22}$ divided by the calculated $\mathrm{B}_{22}$ of the steric only simulation $(\mathrm{K}=0)$ from this work.

\begin{tabular}{|c|c|c|c|c|}
\hline Sample & $\mathbf{R g}_{\mathbf{g}}(\mathbf{n m})$ & $D_{\max }(\mathbf{n m})$ & $B_{22}(\mathrm{ml} / \mathrm{g})$ & $\mathrm{B}_{22} / \mathbf{B}_{22, \mathrm{St}}$ \\
\hline mAb4: $\mathrm{NaCl}$ & 4.6 & 12.0 & -9.16 & -0.93 \\
\hline mAb4: Arg & 5.1 & 12.7 & -0.77 & -0.08 \\
\hline mAb2: $\mathrm{NaCl}$ & 4.9 & 12.3 & -1.43 & -0.14 \\
\hline mAb2: Arg & 5.3 & 12.3 & 3.56 & 0.36 \\
\hline mAb2: None & 4.4 & 12.0 & 9.35 & 0.95 \\
\hline mAb2: $50 \mathrm{NaCl}$ & 5.0 & 12.4 & -0.14 & -0.01 \\
\hline
\end{tabular}



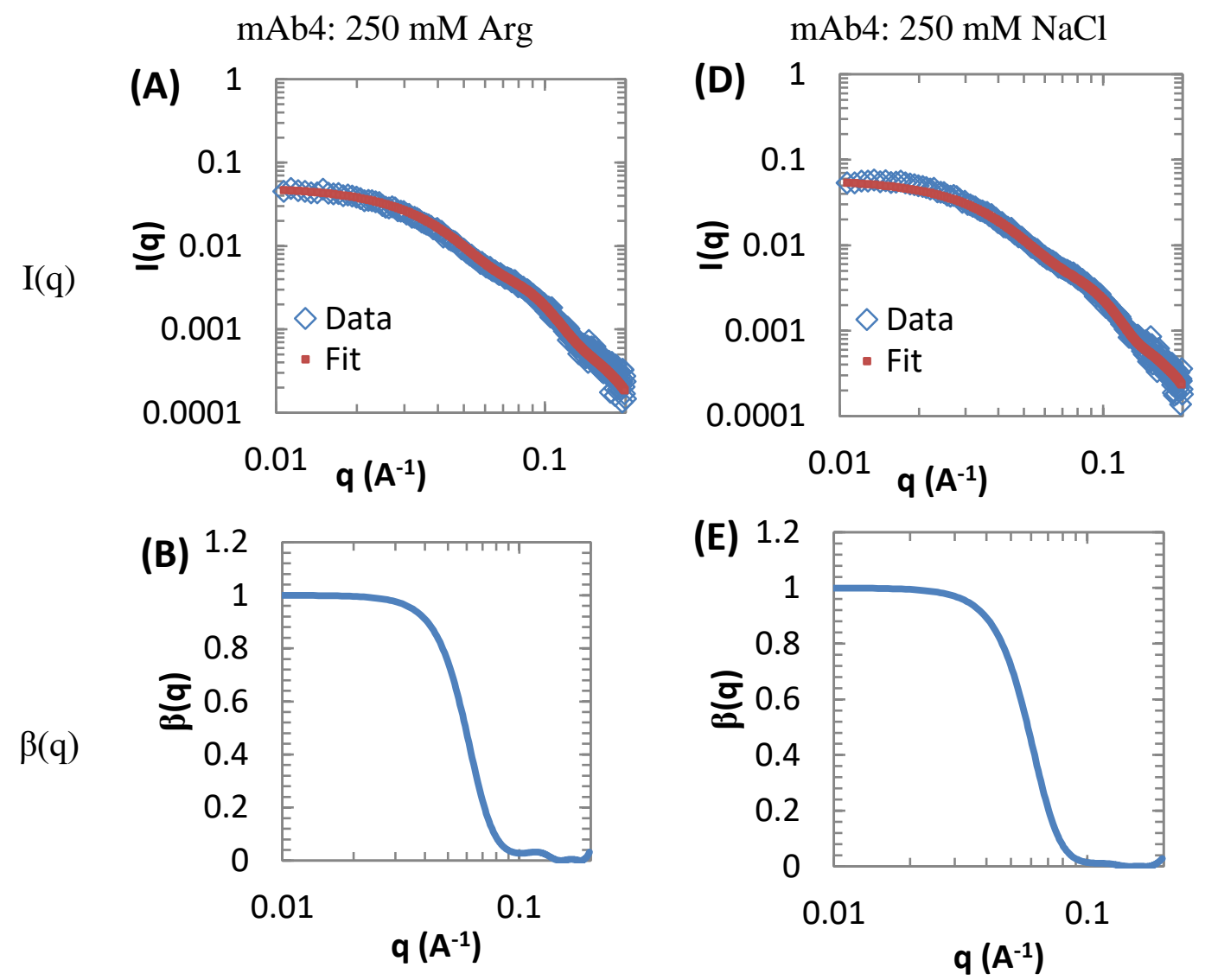

12-

(C)

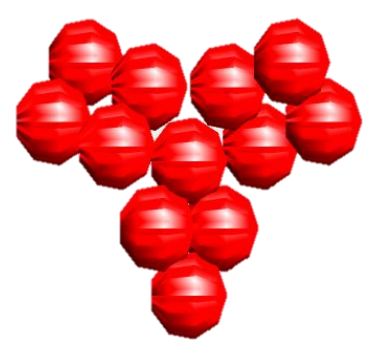

(F)

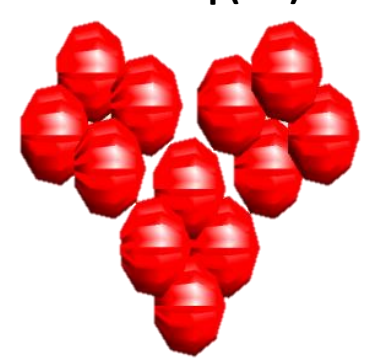



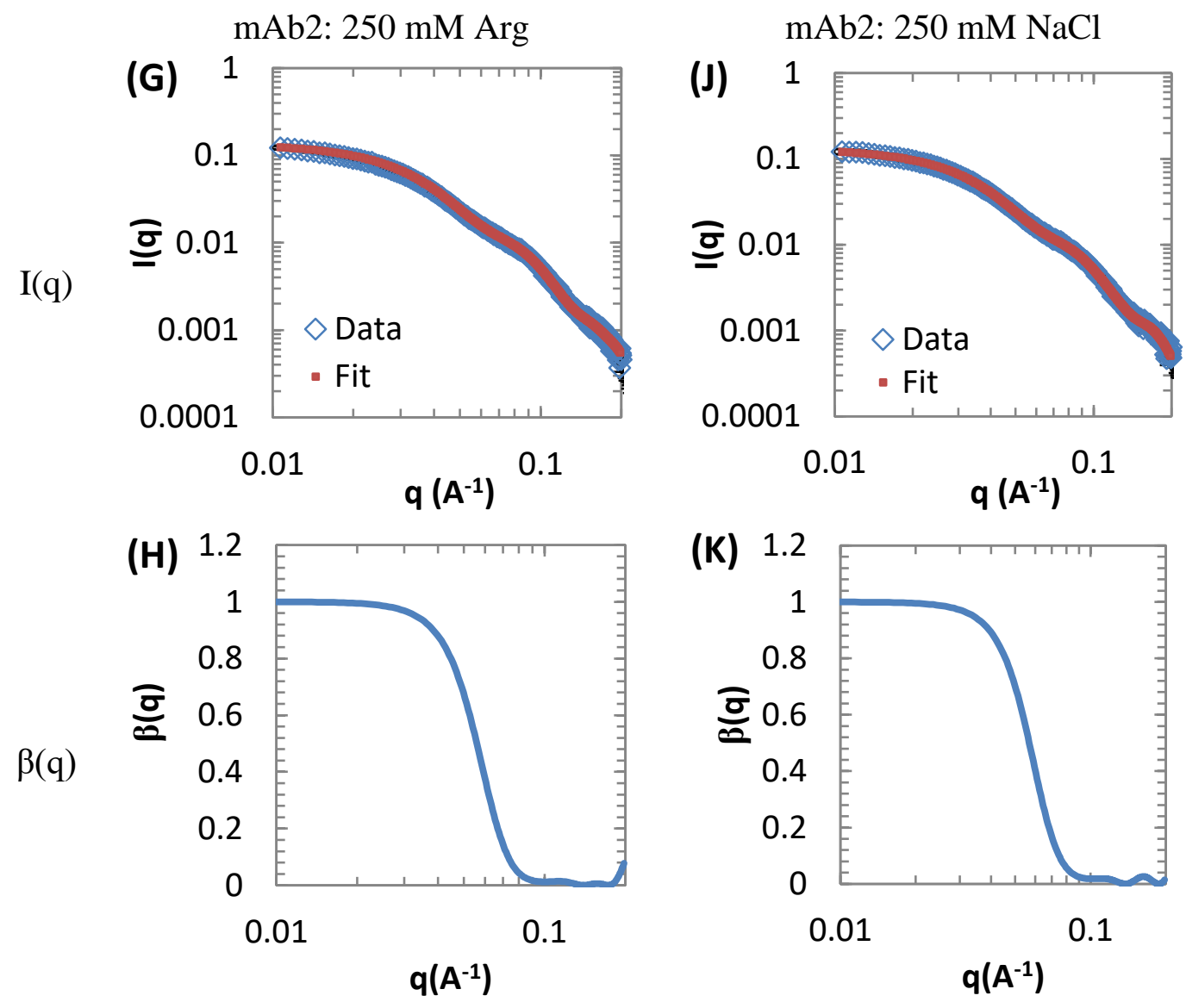

$12-$

(I)

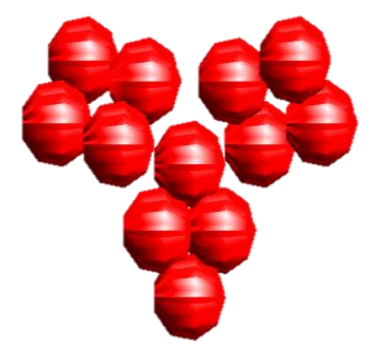

(L)

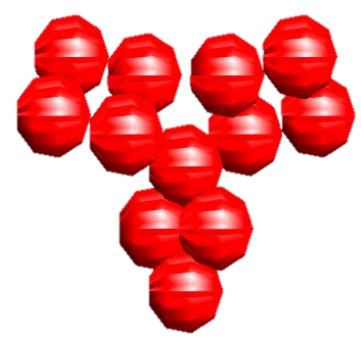



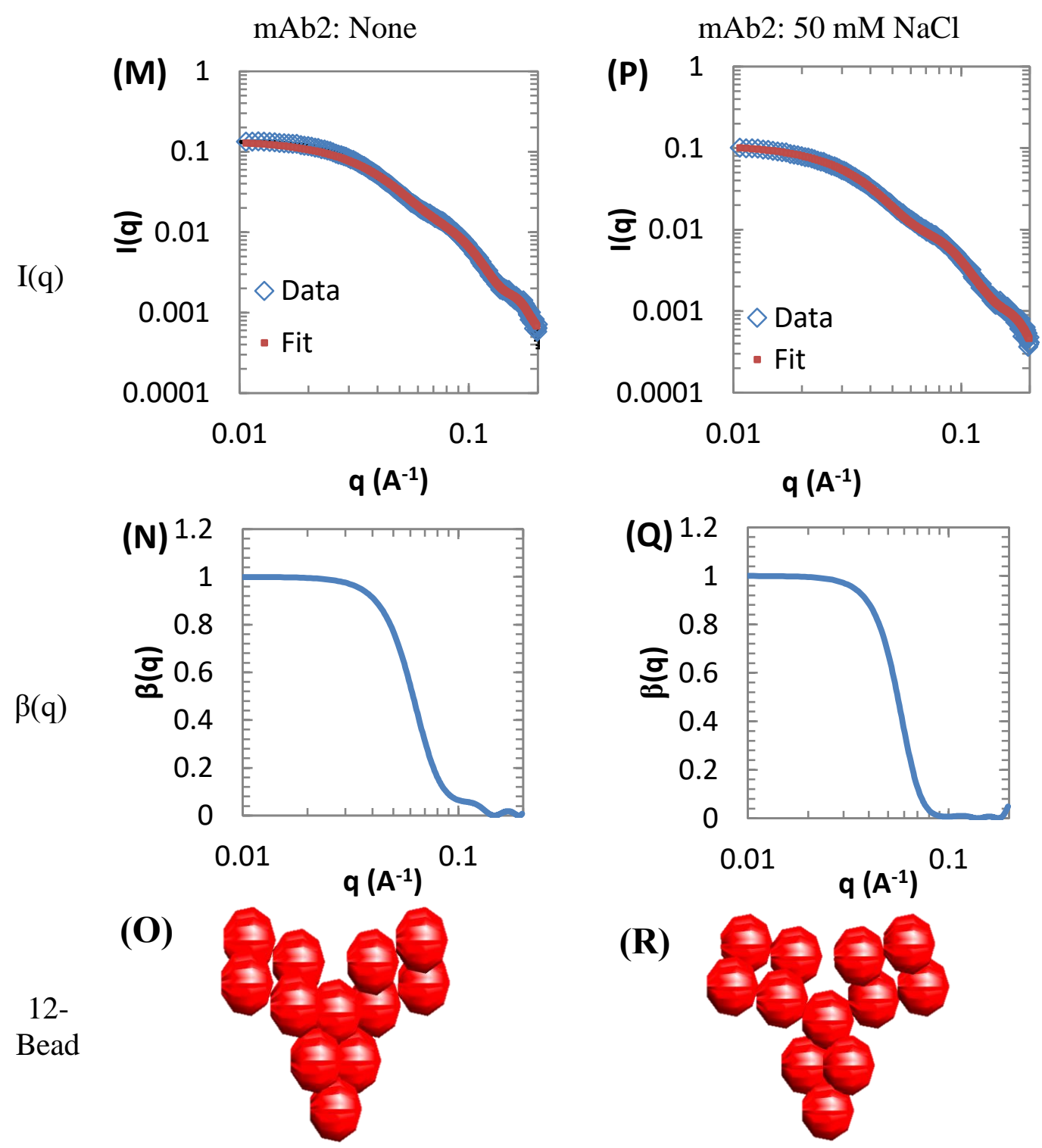

Figure S2.1. Form factor data and 12 bead model fits for mAb2 and mAb4 at $5 \mathrm{mg} / \mathrm{ml}$. (A), (B) and(C) show the measured and fit I(q) from SAXS for $5 \mathrm{mg} / \mathrm{ml} \mathrm{mAb4}$ with $250 \mathrm{mM} \mathrm{Arg}$, the $\beta(\mathrm{q})$ calculated from the fit to $\mathrm{I}(\mathrm{q})$, and a visual representation of the bead model fit to the I(q) data, respectively. (D), (E) and (F) show these same properties for the $5 \mathrm{mg} / \mathrm{ml} \mathrm{mAb4}$ solution with $250 \mathrm{mM} \mathrm{NaCl}$ at $5 \mathrm{mg} / \mathrm{ml}$, while (G), (H) and (I) show these for the $5 \mathrm{mg} / \mathrm{ml} \mathrm{mAb2}$ solution with $250 \mathrm{mM} \mathrm{Arg}$, and (J), (K) and (L) show these for the $5 \mathrm{mg} / \mathrm{ml} \mathrm{mAb2}$ solution with $250 \mathrm{NaCl},(\mathrm{M}),(\mathrm{N})$ and $(\mathrm{O})$ for $5 \mathrm{mg} / \mathrm{ml} \mathrm{mAb2}$ with no co-solute, and $(\mathrm{P}),(\mathrm{Q})$ and $(\mathrm{R})$ for 5 $\mathrm{mg} / \mathrm{ml} \mathrm{mAb2}$ with $50 \mathrm{mM} \mathrm{NaCl}$. 
Table S2.2. Properties of best fit 12 bead structures from SAXS data as well as Dodeca model from CaleroRubio, et al $\{$ Calero-Rubio, 2016 \#1241\}. Fab-Fab and Fab-Fc COM separations are shown visually in Fig. S2.2.

\begin{tabular}{|l|c|c|c|c|c|c|c|}
\hline & $\begin{array}{c}\mathrm{mAb} 2: \\
\mathrm{Arg}\end{array}$ & $\begin{array}{c}\mathrm{mAb} 2: \\
\mathrm{NaCl}\end{array}$ & $\begin{array}{c}\mathrm{mAb} 2: \\
\mathrm{None}\end{array}$ & $\begin{array}{c}\mathrm{mAb} 2: \\
50 \mathrm{NaCl}\end{array}$ & $\begin{array}{c}\text { mAb4: } \\
\text { Arg }\end{array}$ & $\begin{array}{c}\text { mAb4: } \\
\mathrm{NaCl}\end{array}$ & $\begin{array}{c}\text { Calero-Rubio } \\
\text { Dodeca }\end{array}$ \\
\hline $\begin{array}{l}\text { Bead Diameter, } \\
\mathrm{d}_{\mathrm{B}}(\mathrm{nm})\end{array}$ & 3.5 & 3.5 & 3.2 & 3.5 & 3.5 & 3.5 & 3.5 \\
\hline $\begin{array}{l}\text { Fab-Fab COM Separation, } \\
\mathrm{d}_{\text {Fab-Fab }}(\mathrm{nm})\end{array}$ & 8.4 & 8.1 & 8.0 & 8.1 & 7.8 & 7.2 & 9.2 \\
\hline $\begin{array}{l}\text { Fab-Fc COM Separation, } \\
\mathrm{d}_{\text {Fab-Fc }}(\mathrm{nm})\end{array}$ & 6.5 & 6.7 & 5.7 & 6.7 & 6.2 & 6.3 & 8.3 \\
\hline
\end{tabular}

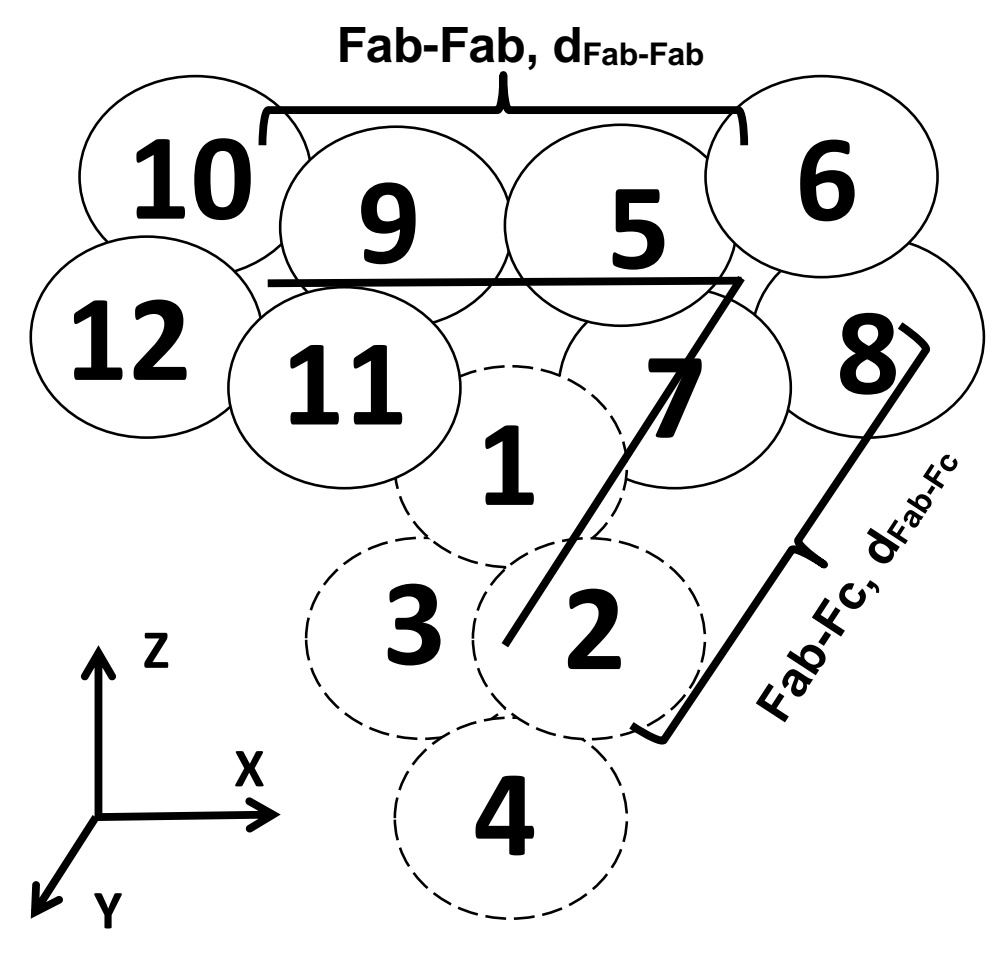


Figure S2.2. Visualization of 12 bead structure. Numbers on beads represent numbering in Table S2.3. X, Y and $\mathrm{Z}$ axes are used for Table S2.3. The distances between Fab regions and Fab and Fc region $\left(\mathrm{d}_{\mathrm{Fab}-\mathrm{Fab}}\right.$ and $\mathrm{d}_{\mathrm{Fab}}$ Fc, respectively) are used in Table S2.2. The All4 model has attractions on all 12 beads, while the All1 model has attractions on beads 4, 6 and 10, and FabFab1 only has attractions on beads 6 and 10 .

Table S2.3. Locations of bead centers for each best fit 12 bead structure. Positions are relative to the COM of the 12 bead structure. Bead numbers and X, Y and Z coordinates match those in Fig. S2.2.

\begin{tabular}{|c|c|c|c|c|c|c|c|c|c|c|c|c|c|c|c|c|c|c|}
\hline \multirow{2}{*}{$\begin{array}{l}\text { Bead } \\
\text { No. }\end{array}$} & \multicolumn{3}{|c|}{ mAb2: Arg } & \multicolumn{3}{|c|}{ mAb2: $\mathrm{NaCl}$} & \multicolumn{3}{|c|}{ mAb2: None } & \multicolumn{3}{|c|}{ mAb2: 50 NaCl } & \multicolumn{3}{|c|}{ mAb4: Arg } & \multicolumn{3}{|c|}{ mAb4: $\mathrm{NaCl}$} \\
\hline & $\mathbf{x}$ & $\mathbf{y}$ & $\mathbf{Z}$ & $\mathbf{x}$ & $\mathbf{y}$ & $\mathbf{Z}$ & $\mathbf{x}$ & $\mathbf{y}$ & $\mathbf{z}$ & $\mathbf{x}$ & $\mathbf{y}$ & $\mathbf{Z}$ & $\mathbf{x}$ & $\mathbf{y}$ & $\mathbf{Z}$ & $\mathbf{x}$ & $\mathbf{y}$ & $\mathbf{Z}$ \\
\hline 1 & 0.0 & 0.0 & -0.7 & 0.0 & 0.0 & -0.9 & 0.0 & 0.0 & -0.5 & 0.0 & 0.0 & -0.9 & 0.0 & 0.0 & -0.6 & 0.0 & 0.0 & -0.9 \\
\hline 2 & 1.5 & 0.3 & -3.3 & 1.1 & -1.0 & -3.6 & 1.2 & 0.6 & -2.7 & 1.1 & -1.0 & -3.6 & 1.4 & 0.5 & -3.2 & 1.1 & 0.9 & -3.5 \\
\hline 3 & -1.4 & -0.2 & -3.3 & -1.1 & 1.1 & -3.6 & -1.1 & -0.7 & -2.7 & -1.1 & 1.1 & -3.6 & -1.4 & -0.5 & -3.2 & -1.1 & -1.0 & -3.5 \\
\hline 4 & 0.0 & 0.0 & -5.9 & 0.0 & 0.0 & -6.3 & 0.0 & 0.0 & -5.0 & 0.0 & 0.0 & -6.3 & 0.0 & 0.0 & -5.8 & 0.0 & 0.0 & -6.0 \\
\hline 5 & 2.1 & 0.0 & 2.5 & 2.0 & 0.0 & 2.6 & 2.2 & 0.0 & 1.9 & 2.0 & 0.0 & 2.6 & 1.8 & 0.0 & 2.3 & 1.5 & 0.0 & 2.5 \\
\hline 6 & 5.0 & -1.8 & 3.3 & 5.0 & -1.7 & 3.3 & 5.1 & 0.8 & 2.9 & 5.0 & -1.7 & 3.3 & 4.6 & -1.8 & 3.2 & 4.8 & -0.5 & 3.4 \\
\hline 7 & 3.4 & 0.9 & 0.0 & 3.1 & 1.0 & 0.3 & 2.3 & 2.0 & -0.1 & 3.1 & 1.0 & 0.3 & 3.2 & 1.0 & 0.0 & 2.4 & 1.5 & 0.1 \\
\hline 8 & 6.3 & -0.8 & 0.8 & 6.1 & -0.6 & 1.0 & 5.3 & 2.8 & 0.9 & 6.1 & -0.6 & 1.0 & 6.0 & -0.9 & 0.9 & 5.7 & 1.0 & 1.0 \\
\hline 9 & -2.1 & 0.0 & 2.5 & -2.0 & 0.0 & 2.6 & -2.2 & 0.0 & 1.9 & -2.0 & 0.0 & 2.6 & -1.8 & 0.0 & 2.3 & -1.5 & 0.0 & 2.5 \\
\hline 10 & -5.0 & 1.8 & 3.3 & -5.0 & 1.6 & 3.3 & -5.1 & -0.8 & 2.9 & -5.0 & 1.6 & 3.3 & -4.6 & 1.8 & 3.2 & -4.8 & 0.5 & 3.4 \\
\hline 11 & -3.3 & -0.9 & 0.0 & -3.1 & -1.0 & 0.3 & -2.4 & -1.9 & -0.1 & -3.1 & -1.0 & 0.3 & -3.2 & -1.0 & 0.0 & -2.4 & -1.5 & 0.1 \\
\hline 12 & -6.3 & 0.8 & 0.8 & -6.1 & 0.6 & 1.0 & -5.3 & -2.8 & 0.9 & -6.1 & 0.6 & 1.0 & -6.0 & 0.9 & 0.9 & -5.7 & -1.0 & 1.0 \\
\hline
\end{tabular}




\section{SECTION S3: COMPARISON OF SAXS AND SLS RESULTS FOR MAB2}

As discussed in the main text the $\mathrm{S}(0)$ from SAXS measurements quantitatively agree with those from SLS measurements of the same mAb solutions. ${ }^{4}$

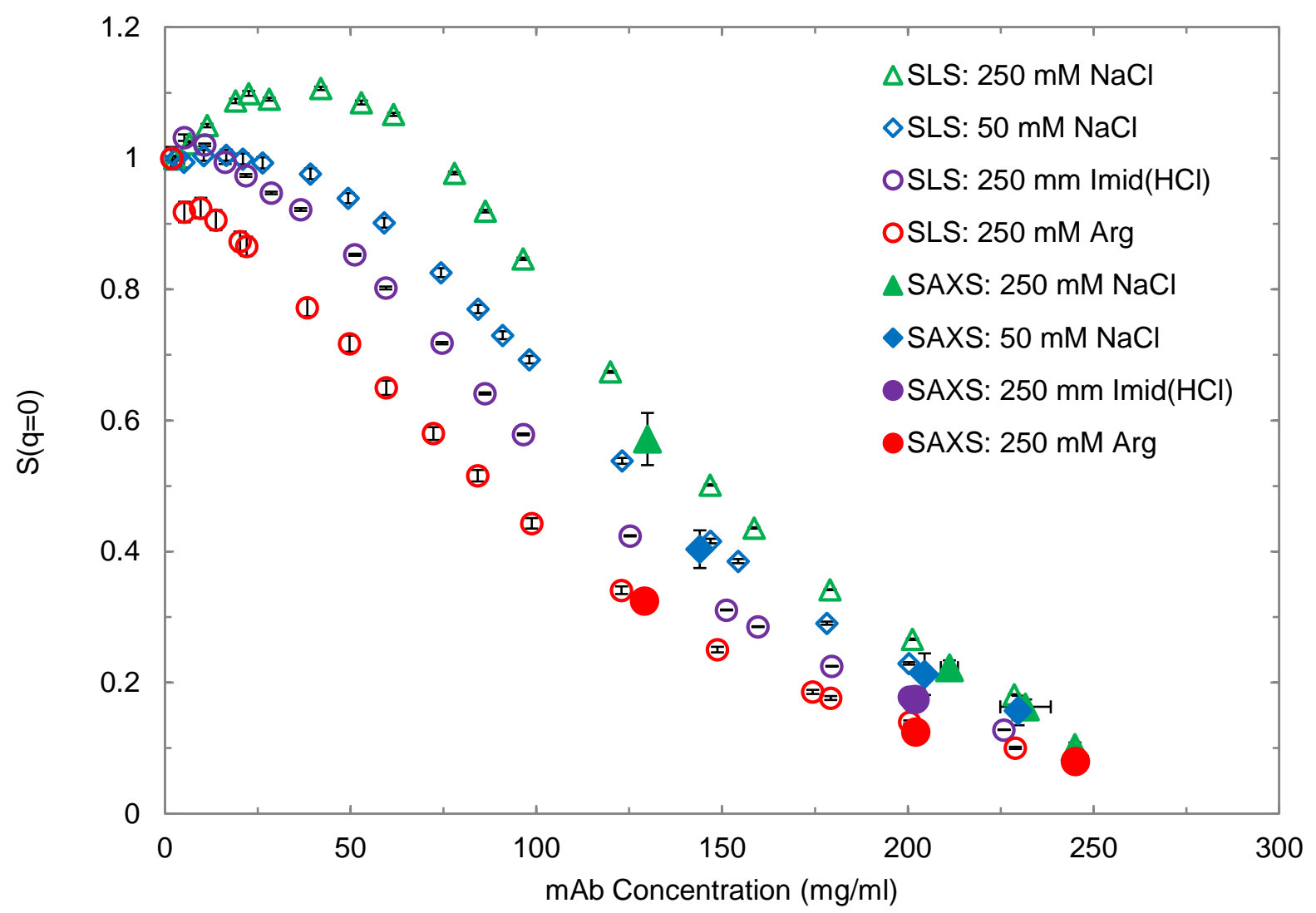

Figure S3.1. Comparisons of $S(q=\sim 0)$ for $S A X S$ and SLS results for $m A b 2$ with various co-solutes. For the SAXS measurements $q=0.0092 \mathrm{~A}^{-1}$, while for SLS $q=0.0002 \mathrm{~A}^{-1}$. SLS data are reported in previous work. ${ }^{4}$ 


\section{SECTiOn S4: S(Q) FOR Both MABS In AdDitional Co-SOLUTE SystemS}

This section presents $\mathrm{S}_{\mathrm{eff}}(\mathrm{q})$ of both $\mathrm{mAbs}$ in different co-solute systems and in the same system at different ionic strengths. Fig. S4.1 demonstrates that the co-solute identity and concentration can be manipulated to obtain a wide range of solution structure, such as upturns at low $\mathrm{q}<0.02$, for both $\mathrm{mAbs}$. The effect of different co-solutes on the solution structure can be analyzed by comparing with the no co-solute control ("None"). Fig. $\mathrm{S} 4.2$ shows the effect of increasing ionic strength on $\mathrm{S}_{\text {eff }}(\mathrm{q})$ for $\mathrm{mAb} 2$ is minor for $\mathrm{NaCl}$ concentrations beyond $250 \mathrm{mM}$.
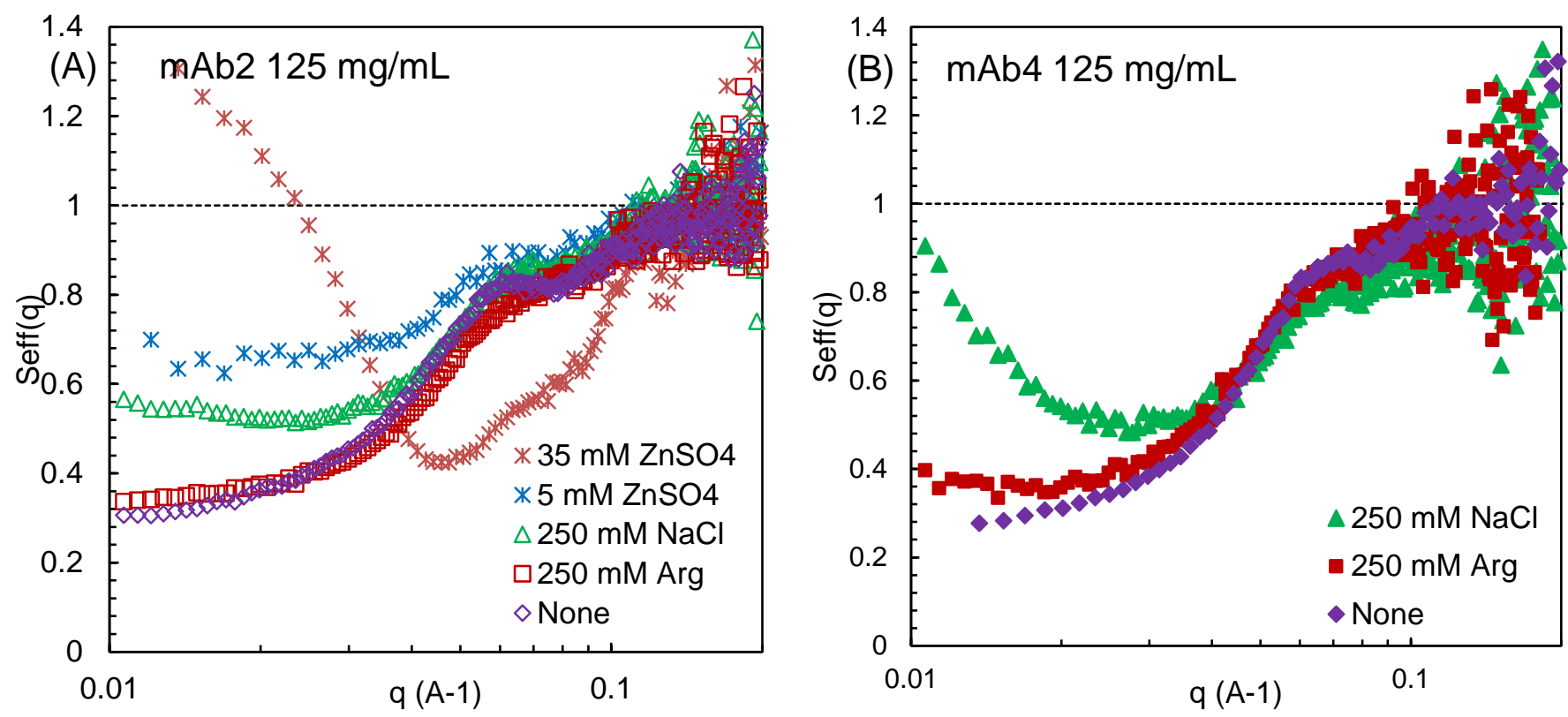

Figure S4.1. $S_{\text {eff }}(q)$ for solutions of (A) $\mathrm{mAb} 2$ at $125 \mathrm{mg} / \mathrm{mL}$ and (B) $\mathrm{mAb} 4$ at $125 \mathrm{mg} / \mathrm{mL}$ in various co-solute systems. Here, "None" refers to the mAb in its respective buffer without additional co-solute (30 mM (Na)Ace for $\mathrm{mAb} 2$ and $30 \mathrm{mM} \mathrm{His}(\mathrm{HCl})$ for $\mathrm{mAb} 4)$. 


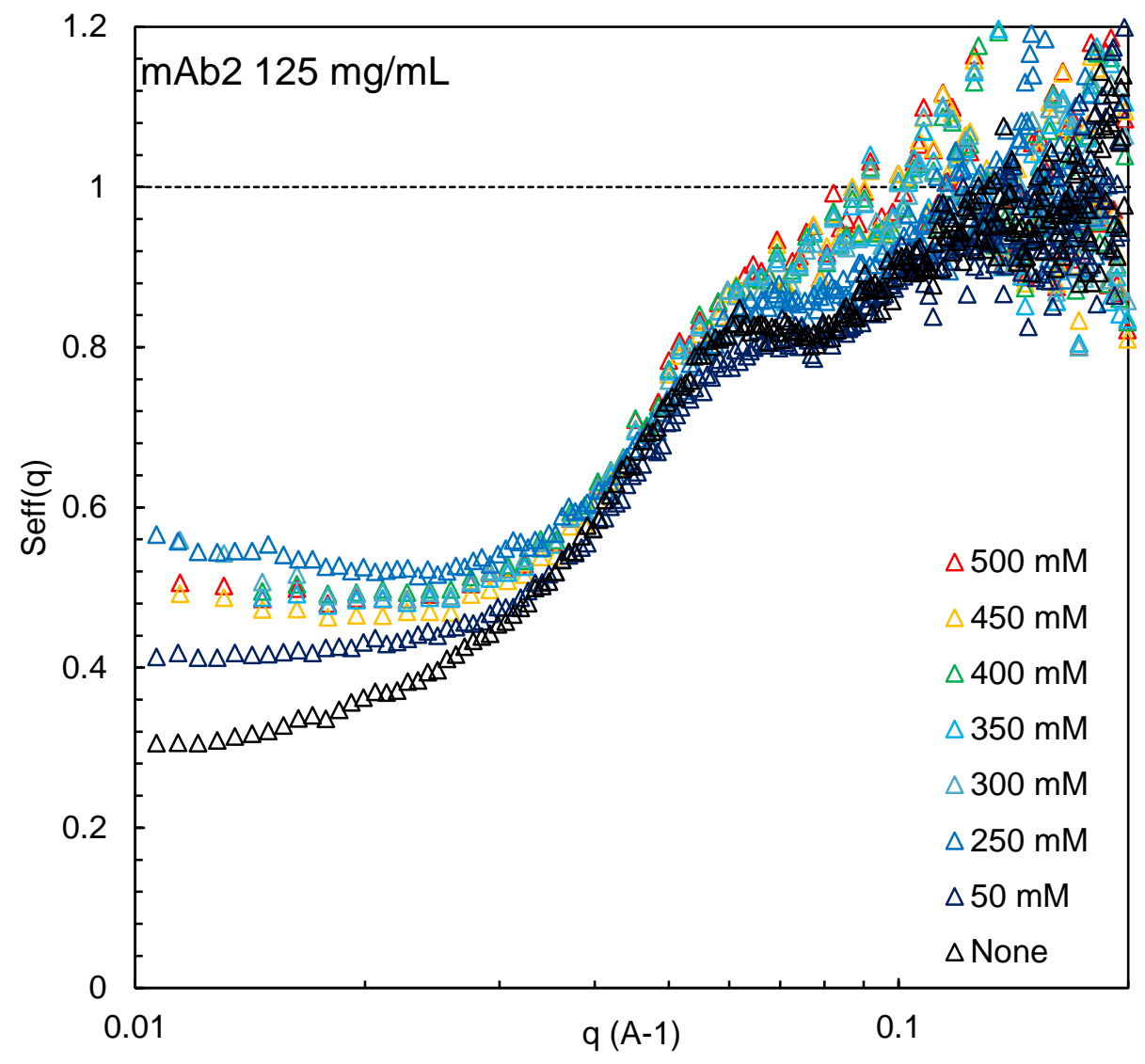

Figure S4.2. $\mathrm{S}_{\text {eff }}(\mathrm{q})$ for $\mathrm{mAb} 2$ at $125 \mathrm{mg} / \mathrm{mL}$ in solutions with various amounts of $\mathrm{NaCl}$ added, from $0 \mathrm{mM}$ to $500 \mathrm{mM}$. 


\section{SECTION S5: High CONCENTRATION SAXS WiTh HARD SPHERE YUKAWA FitS}

The $S_{\text {eff }}(q)$ of a HS potential with $(d=9 \mathrm{~nm})$, shown in Fig. 2, is more repulsive (lower) than the actual data at low q. To model attractions in addition to steric repulsion, each measured $S_{\text {eff }}(q)$ was fit with a spherically isotropic HSY potential (Eqn 2) to yield a first approximation of mAb PPI. Here, a large peak is observed at $\sim 0.06 \mathrm{~A}^{-1}$ or Bragg length of $\sim 10 \mathrm{~nm}$, corresponding to a COM separation similar to the assumed sphere diameter. Unlike spheres, the asymmetric Y-shaped mAbs pack at a series of different length scales, effectively smearing out this peak into a shoulder, as has been seen for many mAbs, ${ }^{5-10}$ and ellipsoidal particles. ${ }^{11}$ Therefore, the HSY model was only fit to $S_{\text {eff }}(q)$ at low q below $0.04 \mathrm{~A}^{-1}$, where it effectively captures the q-dependence over these length scales. The data were also fit at higher mAb concentrations (Fig. S5.1). As was the case for mAb2 solutions, increasing the mAb concentration decreased $S_{\text {eff }}(q)$ for all mAb4 systems, while simultaneously causing them to partially converge. Additionally, the upward curvature in $S_{\text {eff }}(q)$ at low q decreased with $\mathrm{mAb}$ concentration.

As stated in the main text, the best fit $\mathrm{K}$ and $\mathrm{Z}$ for the HSY potentials of mAb2 had characteristic attraction length scales of $\sim 0.7 \mathrm{~nm}$, while those of mAb4 were $\sim 2.25$ to $3 \mathrm{~nm}$. However, most mAb attractions such as vdW, hydrophobic and hydrogen bonding forces are short-ranged $(\sim 0.5 \mathrm{~nm}){ }^{7,10,12-15}$ Anisotropic electrostatic attraction should also be shorter than the solution Debye length $\left(\sim 0.6 \mathrm{~nm}\right.$ in these systems), ${ }^{16}$ making the attraction range of fits to the mAb4 systems unphysical. Similarly long-ranged attractions have been fit to the highly viscous mAbs, GmAb3, and GmAb1 with spherical models, fitting ranges of 1.3 and $4 \mathrm{~nm}$ corresponding to respective solutions with respective Debye lengths of $0.8^{7}$ and $2.3 \mathrm{~nm} .{ }^{10}$ One possible reason why isotropic models may require unphysically long-range attractions to fit certain mAbs is that the attractive regions may be far away from the mAb COM (such as the CDRs). Thus, the distance from the COM is well beyond the length scale of $\sim 0.5 \mathrm{~nm}$ for the actual surface interactions, which would be consistent with the fit length scale of $Z^{-1} \sim 3 \mathrm{~nm}$, as is shown visually in Fig. S5.2. Because the fit values of $Z$ are very different between the two mAbs, the potentials cannot be directly compared by $\mathrm{K}$; therefore, the $\mathrm{B}_{22}$ was calculated for each best fit potential from the integral form of Eqn 4 and is shown in Table S5.1 along with the hard sphere normalized $\mathrm{B}_{22}, \mathrm{~B}_{22} / \mathrm{B}_{22, \mathrm{HS}}$ (with $\mathrm{B}_{22, \mathrm{HS}}=2 \pi \mathrm{d}^{3} / 3$ ). The fit $\mathrm{B}_{22}$ values qualitatively resemble those measured by SLS at dilute (<25 mg/ml) conditions from previous work, ${ }^{17}$ (in Table S5.1) as mAb2: Arg is the least attractive and mAb4: $\mathrm{NaCl}$ is the most attractive. The low concentration measurements indicate $\mathrm{mAb} 2 \mathrm{NaCl}$ as more 
attractive than mAb4: Arg, but this order is reversed for the high concentration fits. Also, the high concentration fits of $\mathrm{B}_{22}$ are consistently higher (less attractive) than those from SLS at low concentration possibly indicating a lower tendency for alignment of attractive sites at higher concentration.

Table S5.1. Parameters of measured $S_{\text {eff }}(q)$ and best fit hard sphere attractive Yukawa potentials to $S_{\text {eff }}(q)$ data for $\mathrm{mAb} 2$ and $\mathrm{mAb} 4$ with $250 \mathrm{mM}$ of listed co-solutes. Values of $\mathrm{B}_{22}$ from SLS mAb data at low concentration are obtained from previous work. ${ }^{17}$ Properties calculated from HSY fits are labeled 'Fit' in the table.

\begin{tabular}{|c|c|c|c|c|c|c|c|c|c|}
\hline $\mathrm{mAb}$ & $\begin{array}{c}\mathrm{Co}- \\
\text { solute }\end{array}$ & $\begin{array}{c}\mathrm{B}_{22} \\
(\mathrm{ml} / \mathrm{g})\end{array}$ & $\begin{array}{c}\mathrm{mAb} \\
\mathrm{Conc} \\
(\mathrm{mg} / \mathrm{ml})\end{array}$ & $\mathrm{S}(0)$ & $\begin{array}{c}\text { Slope (A) } \\
\mathrm{S}\left(\mathrm{q}<0.015 \mathrm{~A}^{-1}\right)\end{array}$ & $\begin{array}{c}\text { Fit } \\
\mathrm{K}\end{array}$ & $\begin{array}{c}\text { Fit } \\
\mathrm{Z}\end{array}$ & $\begin{array}{c}\text { Fit } \mathrm{B}_{22} \\
(\mathrm{ml} / \mathrm{g})\end{array}$ & $\begin{array}{c}\text { Fit } \\
\mathrm{B}_{22} / \mathrm{B}_{22, \mathrm{HS}}\end{array}$ \\
\hline $\mathrm{mAb2}$ & $\mathrm{Arg}$ & 3.56 & 125 & 0.34 & 4.2 & 1.15 & 13 & 3.74 & 0.61 \\
\hline $\mathrm{mAb} 2$ & $\mathrm{Arg}$ & 3.56 & 200 & 0.13 & 2.2 & 0.75 & 13 & 4.72 & 0.77 \\
\hline $\mathrm{mAb} 2$ & $\mathrm{Arg}$ & 3.56 & 250 & 0.08 & 1.3 & 0.85 & 13 & 4.54 & 0.74 \\
\hline $\mathrm{mAb2}$ & $\mathrm{NaCl}$ & -1.43 & 125 & 0.57 & -3.0 & 2.1 & 13 & 0.25 & 0.04 \\
\hline $\mathrm{mAb} 2$ & $\mathrm{NaCl}$ & -1.43 & 200 & 0.22 & 0.76 & 2.1 & 13 & 0.25 & 0.04 \\
\hline $\mathrm{mAb} 2$ & $\mathrm{NaCl}$ & -1.43 & 250 & 0.10 & 0.61 & 1.2 & 13 & 3.62 & 0.59 \\
\hline $\mathrm{mAb4}$ & $\mathrm{Arg}$ & -0.77 & 125 & 0.40 & -8.5 & 0.6 & 3 & -0.61 & 0.10 \\
\hline $\mathrm{mAb} 4$ & $\mathrm{Arg}$ & -0.77 & 165 & 0.25 & -4.9 & 0.7 & 3 & -0.49 & -0.08 \\
\hline $\mathrm{mAb} 4$ & $\mathrm{NaCl}$ & -9.16 & 125 & 0.90 & -58 & 1.4 & 4 & -5.03 & -0.82 \\
\hline $\mathrm{mAb} 4$ & $\mathrm{NaCl}$ & -9.16 & 165 & 0.42 & -17 & 1 & 3 & -3.92 & -0.64 \\
\hline
\end{tabular}



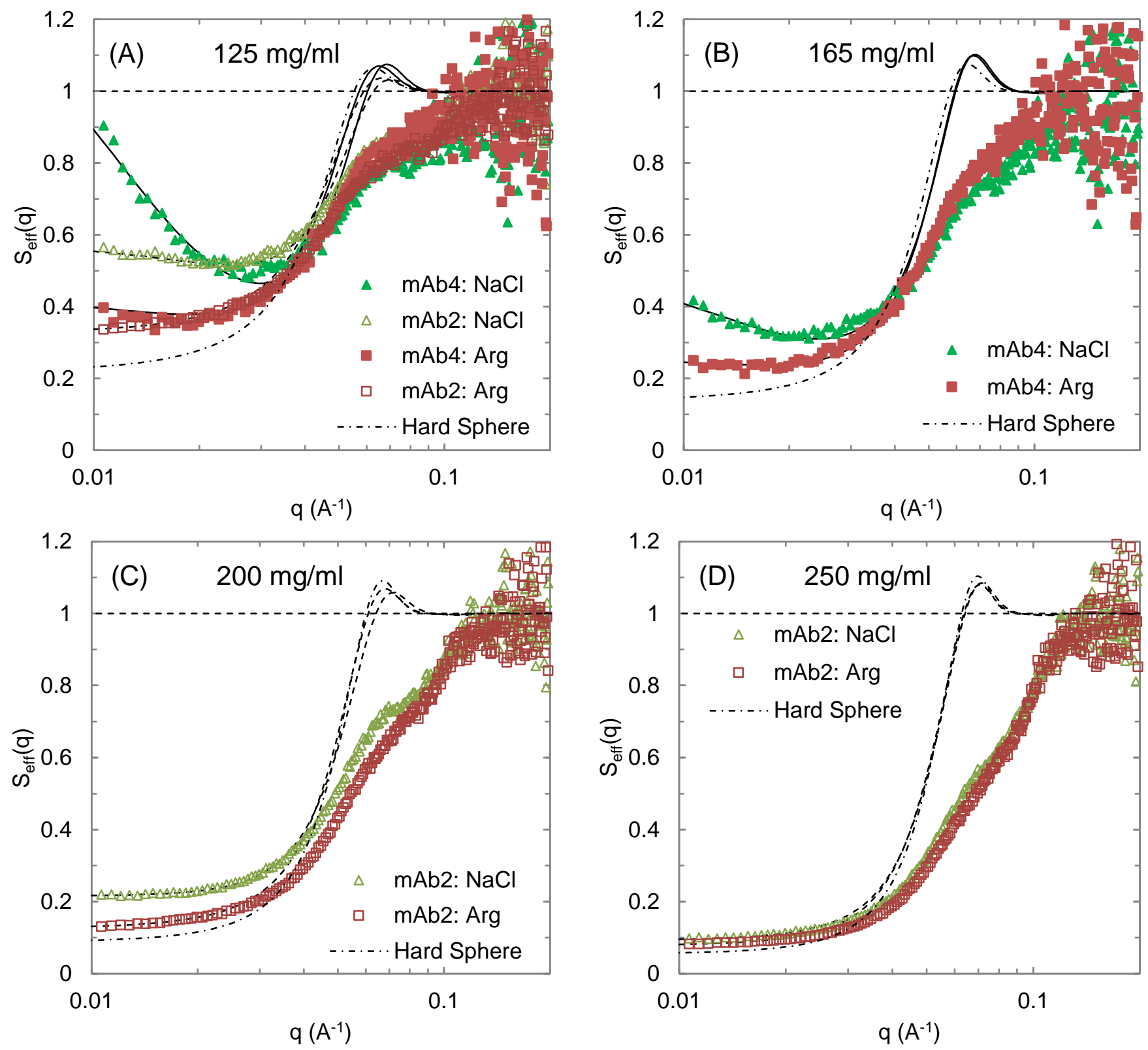

Figure S5.1. $S_{\text {eff }}(q)$ for solutions of mAb2 and mAb4 at (A) $125 \mathrm{mg} / \mathrm{ml}$, (B) $165 \mathrm{mg} / \mathrm{ml}$, (C) $200 \mathrm{mg} / \mathrm{ml}$, and (D) $250 \mathrm{mg} / \mathrm{ml} \mathrm{mAb}$ with $250 \mathrm{mM}$ of listed co-solutes. Lines (other than the black dashed line) are fits to the data using a hard sphere attractive Yukawa potential. The black dashed line is $\mathrm{S}_{\text {eff }}(\mathrm{q})$ for a hard sphere. All spherical fits (HS and HSY) have a diameter of $9 \mathrm{~nm}$. 


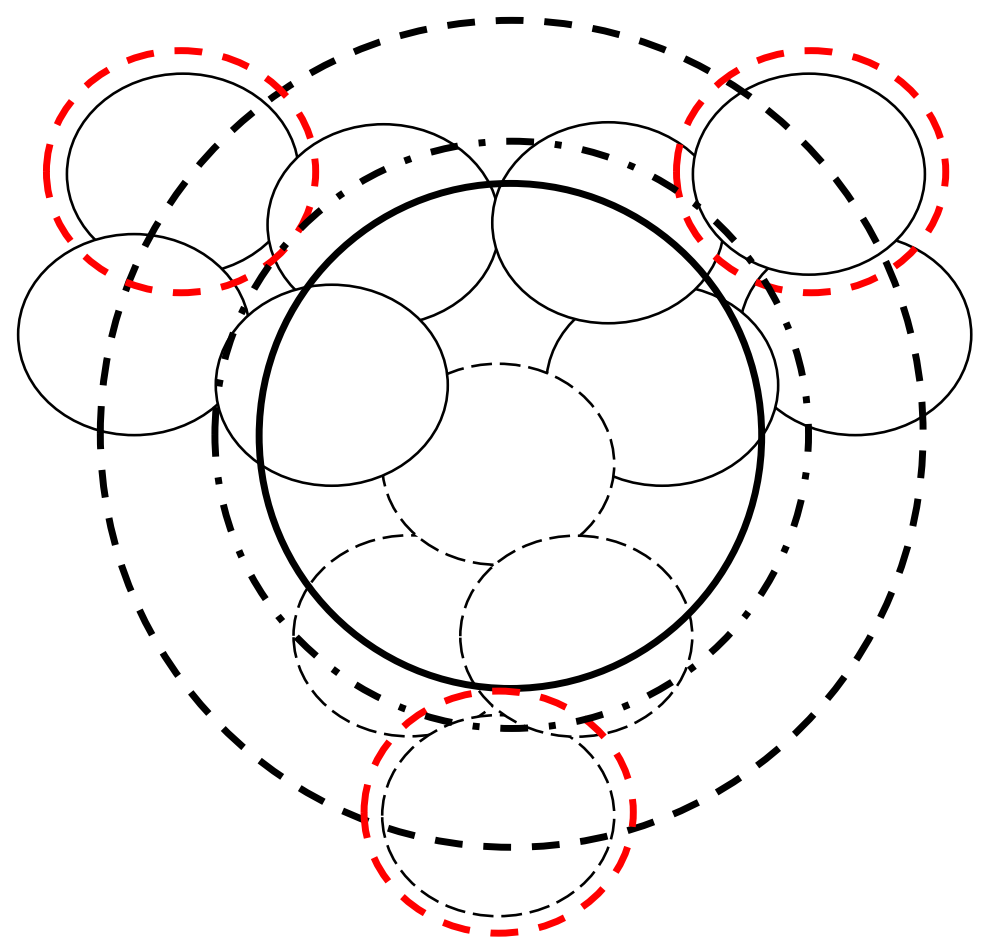

Figure S5.2. Best fit bead structure of mAb2: Arg from $\mathrm{P}(\mathrm{q})$ overlaid with a $9 \mathrm{~nm}$ sphere (solid black line). The black dash-dot line indicates a physically relevant short-range attraction, while the black dashed line indicates an unphysically long range $3 \mathrm{~nm}$ attraction. As can be seen the $3 \mathrm{~nm}$ attraction is required to reach lengths similar to the beads at the Fab and Fc tips, such that if these regions are attractive (indicated by red dashed line) the unphysically long-range attraction may better mimic the behavior than the short-ranged attraction. 


\section{Section S6: Simulations With a Different P(Q): MAB4: NaCl (B) instead of MAb2: Arg (A)}

As mentioned in the main text, and depicted in Fig. S6.1 the simulations of the high concentration data mAbs are not very sensitive to the bead structure in the form factor, for (A) and (B)

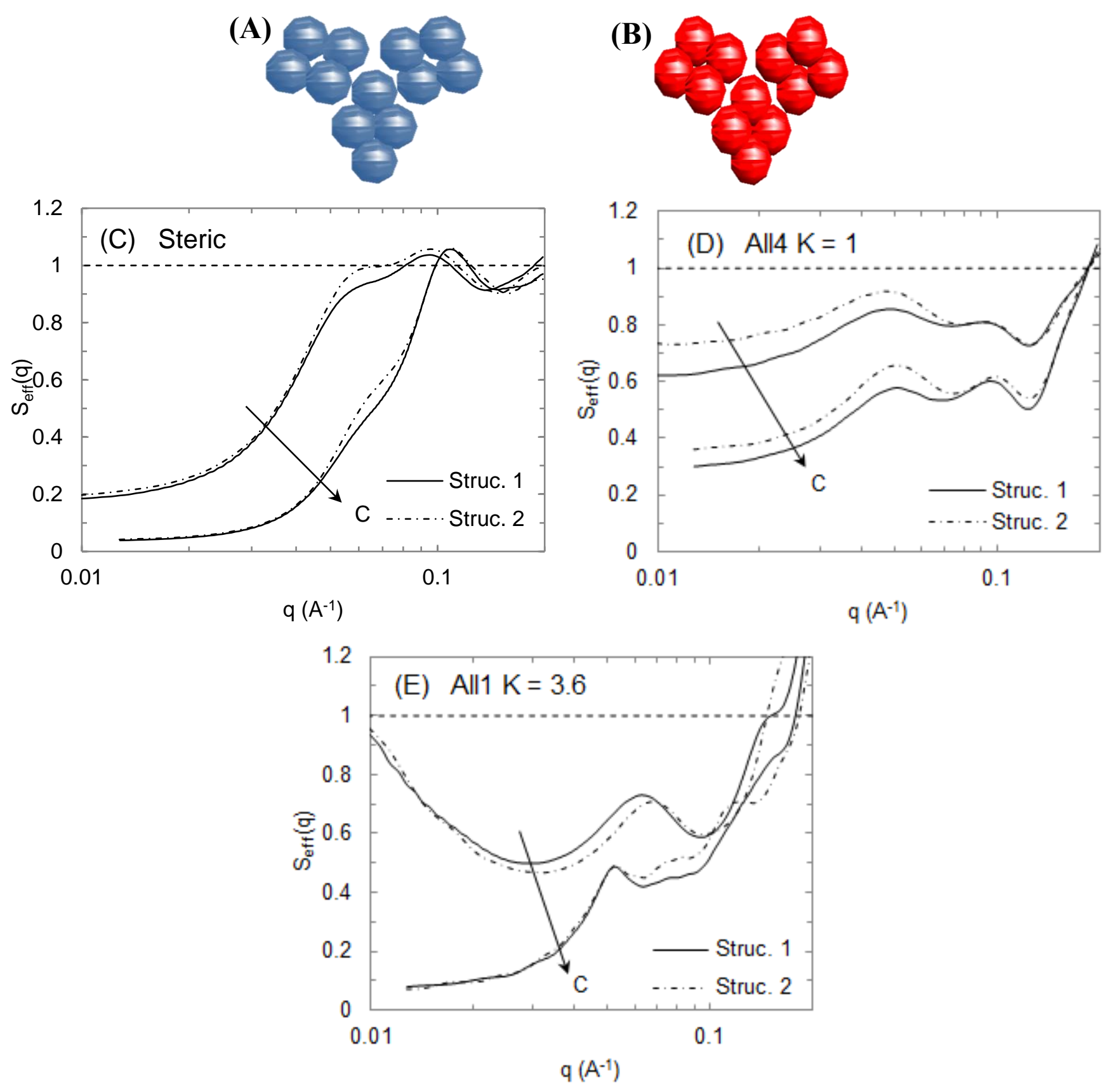


Figures S6.1. Visualizations of best fit 12 bead structure to $\mathrm{P}(\mathrm{q})$ of mAb2: $\mathrm{Arg}(\mathrm{A})$ and mAb4: $\mathrm{NaCl}(\mathrm{B})$. Simulated $S_{\text {eff }}(q)$ at 125 and $250 \mathrm{mg} / \mathrm{ml}$ for 12 bead structures shown in (A) and (B) for steric only (C), All4 $\mathrm{K}=1$ (D) and Al1 K=3.6. In legend, Struc. 1 refers to bead structure of mAb2: Arg, while Struc. 2 refers to the bead structure of mAb4: $\mathrm{NaCl}$, the number afterwards (125 or 250) indicates the mAb concentration.

\section{SECTION S7: COMPARISON OF INTERACTION POTENTIALS WITH THOSE FROM STUdies OF OTHER 12 BEAD MODELS}

As mentioned in the main text and depicted in Fig. S7.1, the combined WCA and Yukawa potential used for the 12-bead models qualitatively resemble the modified Lennard-Jones potential (mLJ) used for short-range attractions by Calero-Rubio, et al., ${ }^{13,18}$ and the van der Waals potential (from Hamaker ${ }^{19}$ ) used by Wang, et al., ${ }^{14}$ which has a fit Hamaker constant of $0.68 \mathrm{kB}$. In particular, the $\mathrm{K}=0.7$ potential (used with the All4 model) has a similar well-depth as the uniform attraction used by Calero-Rubio, et al which had well depths ranging from 0.64 to $0.74 \mathrm{k}_{\mathrm{B}} \mathrm{T}(\mathrm{CR}: 0.64-0.74)^{18}$ in their more recent paper, while $\mathrm{K}=0.9$, matches the welldepth (CR: 0.85) from the earlier work by Calero-Rubio, et al. ${ }^{13}$ Note that the form of the mLJ potential used for 12 bead simulations was adjusted by Calero-Rubio, et al. as the exponents used were 128 and 10 in the original work, ${ }^{13}$ but 128 and 6 in the more recent study. ${ }^{18}$ The attraction length scales used in the current study are in between those used by Calero-Rubio, et al. and Wang, et al. as seen in Fig. S7.1. Fig. S7.2 demonstrates that at low ionic strength $(15 \mathrm{mM})$ electrostatics significantly affect the interaction potential, but at the high ionic strength used in the current study $(270 \mathrm{mM})$ electrostatics negligibly influence interactions compared to local anisotropic attraction (such as from All1 $\mathrm{K}=3.6$ ).

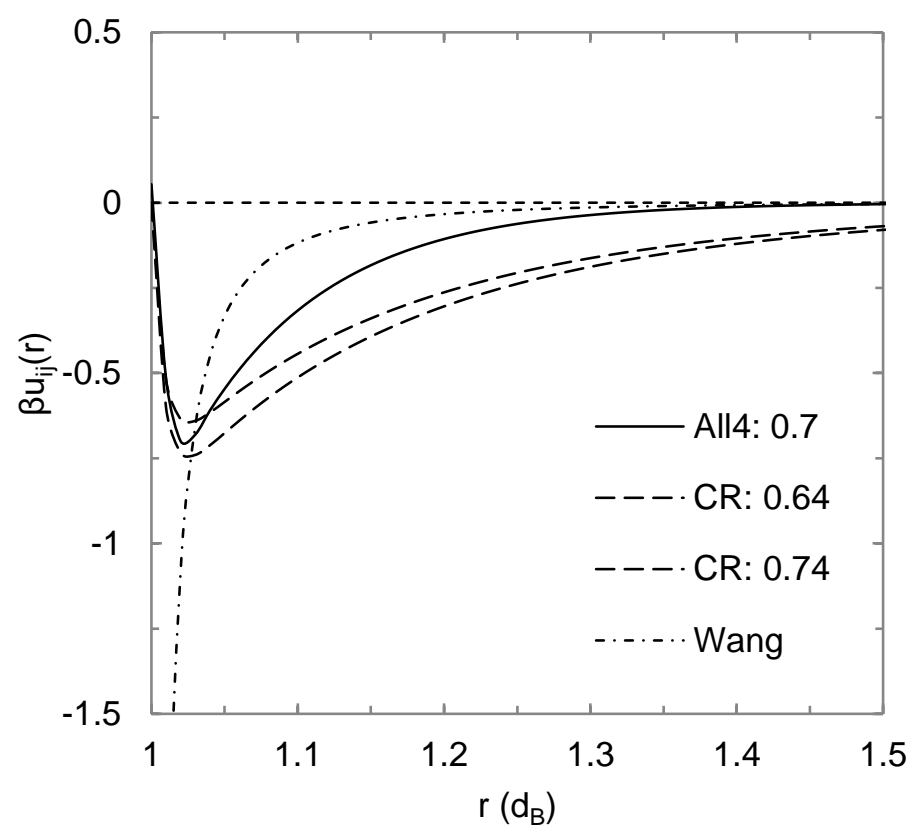

Figure S7.1. Interaction potential between beads, $\mathrm{u}_{\mathrm{ij}}(\mathrm{r})$, where $\mathrm{r}$ is the separation distance between two bead centers of mass of different mAbs in units of bead diameters $\left(d_{B}\right)$, for the $A 114 \mathrm{~K}=0.7$ model in the current work, 
compared with the modified Lennard-Jones potentials used by Calero-Rubio, et al., (CR) as a uniform van der Waals (vdW) attraction for their 12-bead model, ${ }^{13,18}$ and the van der Waals potential used by Wang, et al.${ }^{14}$ The number in the legend corresponds with the value of the potential at its minimum ( $\mathrm{K}$ for HSY and $\varepsilon_{S R}$ for LJ). In Calero-Rubio, et al., 2017 the model was fit to $\mathrm{mAb}$ data and the best fit $\varepsilon_{\mathrm{SR}}$ ranged from 0.64 to $0.74 \mathrm{k}_{\mathrm{B}} \mathrm{T},{ }^{18}$ while Wang, et al. used a van der Waals potential from Hamaker, ${ }^{19}$ with Hamaker a constant $0.68 \mathrm{k}_{\mathrm{B}} \mathrm{T} .{ }^{14}$
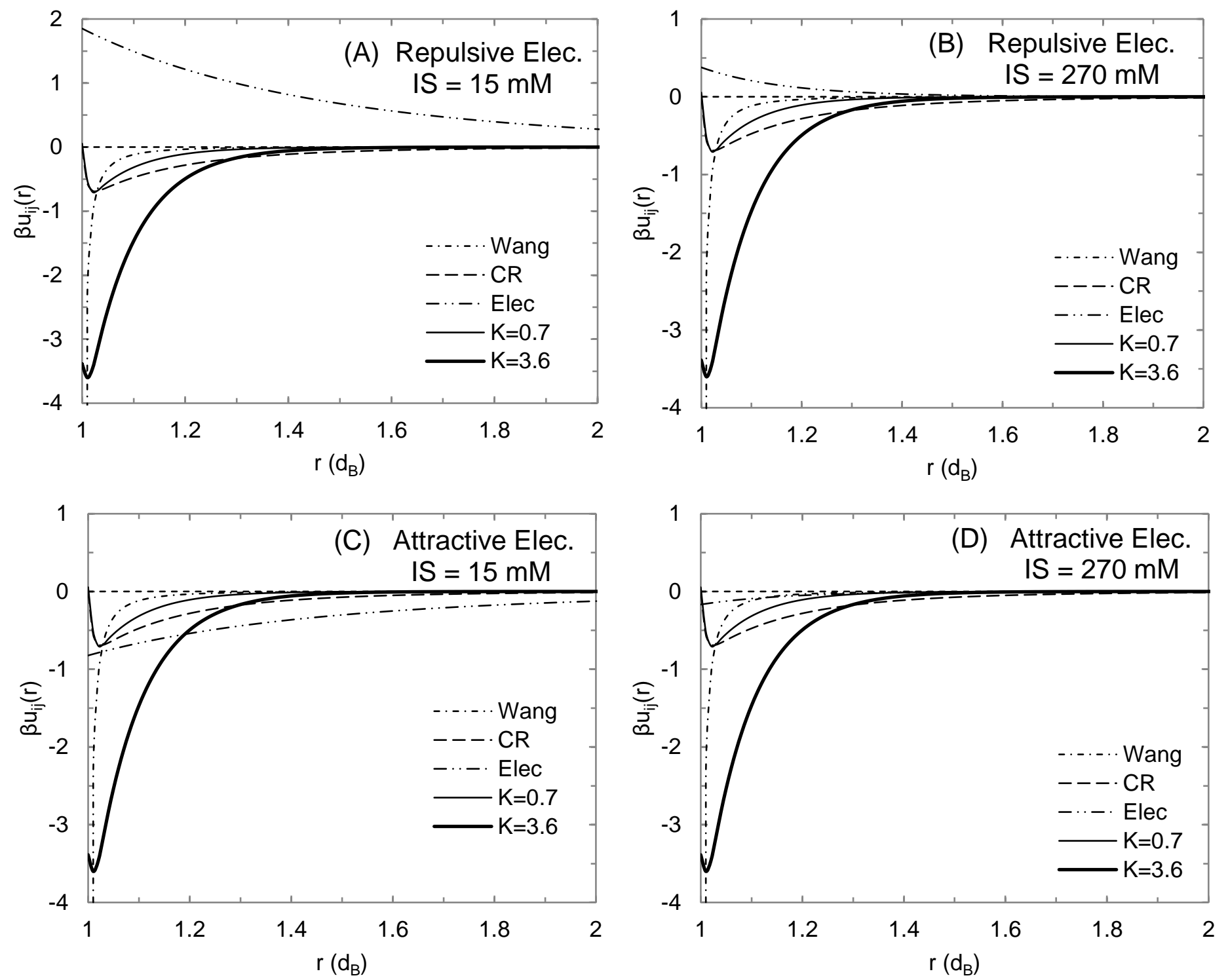

Figure S7.2. Interaction potential between beads, $\mathrm{u}_{\mathrm{ij}}(\mathrm{r})$, where $\mathrm{r}$ is the separation distance between two bead centers of mass of different mAbs in units of bead diameters $\left(\mathrm{d}_{\mathrm{B}}\right)$, for the van der Waals potential from Wang, et al. (Wang), the average $\left(\varepsilon_{S R}=0.69 \mathrm{k}_{\mathrm{B}} \mathrm{T}\right) \mathrm{mLJ}$ potential from Calero-Rubio, et al. $(\mathrm{CR})$, the $\mathrm{K}=0.7$ potential from the current study (used with the All4 model to fit $\mathrm{mAb2}$ : Arg), the $\mathrm{K}=3.6$ potential from the current study (used with the All1 model to fit $\mathrm{mAb} 4: \mathrm{NaCl}$ ) and the electrostatic potential for a given ionic strength, IS, and bead charge, q, (in units of fundamental charge, e) used by both Wang, et al. and Calero-Rubio, et al. The IS and 
bead charges are (A) IS $=15 \mathrm{mM}, \mathrm{q}^{2}=20.25$ to represent the max repulsion experienced between any two beads from the simulations by Wang, et al. (both beads have a charge of $4.5 \mathrm{e}$ ) at the ionic strength of most of the simulations tested by Wang, et al. and Calero-Rubio, et al., (B) IS $=270 \mathrm{mM}, \mathrm{q}^{2}=20.25$ to represent the same charge as (A), but at the IS equal to the data in the current study, (C) IS $=15 \mathrm{mM}, \mathrm{q}^{2}=-9$ to represent the maximum attraction experienced between any two beads from simulations by Wang, et al. (one bead has charge 4.5e, while the other has $-2 \mathrm{e}$ ), and (D) IS $=270 \mathrm{mM}, \mathrm{q}^{2}=-9$.

\section{Section S8: Real Space Visualizations of Bead Model Simulations}

To help visualize some of the discussion in the main text, some additional figures displaying types of $\mathrm{mAb}$ $\mathrm{mAb}$ interactions and interaction sites are included below.

(A)

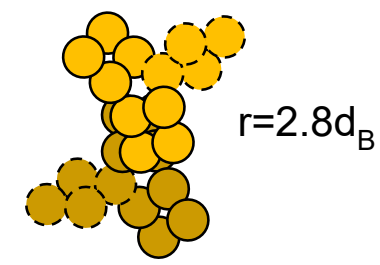

(F)

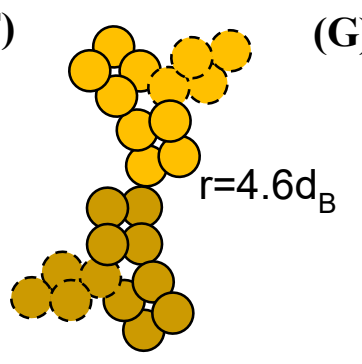

(B)
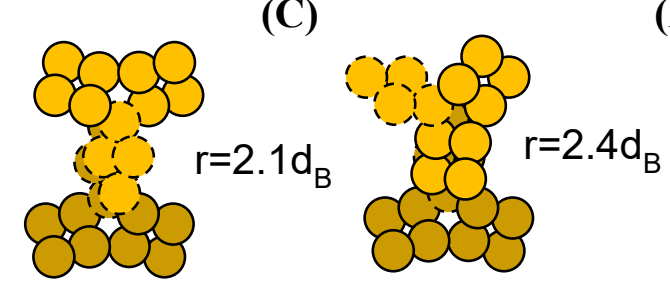

(H)

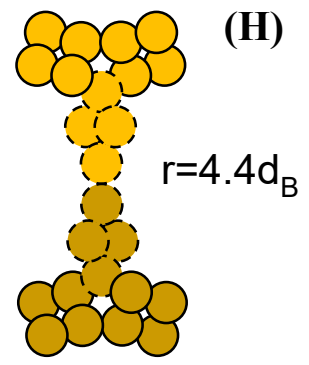

(D)
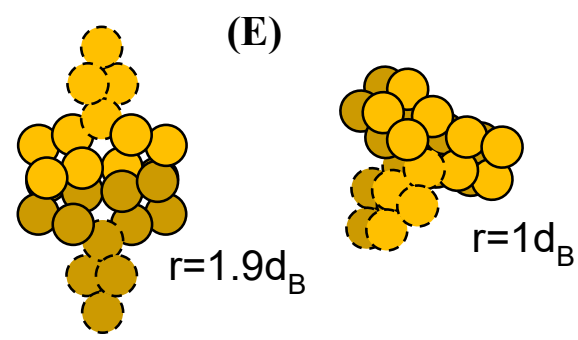

(I)

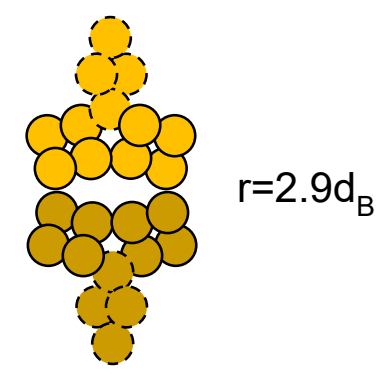

Figure S8.1. Visual representations of two-body mAb interaction conformations. Listed $r$ value is COM separation in the given conformation. (A) Fab-Fab stacking with the COM of each Fab stacked directly on top of each other. This conformation is shown in the inset of in Fig. 5B. (B) Fc-Fc stacking with the COM of each Fc stacked directly on top of each other. (C) Fab-Fc stacking with the COM of one Fab stacked directly on top of the COM of the other Fc. (D) Double Fab stacking. (E) Direct mAb-mAb stacking with the COM of one $\mathrm{mAb}$ stacked directly on that of the other mAb. Conformations A-E, as well as deviations of these models, are present in the All4 model as multiple beads may simultaneously interact. Conformation E causes the tall narrow peaks in the $\mathrm{g}_{\mathrm{COM}}(\mathrm{r})$ of All4 models with high attraction $(\mathrm{K} \geq 0.9)$, as single stacking causes a peak at $\mathrm{r}=\mathrm{d}_{\mathrm{B}}$, while having three mAbs stack together causes a peak at $r=2 d_{B}$. When $K=1.2$, peaks indicating stacks of $\geq 4$ mAbs are also present. (F) Maximum COM separation with Fab-Fab contact involving either beads 6 or 10 from Fig. S2.2. This conformation corresponds with the inset in Fig. 6B. (G) Maximum COM separation with Fc-Fc contact (bead 4 from Fig. S2.2). (H) Maximum COM separation with a Fab-Fc contact with either bead 6 or 10 from the Fab contacting bead 4. (I) Maximum COM separation with double Fab-Fab contacts involves both beads 6 and 10. Conformations F-I (as well as deviations in angles and contacts points) are present in the All1 
model, while conformations F and I are present in the FabFab1 model. The All1 model also has some stacking (conformation $\mathrm{E}$ ) shown by the small peak in $\mathrm{g}_{\mathrm{COM}}(\mathrm{r})$ at $\mathrm{r}=\mathrm{d}_{\mathrm{B}}$ as this is the only conformation that involves contacts with all three attractive beads; however, it does not occur for FabFab1 as conformation I and its deviations involve all of the attractive bead contacts for this model.

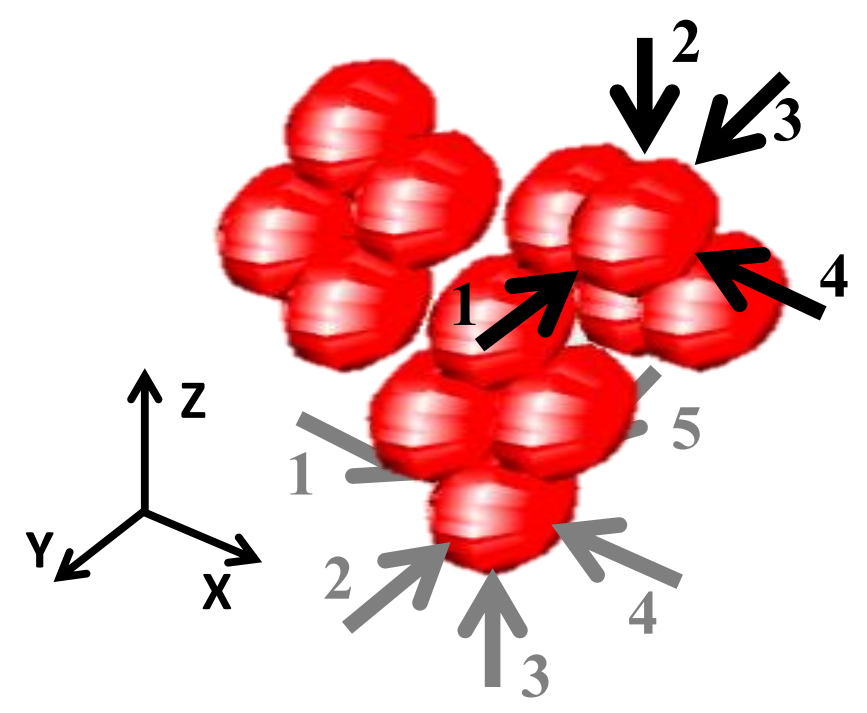

Figure S8.2. Visual representation of 12 bead model with arrows indicating contact surfaces for attracting mAbs. Black arrows 1-4 indicate that 4 mAbs are potentially able to simultaneously interact with attractive Fab bead (6 or 10 from Fig. S2.2), while gray arrows 1-5 indicate that 5 mAbs can potentially simultaneously interact with bead 4 (from Fig. S2.2) in the Fc. Therefore, a single All1 mAb should be essentially saturated with 13 nearest neighbors, while a FabFab1 mAb should be saturated with 8 . 
Section S9: Results For All Bead Models at 125 Mg/Ml With Additional K VAlues, P(N) AND The TRANSFORMED GCOM(R)

For clarity some of the simulated $\mathrm{K}$ values for the different models (All4, All1, and FabFab1) were not shown in the main text, so the following section includes figures for all tested $\mathrm{K}$ values. The differential CSDs and transformed $\operatorname{gCOM}_{\mathrm{CO}}(\mathrm{r})$ figures are also shown. 

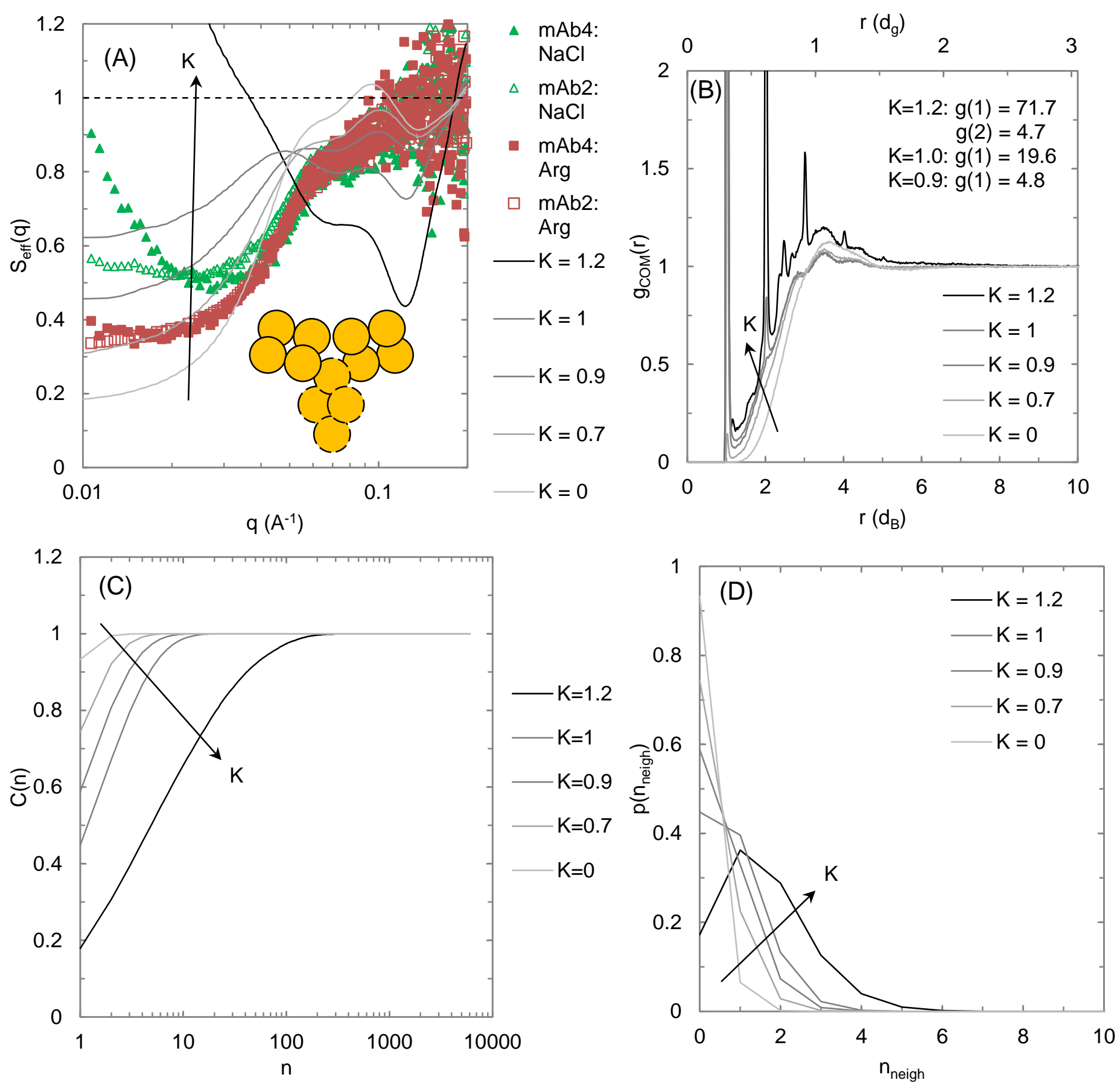

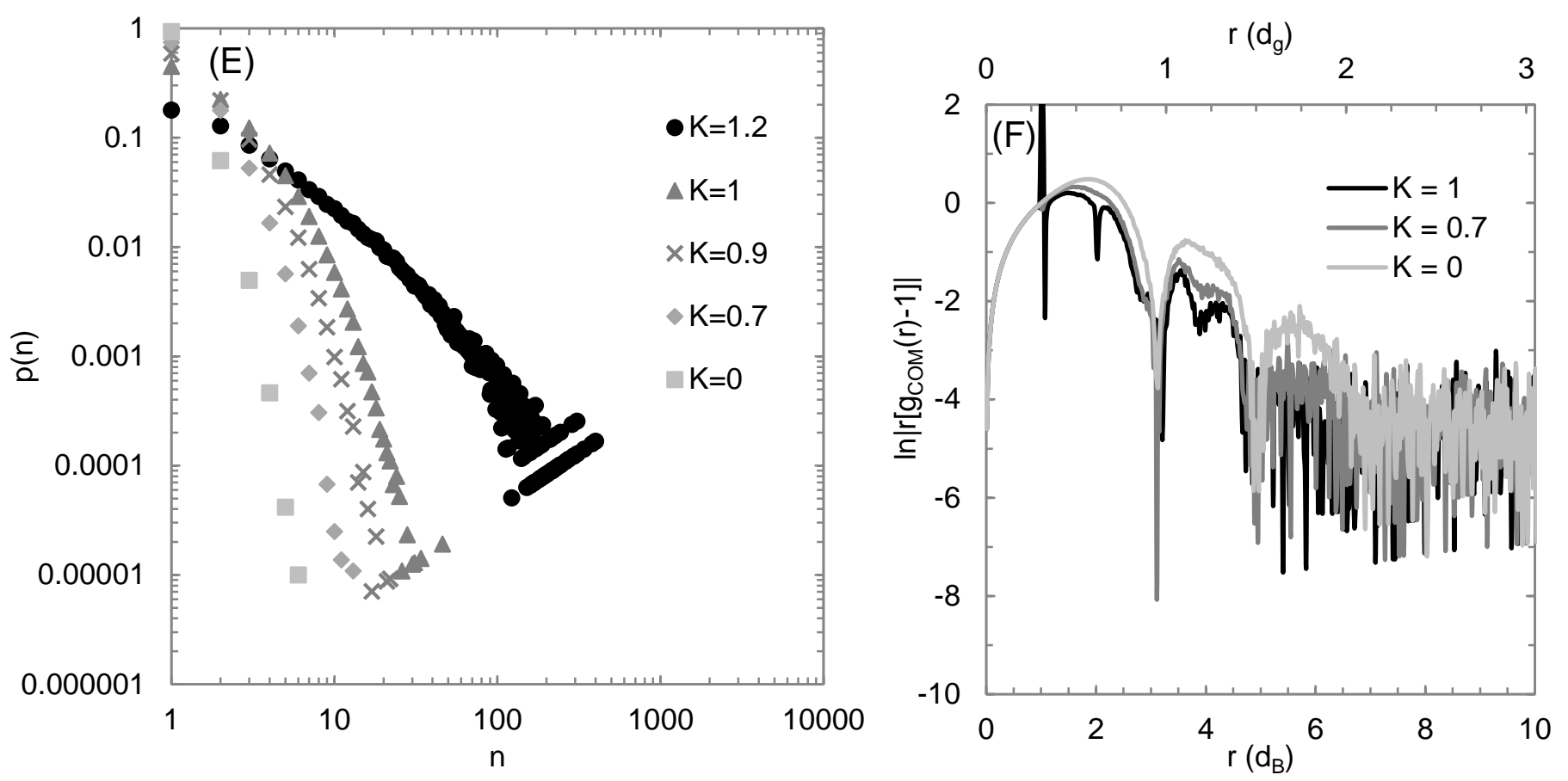

Figure S9.1. (A) $\mathrm{S}_{\text {eff }}(\mathrm{q}$ ) of $\mathrm{mAb}$ solutions at $125 \mathrm{mg} / \mathrm{ml}$ (points) and all $125 \mathrm{mg} / \mathrm{ml}$ All4 simulations at various $\mathrm{K}$ (lines). (B) Radial distribution functions, $\mathrm{g}_{\mathrm{COM}}(\mathrm{r})$, of corresponding All4 simulations, peaks off the graph scale are listed on the graph. (C) Cumulative CSDs of corresponding All4 simulations. (D) Nearest neighbor distributions of corresponding All4 simulations. (E) CSD of corresponding All4 simulations. (F) Transformed $\mathrm{g}_{\mathrm{COM}}(\mathrm{r}), \ln \left|\mathrm{r}\left[\mathrm{g}_{\mathrm{COM}}(\mathrm{r})-1\right]\right|$ to emphasize long range oscillations in $\mathrm{g}_{\mathrm{COM}}(\mathrm{r})$ of select systems ${ }^{20}$ Oscillations at long range $(r>\sim 5)$ decrease with $K$ from 0 to 0.7 to 1 signifying reduced order in long range structure with $K$ (others systems are excluded for graph clarity). 

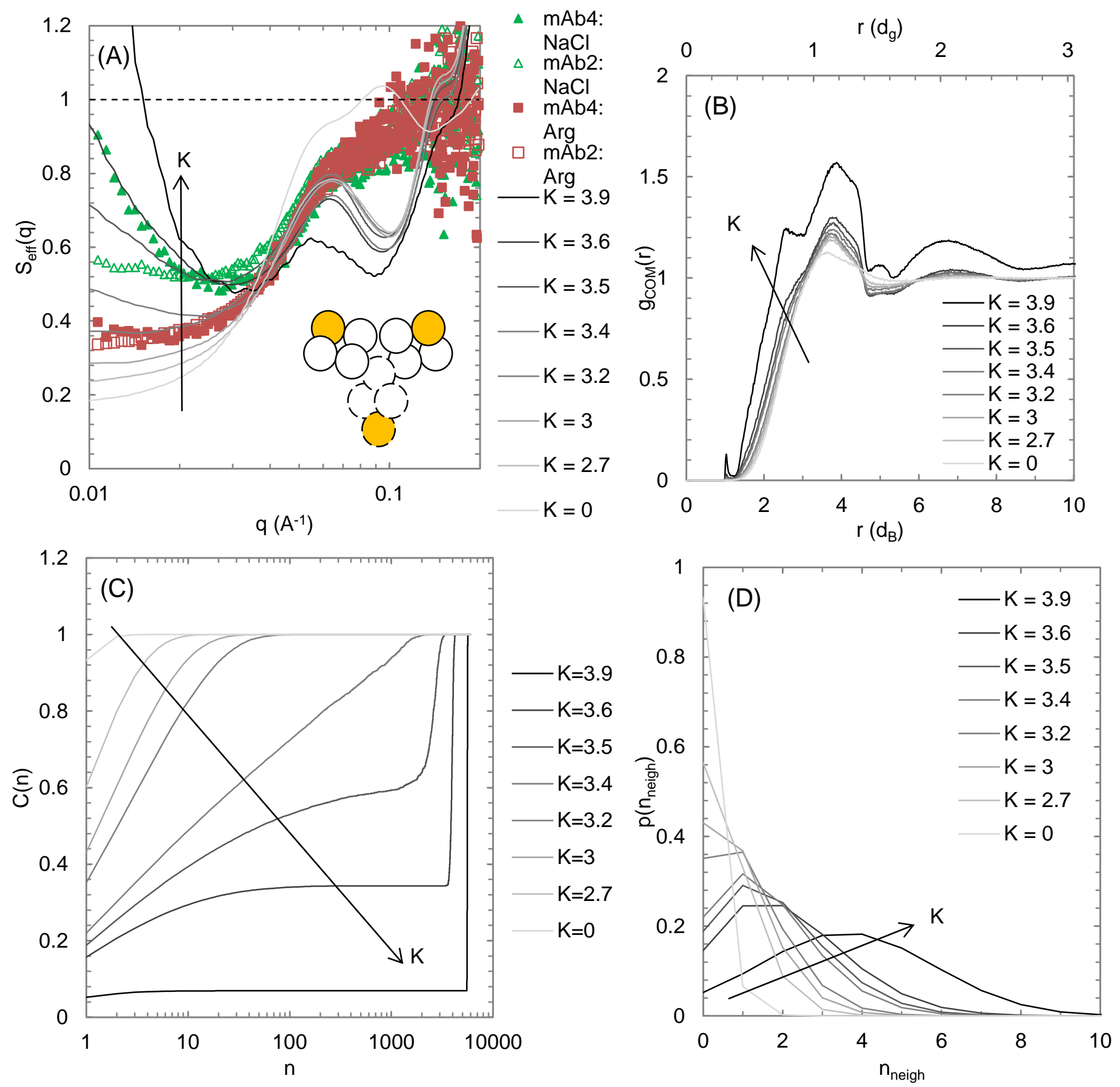

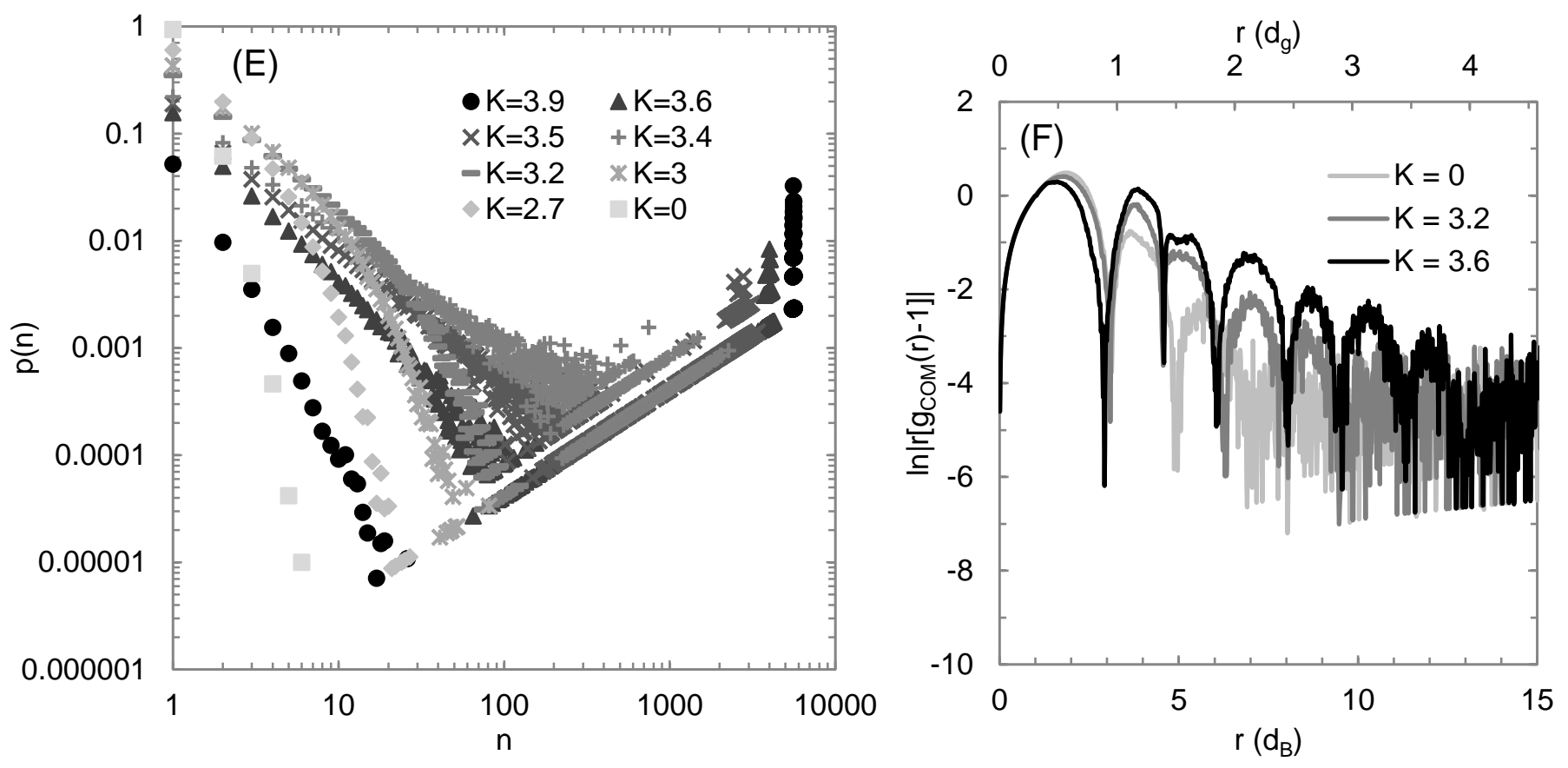

Figure S9.2. (A) $\mathrm{S}_{\text {eff }}(\mathrm{q})$ of $\mathrm{mAb}$ solutions at $125 \mathrm{mg} / \mathrm{ml}$ (points) and all $125 \mathrm{mg} / \mathrm{ml}$ All1 simulations at various $\mathrm{K}$ (lines). (B) Radial distribution functions, $\mathrm{g}_{\mathrm{COM}}(\mathrm{r})$, of corresponding All1 simulations. (C) Cumulative CSDs of corresponding All1 simulations. (D) Nearest neighbor distributions of corresponding All1 simulations. (E) CSD of corresponding All1 simulations. (F) Transformed $g_{\text {COM }}(r), \ln \left|r\left[g_{\text {СOM }}(r)-1\right]\right|$ to emphasize long range oscillations in $\mathrm{g}_{\mathrm{COM}}(\mathrm{r})$ of select systems. ${ }^{20}$ Oscillations at long range (r> 5) increase with $\mathrm{K}$ from 0 to 3.2 to 3.6 signifying increased order in long range structure with $\mathrm{K}$ (others systems are excluded for graph clarity). 

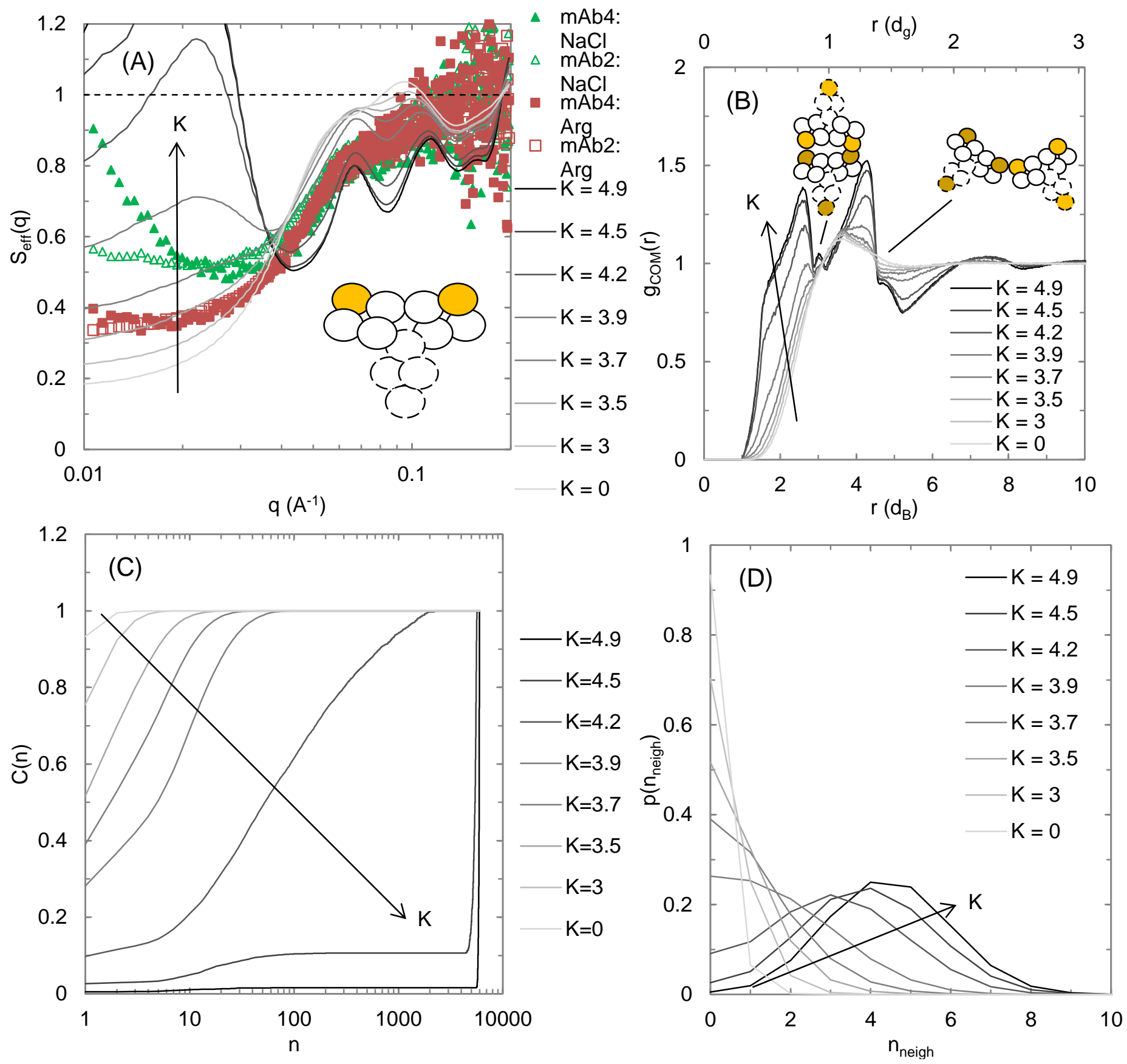

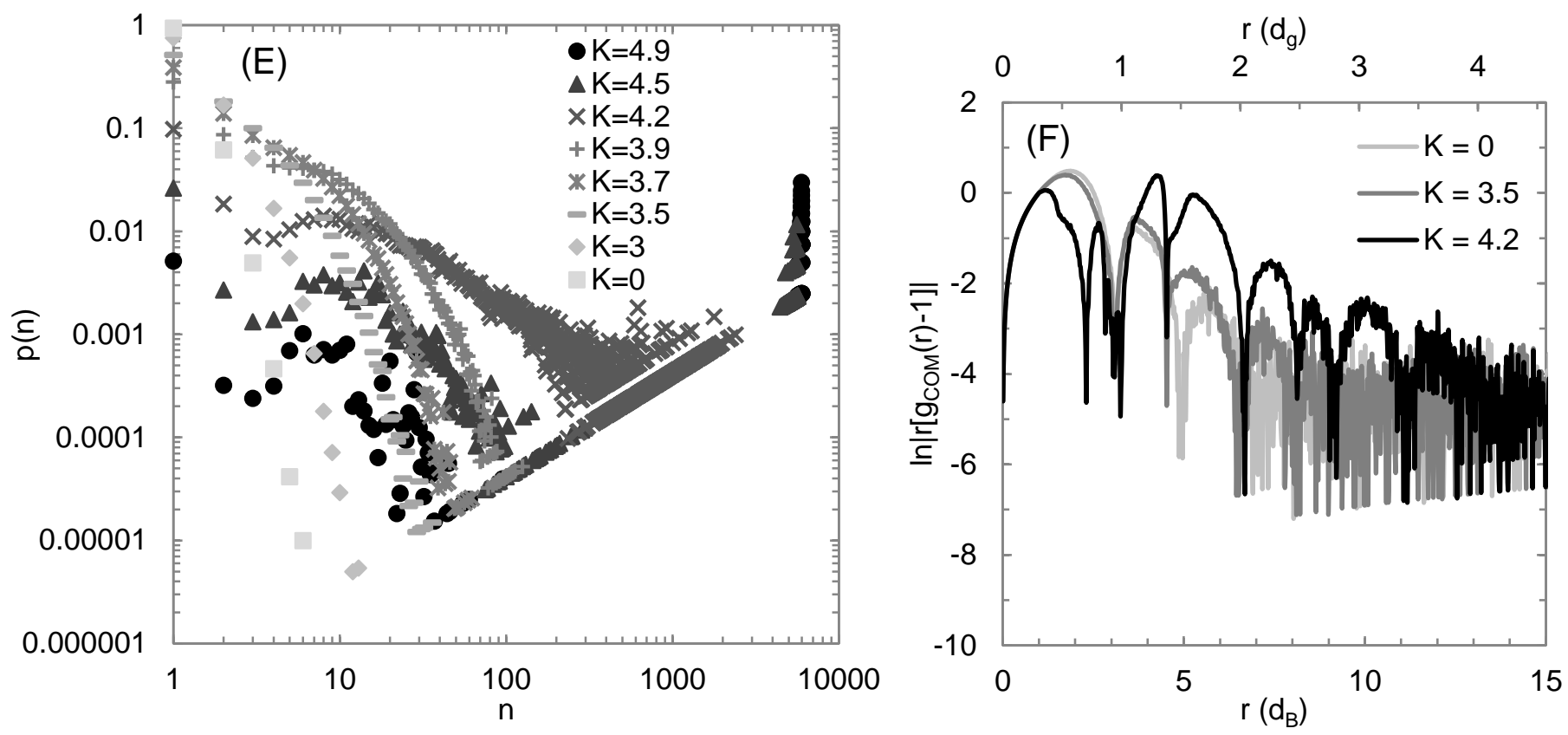

Figure S9.3. (A) $S_{\text {eff }}(q)$ of $\mathrm{mAb}$ solutions at $125 \mathrm{mg} / \mathrm{ml}$ (points) and all $125 \mathrm{mg} / \mathrm{ml} \mathrm{FabFab1} \mathrm{simulations} \mathrm{at}$ various K (lines). (B) Radial distribution functions, g $\mathrm{g}_{\mathrm{CM}}(\mathrm{r})$, of corresponding FabFab1 simulations. The inset indicate the maximum COM separation for 2 bead and 1 bead contacts (from left to right) which have COM separations corresponding with the end of each peak. (C) Cumulative CSDs of corresponding FabFab1 simulations. (D) Nearest neighbor distributions of corresponding FabFab1 simulations. (E) CSD of corresponding FAbFab1 simulations. (F) Transformed $g_{\mathrm{COM}}(\mathrm{r}), \ln \left|\mathrm{r}\left[\mathrm{g}_{\mathrm{COM}}(\mathrm{r})-1\right]\right|$ to emphasize long range oscillations in $\mathrm{g}_{\mathrm{COM}}(\mathrm{r})$ of select systems. ${ }^{20}$ Oscillations at long range (r> 5) increase with $\mathrm{K}$ from 0 to 3.5 to 4.2 signifying increased order in long range structure with $\mathrm{K}$ (others systems are excluded for graph clarity). 


\section{SeCtion S10: FabFab1 Model Discussion}

At low attraction $(K=3.5)$ the FabFab1 model, shown in Fig. S9.3A, closely fits the mAb2: Arg data at low q (similar to All4 and All1). As $\mathrm{K}$ is increased an intermediate range order (IRO) peak is formed near $\mathrm{q} 0.02 \mathrm{~A}^{-1}$, which is very different from the mAb data reported in this paper as well as throughout literature. ${ }^{5-7}$,

${ }^{9-10}$ At high $q$ the FabFab1 model has two peaks one at q 0.06 $\mathrm{A}^{-1}$, similar but smaller than the peak in All1, and a second peak at $\mathrm{q} \sim 0.1 \mathrm{~A}^{-1}$. The measured $\mathrm{S}(\mathrm{q})$ data of mAb2 and mAb4 do not show these peaks, making this model qualitatively different from the data, but the magnitude of the peaks mostly fit throughout the noise of the data in this range, indicating that although the data does not have as defined structure as the model, it does generally have similar amounts of short-range packing. This behavior can also be seen in the $g_{\mathrm{COM}}(\mathrm{r})$ for FabFab1 shown in Fig. S9.3B, in which the $\mathrm{g}_{\mathrm{COM}}(\mathrm{r})$ peak within the first coordination shell (r less than the dashdot line) splits into two peaks as $\mathrm{K}$ is increased. Of these two peaks the one at higher $\mathrm{r}\left(\mathrm{r} \sim 4.5 \mathrm{~d}_{\mathrm{B}}\right)$ corresponds with the peak at $\mathrm{S}_{\text {eff }}\left(\mathrm{q} \sim 0.06 \mathrm{~A}^{-1}\right)$ and its peak is at only slightly smaller $\mathrm{r}$ than the following trough, indicating that the COM separation in this peak is very close to the maximum possible between adjacent mAbs while maintaining one attractive bead in contact (which is indicated by the trough and shown visibly in Fig. S8.1F and the rightmost inset in Fig. S9.3B). The interior peak $\left(r \sim 2.8 d_{B}\right)$ corresponds with the peak at $S_{\text {eff }}\left(q \sim 0.1 A^{-1}\right)$ and its trough matches the $\mathrm{r}$ representing the maximum distance between mAbs with both Fab domains in contact simultaneously (visualized in leftmost inset and Fig. S8.1I). These are the only two conformations (from Fig. S8.1) this model will prominently assume due to having only one attractive bead per domain. The broadness of the peaks results from the different contact points and angles between the mAb COMs and bead contacts. These contacts and angles are affected by multiple other mAbs simultaneously binding to the attractive Fab bead(s) of a given mAb. Fig. S11.1 shows that relative to the peak at $r \sim d_{g}$ the $g_{C O M}(r)$ at $r<d_{g}$ increases more with $K$ for the FabFab1 and All4 model than the All1, which likely explains why the $S_{\text {eff }}(q)$ of these models at high q more closely resemble the actual mAb data. It can also be noted that for both All4 and All1 the most energetically favorable position is stacking the mAbs directly on top of each other (as shown in Fig. S8.1E), this is not necessarily true for FabFab1 as there are multiple orientations that allow for both attractive beads of one mAb to simultaneously interact with the attractive beads on another mAb (Fig. S8.1I). Therefore, FabFab1 does not show any peak in $\mathrm{g}_{\mathrm{COM}}(\mathrm{r})$ at $\mathrm{r}=\mathrm{d}_{\mathrm{B}}$ at any $\mathrm{K}$, while All4 shows weak peaks at low $\mathrm{K}$ and very tall peaks at high 
$\mathrm{K}$, because stacking is much more energetically favorable than other orientations, while All1 has a weak peak at $\mathrm{r}=\mathrm{d}_{\mathrm{B}}$ when $\mathrm{K}$ is high, because stacking is the most favorable orientation, but not as significantly as for All4.

Increasing $\mathrm{K}$ also has a large effect on $\mathrm{mAb}$ behavior in the FabFab1 model at long range as can be seen by the increase in periodicity in $\mathrm{g}_{\mathrm{COM}}(\mathrm{r})$ at $\mathrm{r}$ beyond the second trough Fig. S9.3B (and more clearly in the transformed $\mathrm{g}_{\mathrm{COM}}(\mathrm{r})$ in Fig. S9.3F). ${ }^{20}$ This can also be seen in the cumulative CSD and normal CSD in Fig. S9.3C and E, respectively, as the amount of self-association increases drastically with $\mathrm{K}$, even causing percolating networks when $\mathrm{K} \geq 4$.2. In fact for the same $\mathrm{B}_{22} / \mathrm{B}_{22, \mathrm{St}}$, or $\mathrm{K}_{\mathrm{tot}}$, the FabFab1 model causes significantly more self-association than either the All4 or All1 models, as shown in Fig. S11.2 and Tables 2 and S13.3. In addition to the high amount of self-association and networks for this model, the CSD (Fig. S9.3E) shows that this model also tends to have preferred cluster sizes of $\sim 10 \mathrm{mAbs}$, corresponding with the IRO peak in $S_{\text {eff }}(q)$. Typically these types of clustered distributions require a long-range repulsive force to limit growth, but for FabFab1 the 10 beads without attraction on each $\mathrm{mAb}$ are able to form a steric barrier that resists binding of additional mAbs leading to a preferred cluster size. However, at high enough K some of these clusters will still associate and can form percolating networks, resulting in cluster percolated solutions, as have been discussed in previous work. ${ }^{21}$ The extent of cluster formation, and eventually percolation, results from the distribution of neighboring mAbs with just one or both attractive beads in contact. In the extreme case that all neighbors bond by both attractive beads, this configuration is self-limiting with a maximum cluster size of 4 or 5. However, if mAbs only associate with 1 of their $2 \mathrm{Fab}$ arms, the other Fab arm is free to further self-associate and expand the cluster. If 2 or more mAbs do so with a reference mAb ad infinitum, then this type of configuration will enable branching and can eventually cause percolation. The FabFab1 model also has more contacting neighbors than the other models for the same $\mathrm{B}_{22}$ as shown in Fig. S11.3, despite having fewer attractive beads ( 2 instead of 3 or 12). This occurs because the FabFab1 model has the strongest attractive sites and single site contacts are higher entropy than multiple site contacts as discussed in the main paper. However, as can also be seen in Fig. S11.3, as more mAbs come in contact whether due to increased attraction or $\mathrm{mAb}$ concentration, eventually the attractive sites become saturated and the All1 model which has an additional attractive site can have more contacting neighbors. For example, in Fig. S11.3C, at $125 \mathrm{mg} / \mathrm{ml}$ and $\mathrm{B}_{22} / \mathrm{B}_{22, \mathrm{St}}=$ 0.25 the FabFab1 model still has more contacts on average than All1, but the All1 has a wider distribution of contacts and has more mAbs with $\geq 8$ contacts (as 8 contacts is about the maximum for a mAb in FabFab1, see Fig. S8.2). When the concentration is increased to $250 \mathrm{mg} / \mathrm{ml}$ for the same attraction (Fig. S11.3F) the All1 
model not only has more mAbs with $\geq 7$ contacts, but also has more average neighbors as the FabFab1 attractive beads have started to become saturated.

\section{Section S11: Bead Model Comparisons at Equivalent B22}

As discussed in the main text, the comparisons of the different models at equivalent $\mathrm{B}_{22}$ are included in this section for $\mathrm{g}_{\mathrm{COM}}(\mathrm{r})$, cumulative CSD, and nearest neighbor distributions.
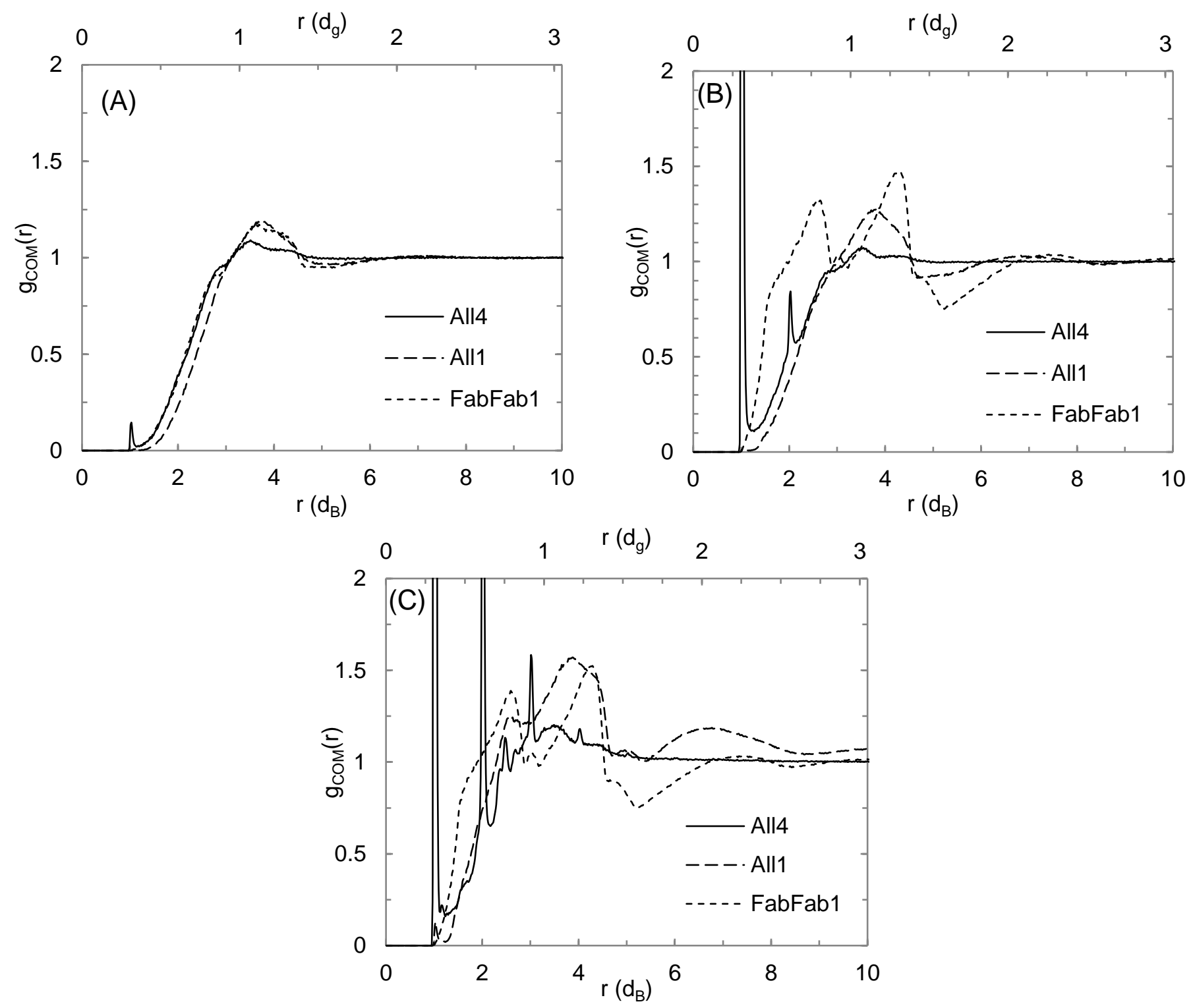

Figures S11.1. (A) Radial distribution functions, g $\mathrm{COM}(\mathrm{r})$, of All4, All1 and FabFab1 simulations with $\mathrm{B}_{22} / \mathrm{B}_{22, \mathrm{St}}$ $=0.75$ at $125 \mathrm{mg} / \mathrm{ml}$. K values equal 0.7, 2.7 and 3.7 for the respective models. (B) $\mathrm{g}_{\mathrm{COM}}(\mathrm{r})$ of All4, All1 and 
FabFab1 simulations with $\mathrm{B}_{22} / \mathrm{B}_{22, \mathrm{St}}=0.50$ at $125 \mathrm{mg} / \mathrm{ml}$. $\mathrm{K}$ values equal $1.0,3.5$ and 4.5 for the respective models. (C) $\mathrm{g}_{\mathrm{COM}}(\mathrm{r})$ of All4, All1 and FabFab1 simulations with $\mathrm{B}_{22} / \mathrm{B}_{22, \mathrm{St}}=0.25$ at $125 \mathrm{mg} / \mathrm{ml}$. K values equal $1.2,3.9$, and 4.9 for their perspective models.
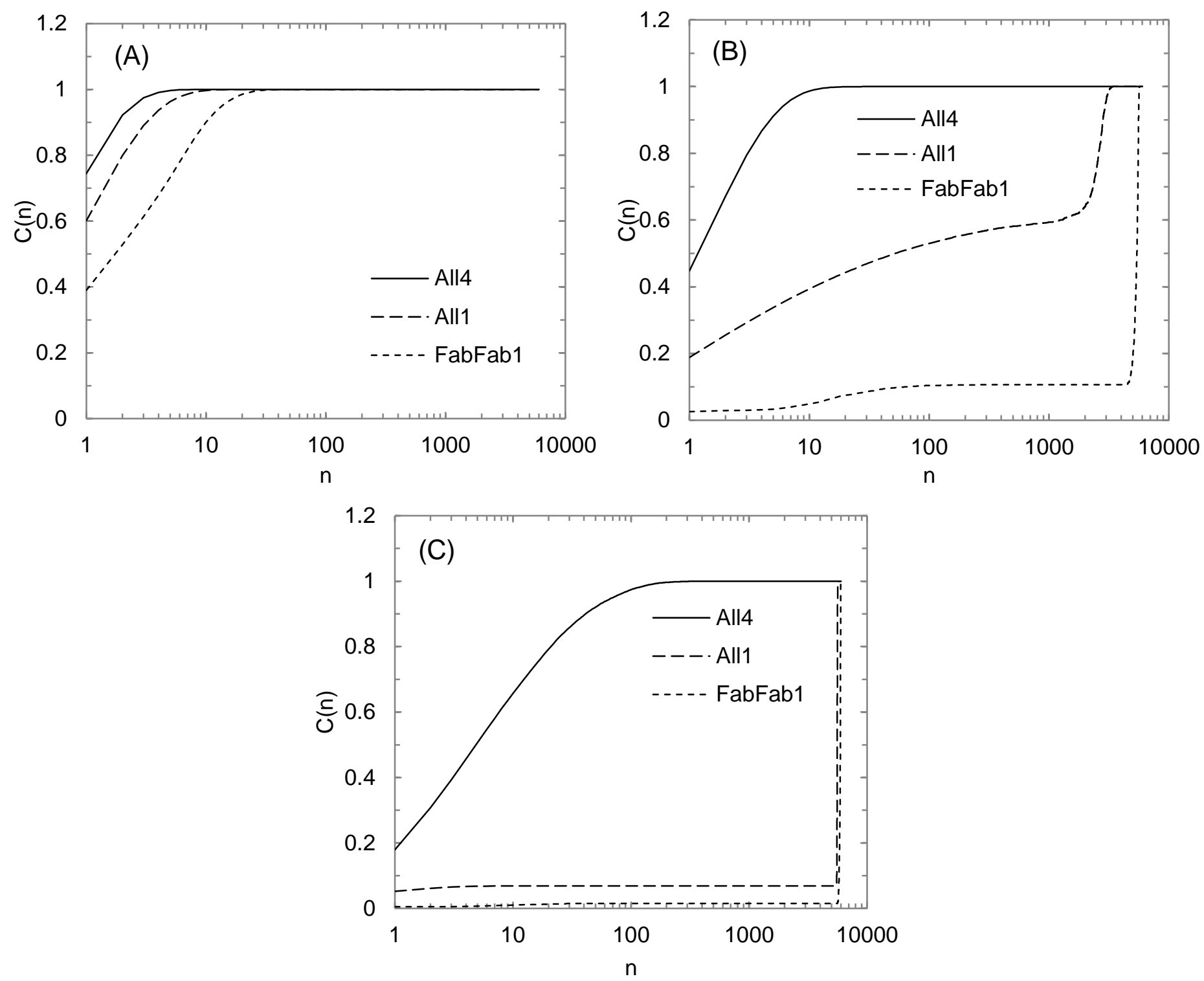

Figure S11.2. (A) Cumulative cluster size distributions, C(n), of All4, All1 and FabFab1 simulations with $\mathrm{B}_{22} / \mathrm{B}_{22, \mathrm{St}}=0.75$ at $125 \mathrm{mg} / \mathrm{ml}$. K values equal 0.7, 2.7 and 3.7 for the respective models. (B) $\mathrm{C}(\mathrm{n})$ of All4, All1 and FabFab1 simulations with $\mathrm{B}_{22} / \mathrm{B}_{22, \mathrm{St}}=0.50$ at $125 \mathrm{mg} / \mathrm{ml}$. $\mathrm{K}$ values equal $1.0,3.5$ and 4.5 for the respective models. (C) $\mathrm{C}(\mathrm{n})$ of All4, All1 and FabFab1 simulations with $\mathrm{B}_{22} / \mathrm{B}_{22, \mathrm{St}}=0.25$ at $125 \mathrm{mg} / \mathrm{ml}$. $\mathrm{K}$ values equal $1.2,3.9$ and 4.9 for the respective models. 

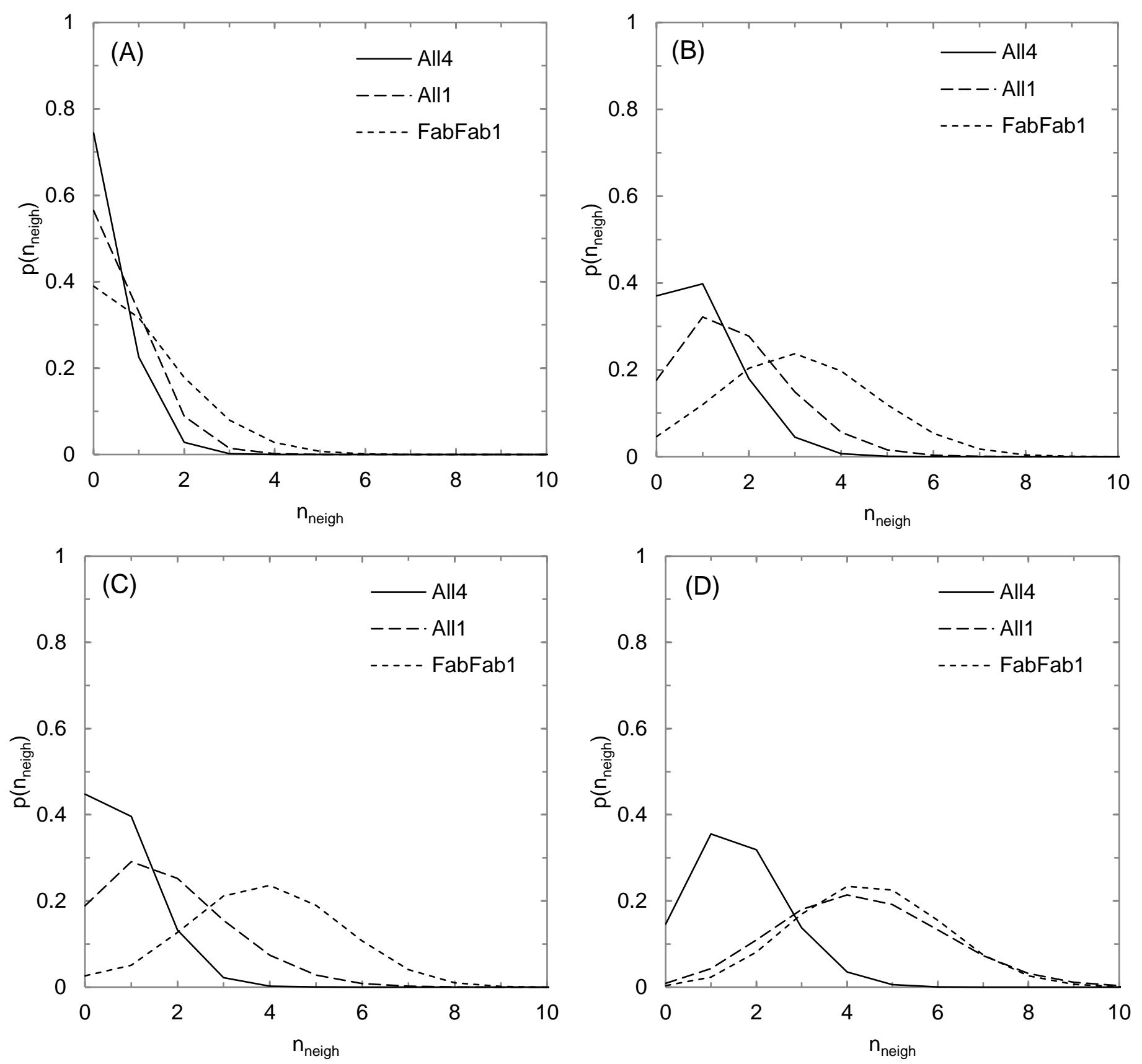

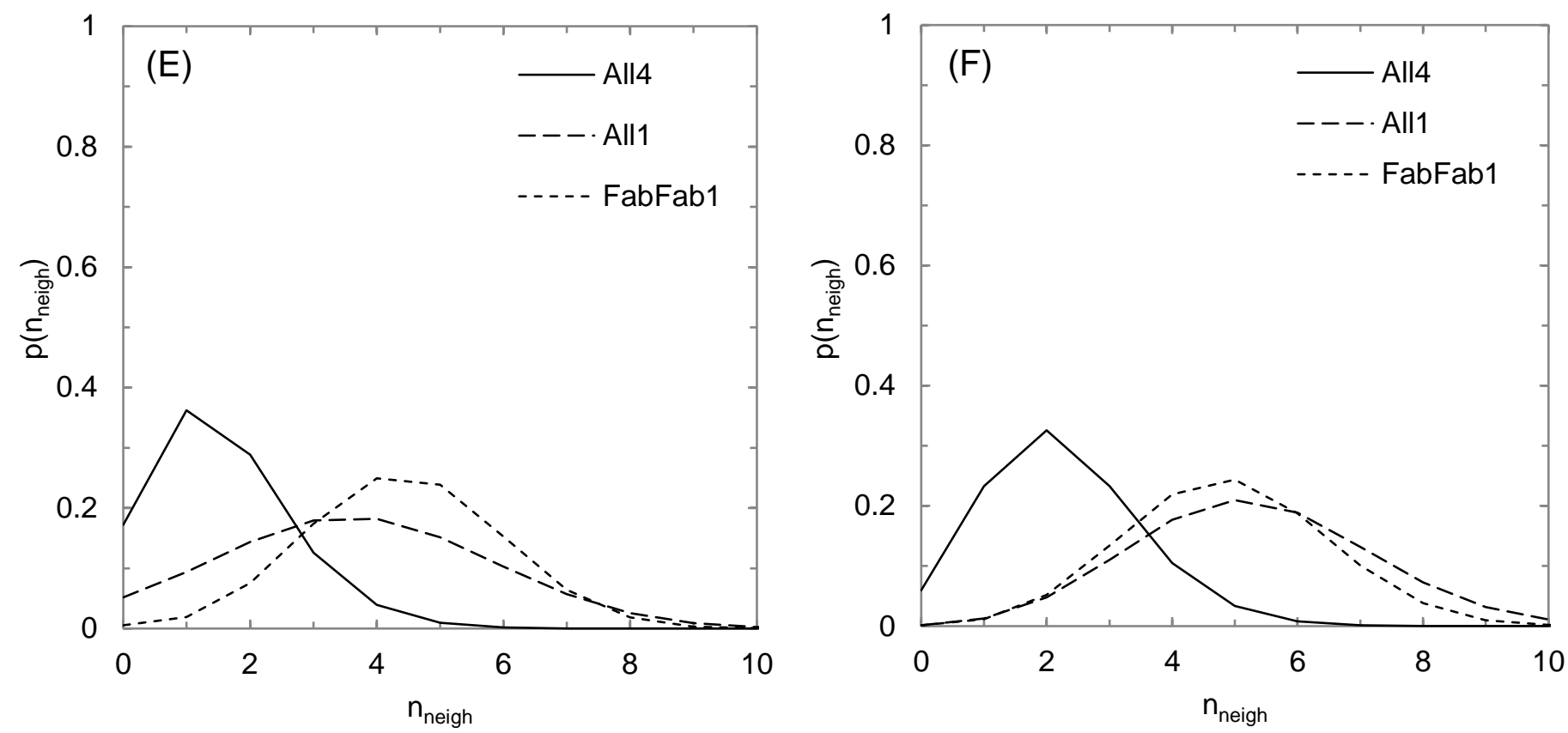

Figure S11.3. (A) Nearest neighbor distributions, $\mathrm{p}\left(\mathrm{n}_{\text {neigh }}\right)$, of All4, All1 and FabFab1 simulations with $\mathrm{B}_{22} / \mathrm{B}_{22, \mathrm{St}}=0.75$ at $125 \mathrm{mg} / \mathrm{ml}$. K values equal 0.7, 2.7 and 3.7 for the respective models. $(\mathrm{B}) \mathrm{p}\left(\mathrm{n}_{\text {neigh }}\right)$, of All4, All1 and FabFab1 simulations with $\mathrm{B}_{22} / \mathrm{B}_{22, \mathrm{St}}=0.75$ at $250 \mathrm{mg} / \mathrm{ml}$. K values equal $0.7,2.7$ and 3.7 for the respective models. $(\mathrm{C}) \mathrm{p}\left(\mathrm{n}_{\text {neigh }}\right)$ of All4, All1 and FabFab1 simulations with $\mathrm{B}_{22} / \mathrm{B}_{22, \mathrm{St}}=0.50$ at $125 \mathrm{mg} / \mathrm{ml}$. K values equal 1.0, 3.5 and 4.5 for the respective models. (D) $\mathrm{p}\left(\mathrm{n}_{\text {neigh }}\right)$ of All4, All1 and FabFab1 simulations with $\mathrm{B}_{22} / \mathrm{B}_{22, \mathrm{St}}=0.50$ at $250 \mathrm{mg} / \mathrm{ml}$. K values equal 1.0, 3.5 and 4.5 for the respective models. $(\mathrm{E}) \mathrm{p}\left(\mathrm{n}_{\text {neigh }}\right)$ of All4, All1 and FabFab1 simulations with $\mathrm{B}_{22} / \mathrm{B}_{22, \mathrm{St}}=0.25$ at $125 \mathrm{mg} / \mathrm{ml}$. K values equal 1.2, 3.9 and 4.9 for the respective models. $(\mathrm{F}) \mathrm{p}\left(\mathrm{n}_{\text {neigh }}\right)$ of All4, All1 and FabFab1 simulations with $\mathrm{B}_{22} / \mathrm{B}_{22, \mathrm{St}}=0.25$ at $250 \mathrm{mg} / \mathrm{ml}$. K values equal 1.2, 3.9 and 4.9 for the respective models. 


\section{SECTION S12: EFFECT OF MAB ConCENTRATION ON Simulations}

This section shows that at concentrations greater than $125 \mathrm{mg} / \mathrm{ml} \mathrm{FabFab1} \mathrm{K}=3.5$ fits mAb2: Arg at low q, but not intermediate $\mathrm{q}\left(0.02 \mathrm{~A}^{-1}<\mathrm{q}<0.04 \mathrm{~A}^{-1}\right)$ due to the formation of an IRO shoulder, while All1 $\mathrm{K}=3.2$ fits mAb4: Arg across concentrations (Fig. S12.1). It also demonstrates how increasing mAb concentration decreases $\mathrm{S}(0)$, and the upward curvature in $\mathrm{S}_{\mathrm{eff}}(\mathrm{q})$ at low $\mathrm{q}$, causing the models of different $\mathrm{K}$ to start to converge. This is shown for the mAb data and the All4 (Fig. S12.2) and All1 (Fig. S12.3) simulations below (this effect is clearly more dramatic for the All1 than the All4 model, but is present in both). The convergence with concentration allows some models to fit at high concentration, while being too attractive at low concentration as shown for $\mathrm{mAb2}$ : $\mathrm{NaCl}$ and $\mathrm{All4} \mathrm{K}=0.7$ in Fig. S12.4. Finally, the effect of mAb concentration on the steric only model (Fig. S12.5) and on all of the best fit simulations from Fig. 7 are affected by concentration in terms of $\mathrm{g}_{\mathrm{COM}}(\mathrm{r})$, cumulative $\mathrm{CSD}$, nearest neighbor distribution and transformed $\mathrm{g}_{\mathrm{COM}}(\mathrm{r})$ are also shown (Figs. S12.6 - S12.9).
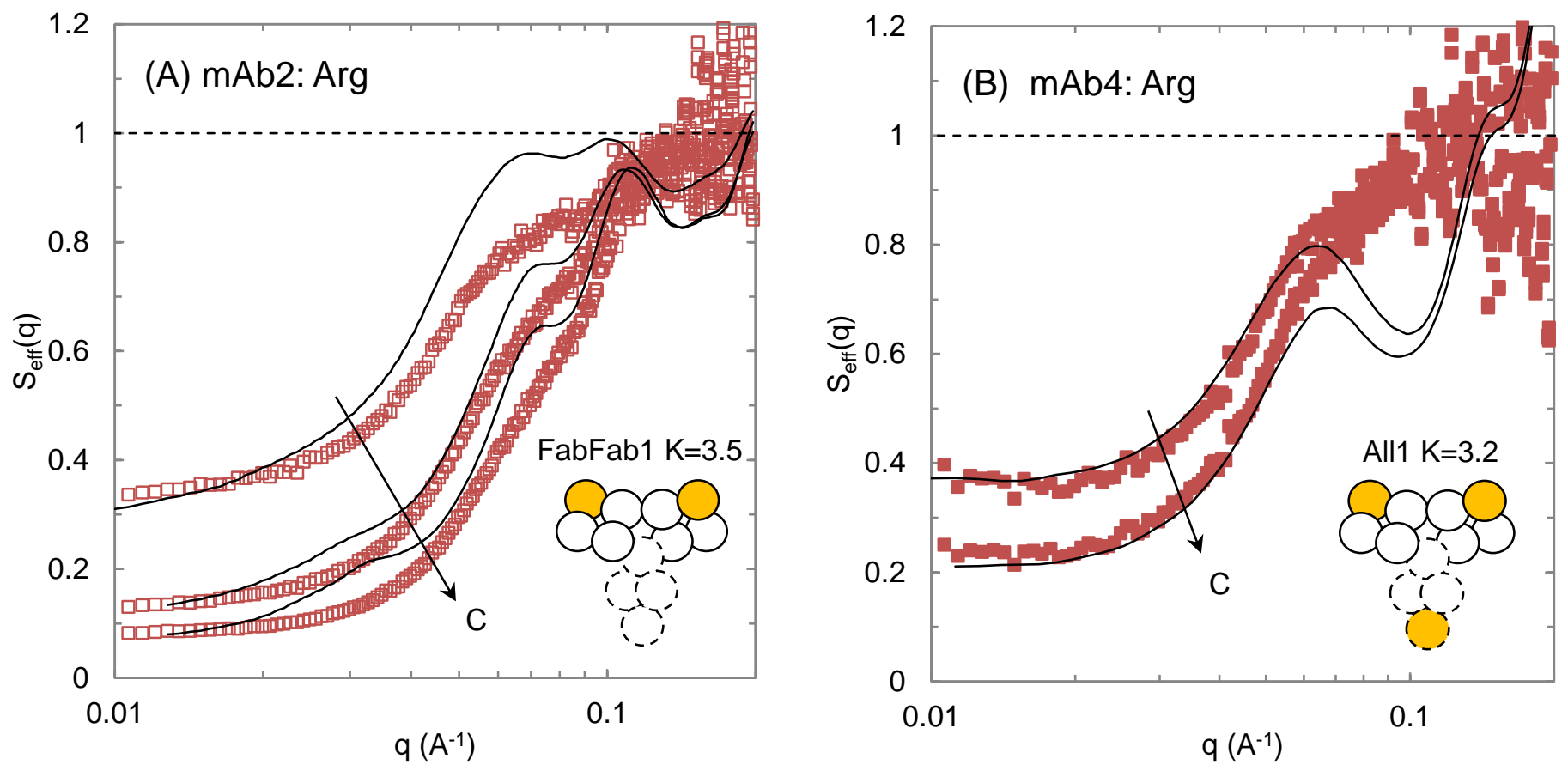

Figure S12.1. $S_{\text {eff }}(q)$ versus $\mathrm{mAb}$ concentration for $(A) \mathrm{mAb} 2$ : Arg data at 125, 200 and $250 \mathrm{mg} / \mathrm{ml}$ fit with FabFab K=3.5 and (B) mAb4: Arg at 125 and 165 mg/ml fit with All1 K=3.2. 


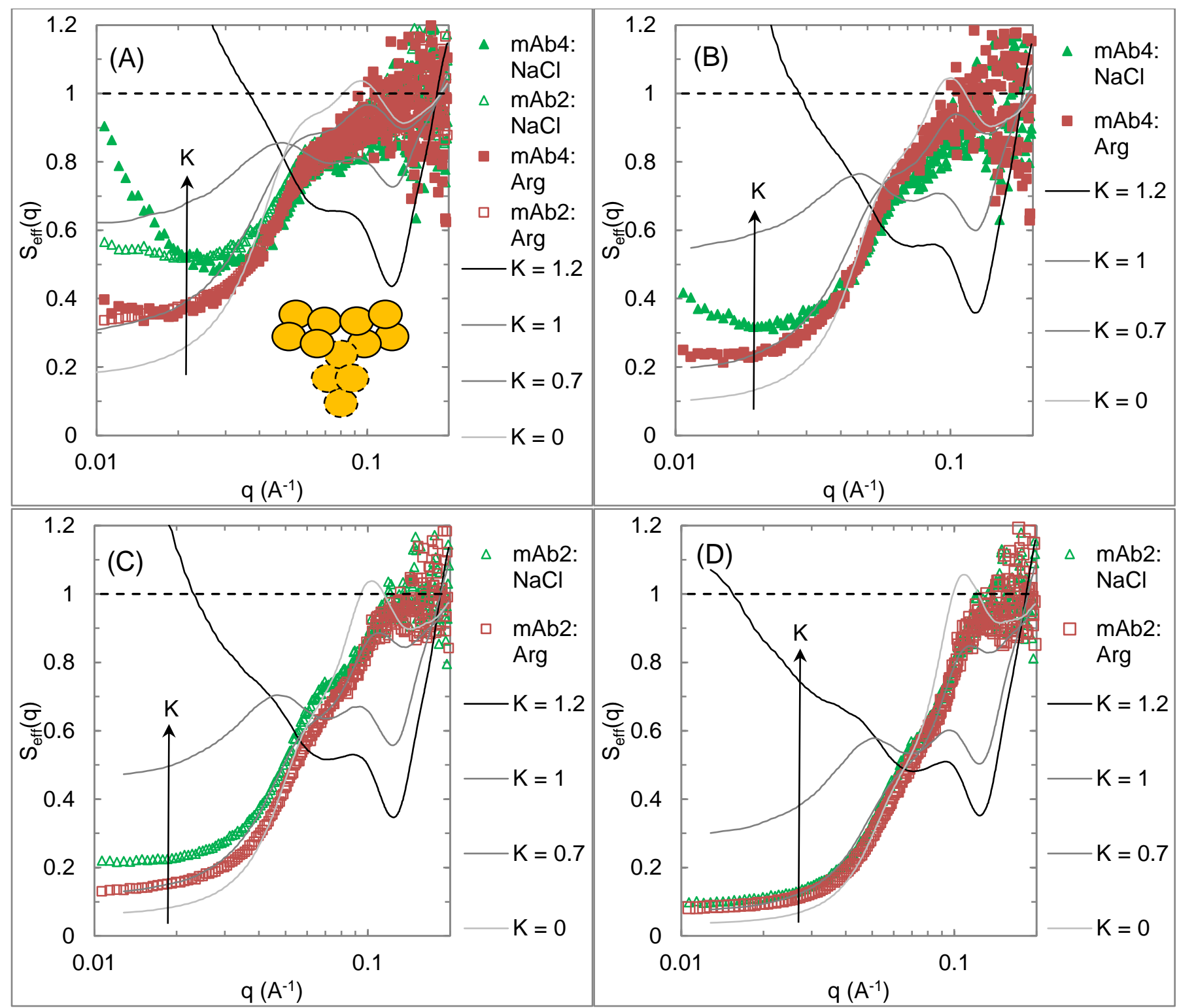

Figures S12.2. $\mathrm{S}_{\text {eff }}(\mathrm{q})$ of mAb data and All4 model for different $\mathrm{K}$ at mAb concentrations of (A) 125, (B) 165, (C) 200 , and (D) $250 \mathrm{mg} / \mathrm{ml}$. Increasing the mAb concentration causes the $\mathrm{S}(0)$ of all systems to decrease, and causes the difference in $S(0)$ between systems with different $K$ to decrease. 

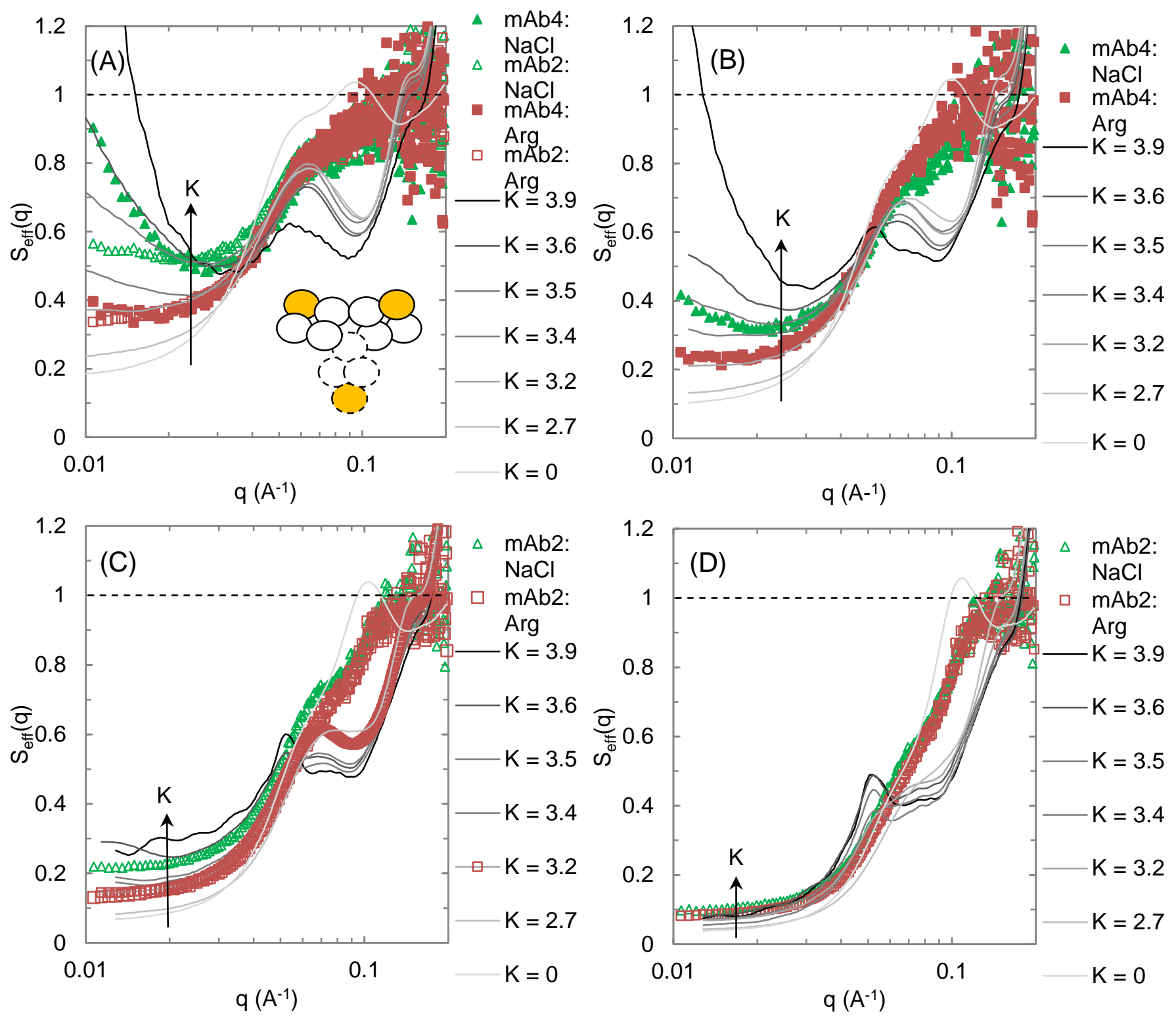

Figures S12.3. $\mathrm{S}_{\text {eff }}(\mathrm{q})$ of mAb data and All1 model for different $\mathrm{K}$ at mAb concentrations of (A) 125, (B) 165, (C) 200 , and (D) $250 \mathrm{mg} / \mathrm{ml}$. Increasing the $\mathrm{mAb}$ concentration causes the $\mathrm{S}(0)$ of all systems to decrease, the difference in $\mathrm{S}(0)$ between systems with different $\mathrm{K}$ to decrease, and causes the upward curvature in $S_{\text {eff }}(q)$ at low q to decrease. 


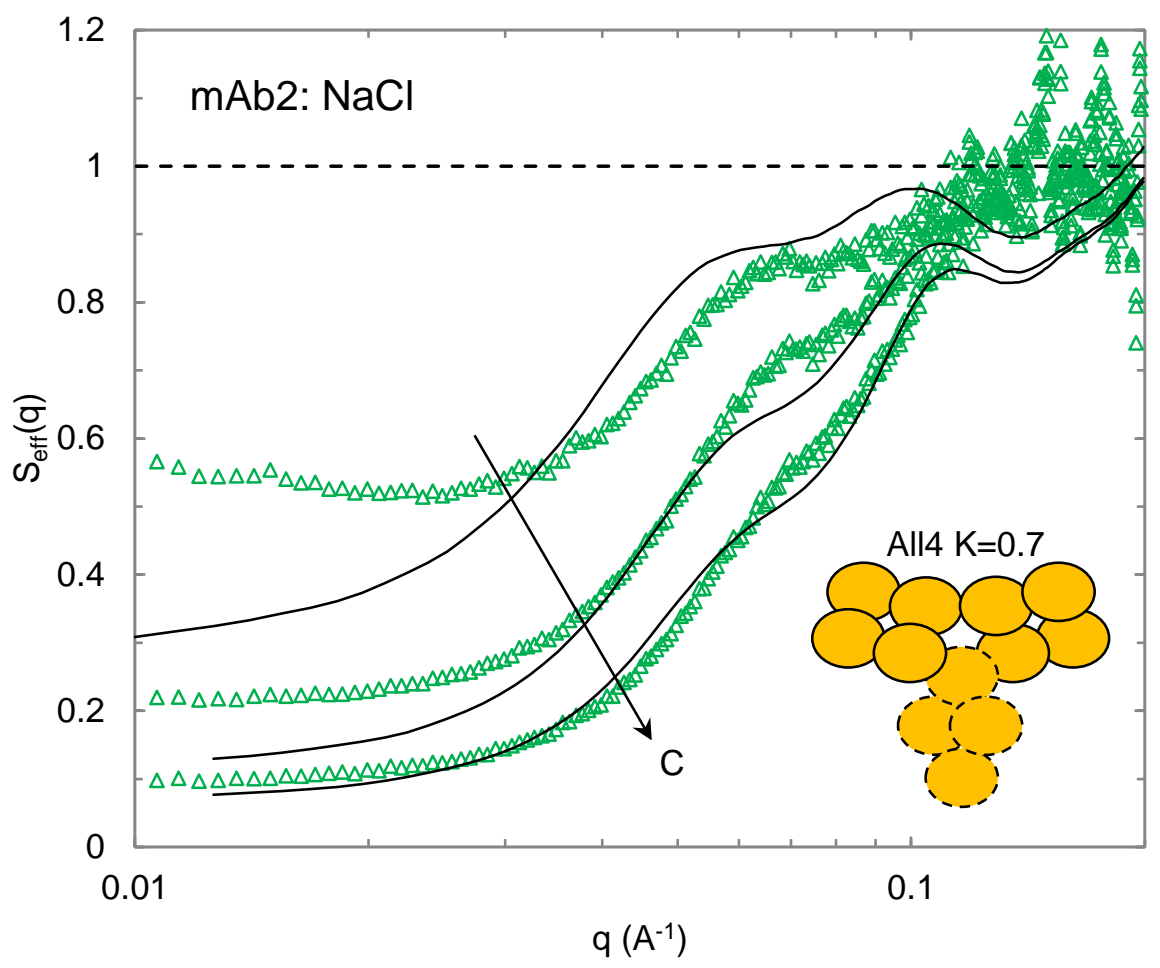

Figures S12.4. $\mathrm{S}_{\text {eff }}(\mathrm{q})$ of $\mathrm{mAb} 2: \mathrm{NaCl}$ at 125,200 and $250 \mathrm{mg} / \mathrm{ml}$ (points) with simulation results from All4 $\mathrm{K}=0.7$ (lines) versus concentration. The model fits the data at the highest concentration $(250 \mathrm{mg} / \mathrm{ml})$ where the models converge, but it does not at the lower concentrations. 

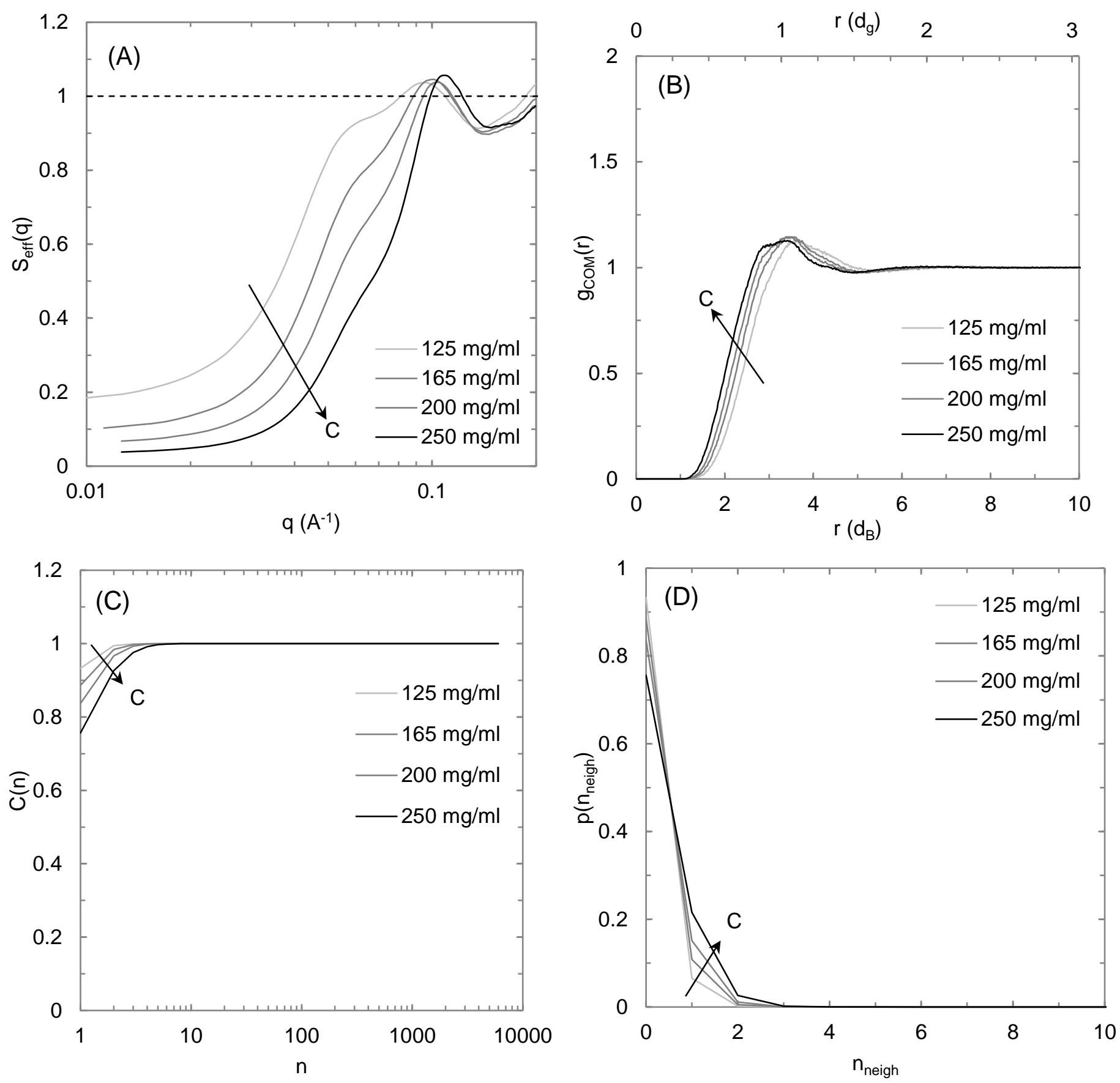

Figure S12.5. (A) $S_{\text {eff }}(q)$ of steric only simulations versus mAb concentration (B) Radial distribution functions, $\mathrm{g}_{\mathrm{COM}}(\mathrm{r})$, of corresponding simulations. (C) Cumulative CSDs of corresponding simulations. (D) Nearest neighbor distributions of corresponding simulations. 

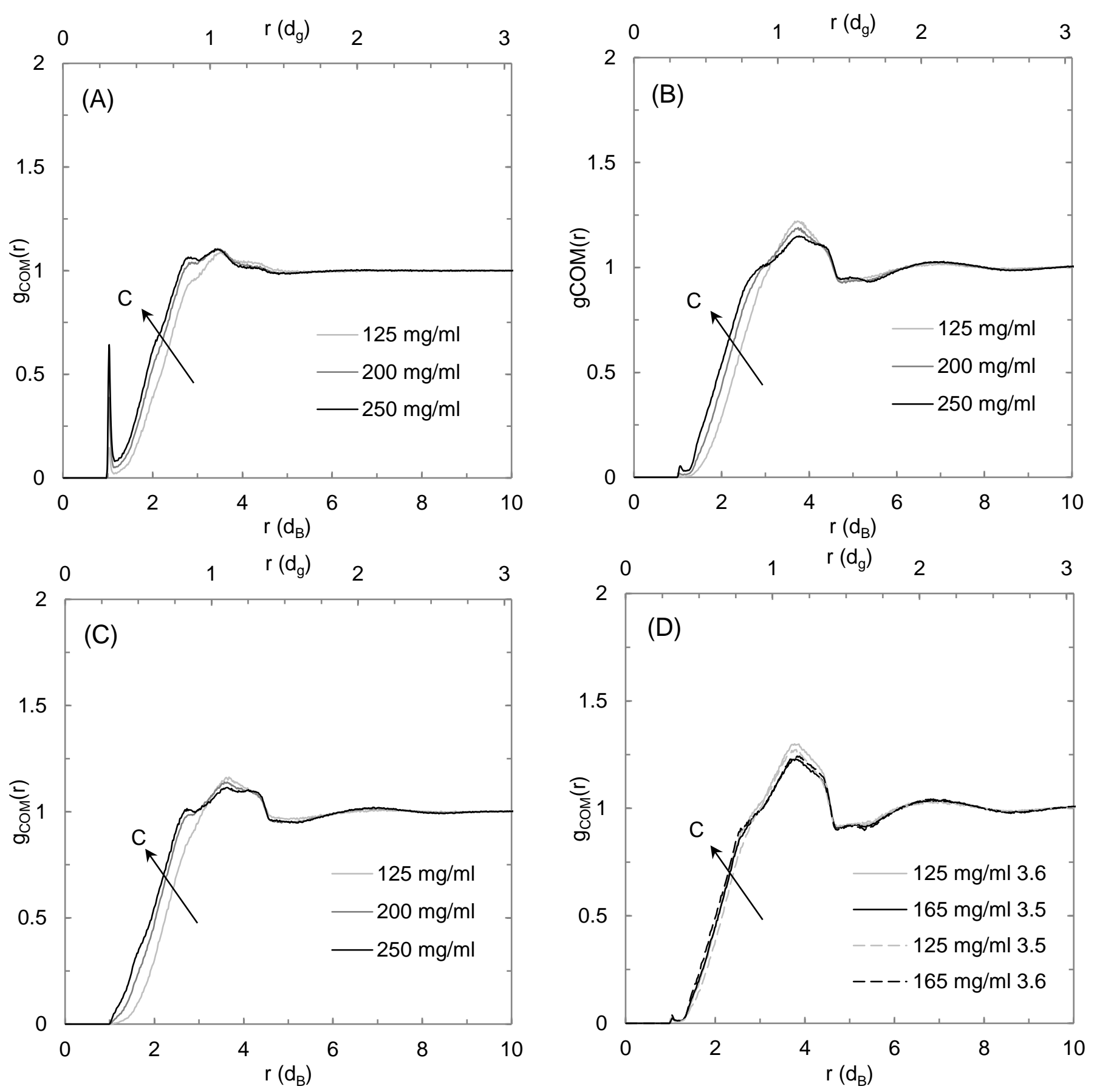

Figure S12.6. Radial distribution functions, $\mathrm{g}_{\mathrm{COM}}(\mathrm{r})$, for each best fit simulation in Fig. 7 across the concentrations measured for the best fit data. (A) All4 K=0.7, which fit mAb2: Arg, (B) All1 K=3.2, which fit mAb2: Arg, (C) FabFab1: K=3.5, which fit mAb2: Arg, and (D) All1 K=3.5 and 3.6, as All1 K=3.6 fit mAb4: $\mathrm{NaCl}$ at $125 \mathrm{mg} / \mathrm{ml}$, while All1 K=3.5 fit mAb4: $\mathrm{NaCl}$ at $165 \mathrm{mg} / \mathrm{ml}$. Solid lines represent the simulations that 
actually fit the data (All1 $\mathrm{K}=3.6$ at $125 \mathrm{mg} / \mathrm{ml}$ and All1 $\mathrm{K}=3.5$ at $165 \mathrm{mg} / \mathrm{ml}$ ) while the dashed lines show the results at the other concentration (All1 $\mathrm{K}=3.5$ at $125 \mathrm{mg} / \mathrm{ml}$ and All1 $\mathrm{K}=3.6$ at $165 \mathrm{mg} / \mathrm{ml}$ ).
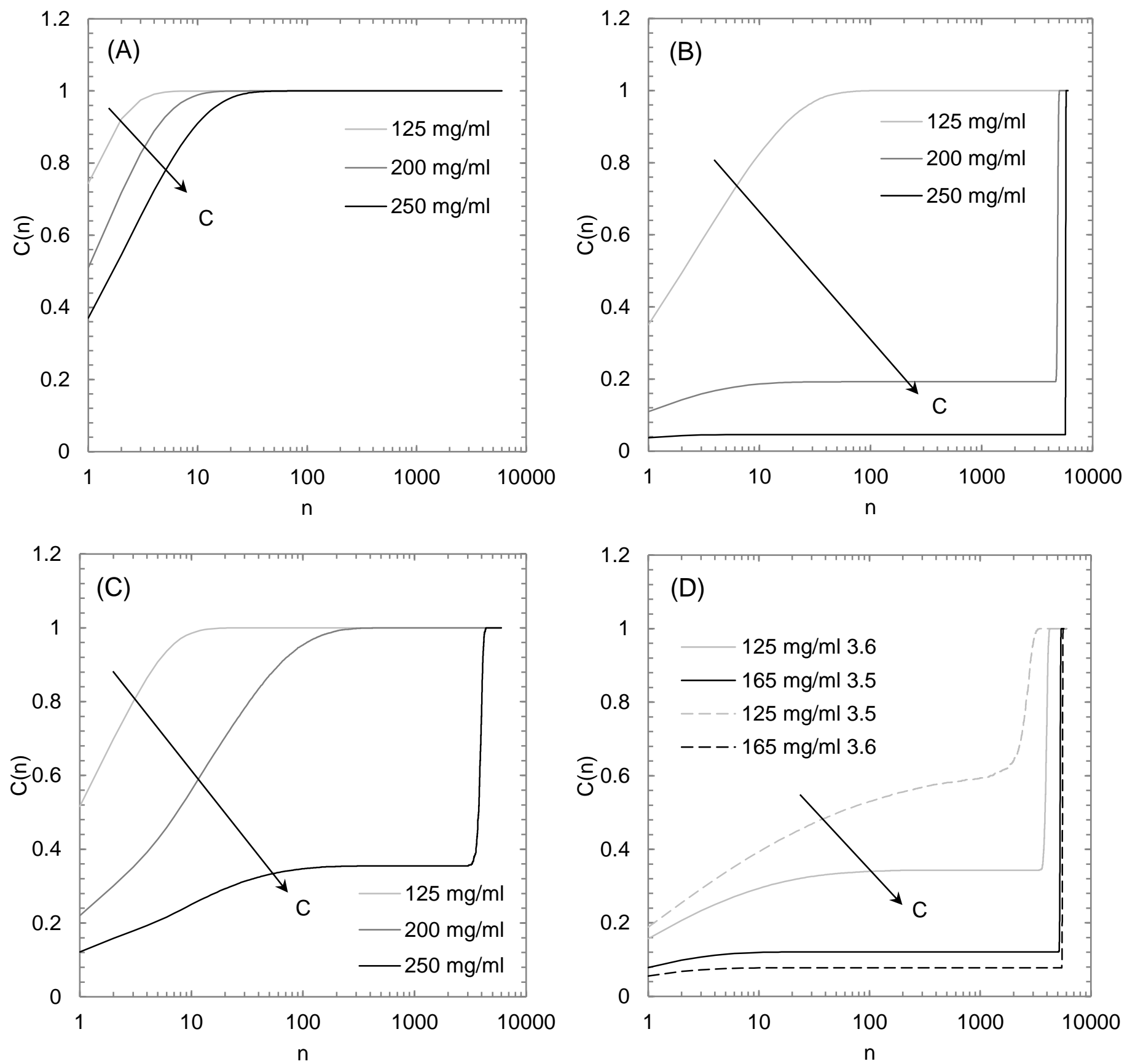

Figure S12.7. Cumulative cluster size distributions, C(n), for each best fit simulation in Fig. 7 across the concentrations measured for the best fit data. (A) All4 K=0.7, which fit mAb2: Arg, (B) All1 K=3.2, which fit mAb2: Arg, (C) FabFab1: K=3.5, which fit mAb2: Arg, and (D) All1 K=3.5 and 3.6, as All1 K=3.6 fit mAb4: $\mathrm{NaCl}$ at $125 \mathrm{mg} / \mathrm{ml}$, while All $\mathrm{K}=3.5$ fit mAb4: $\mathrm{NaCl}$ at $165 \mathrm{mg} / \mathrm{ml}$. Solid lines represent the simulations that 
actually fit the data (All1 $\mathrm{K}=3.6$ at $125 \mathrm{mg} / \mathrm{ml}$ and $\mathrm{All1} \mathrm{K}=3.5$ at $165 \mathrm{mg} / \mathrm{ml}$ ) while the dashed lines show the results at the other concentration (All1 $\mathrm{K}=3.5$ at $125 \mathrm{mg} / \mathrm{ml}$ and All1 $\mathrm{K}=3.6$ at $165 \mathrm{mg} / \mathrm{ml}$ ).
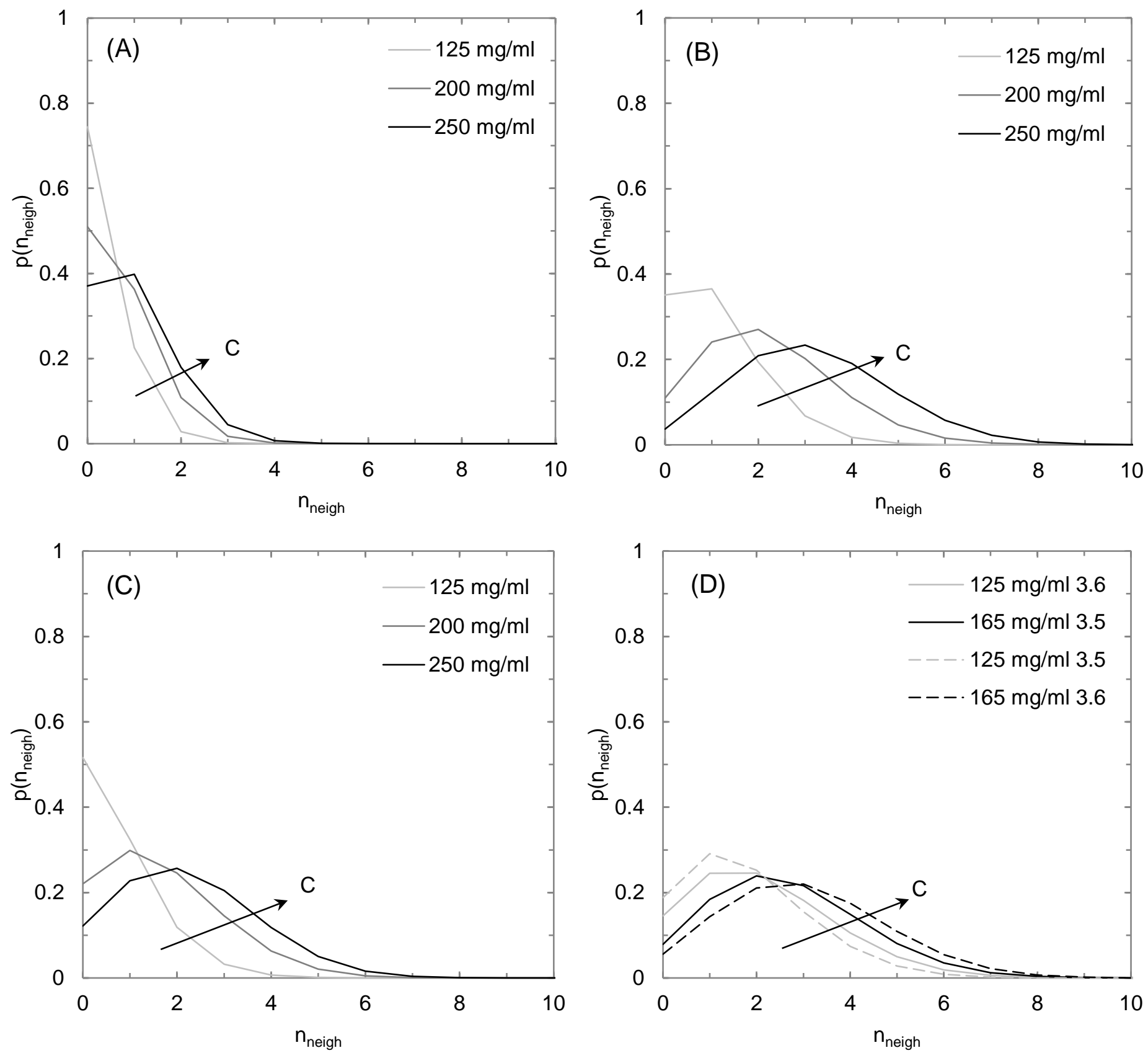

Figure S12.8. Nearest neighbor distributions, $p\left(n_{n e i g h}\right)$, for each best fit simulation in Fig. 7 across the concentrations measured for the best fit data. (A) All4 K=0.7, which fit mAb2: Arg, (B) All1 K=3.2, which fit mAb2: Arg, (C) FabFab1: K=3.5, which fit mAb2: Arg, and (D) All1 K=3.5 and 3.6, as All1 K=3.6 fit mAb4: $\mathrm{NaCl}$ at $125 \mathrm{mg} / \mathrm{ml}$, while All $1 \mathrm{~K}=3.5$ fit $\mathrm{mAb} 4: \mathrm{NaCl}$ at $165 \mathrm{mg} / \mathrm{ml}$. Solid lines and filled symbols represent the simulations that actually fit the data (All1 $\mathrm{K}=3.6$ at $125 \mathrm{mg} / \mathrm{ml}$ and All $1 \mathrm{~K}=3.5$ at $165 \mathrm{mg} / \mathrm{ml}$ ) while the 
dashed lines and hollow symbols show the results at the other concentration (All1 $\mathrm{K}=3.5$ at $125 \mathrm{mg} / \mathrm{ml}$ and All1 $\mathrm{K}=3.6$ at $165 \mathrm{mg} / \mathrm{ml}$ ).
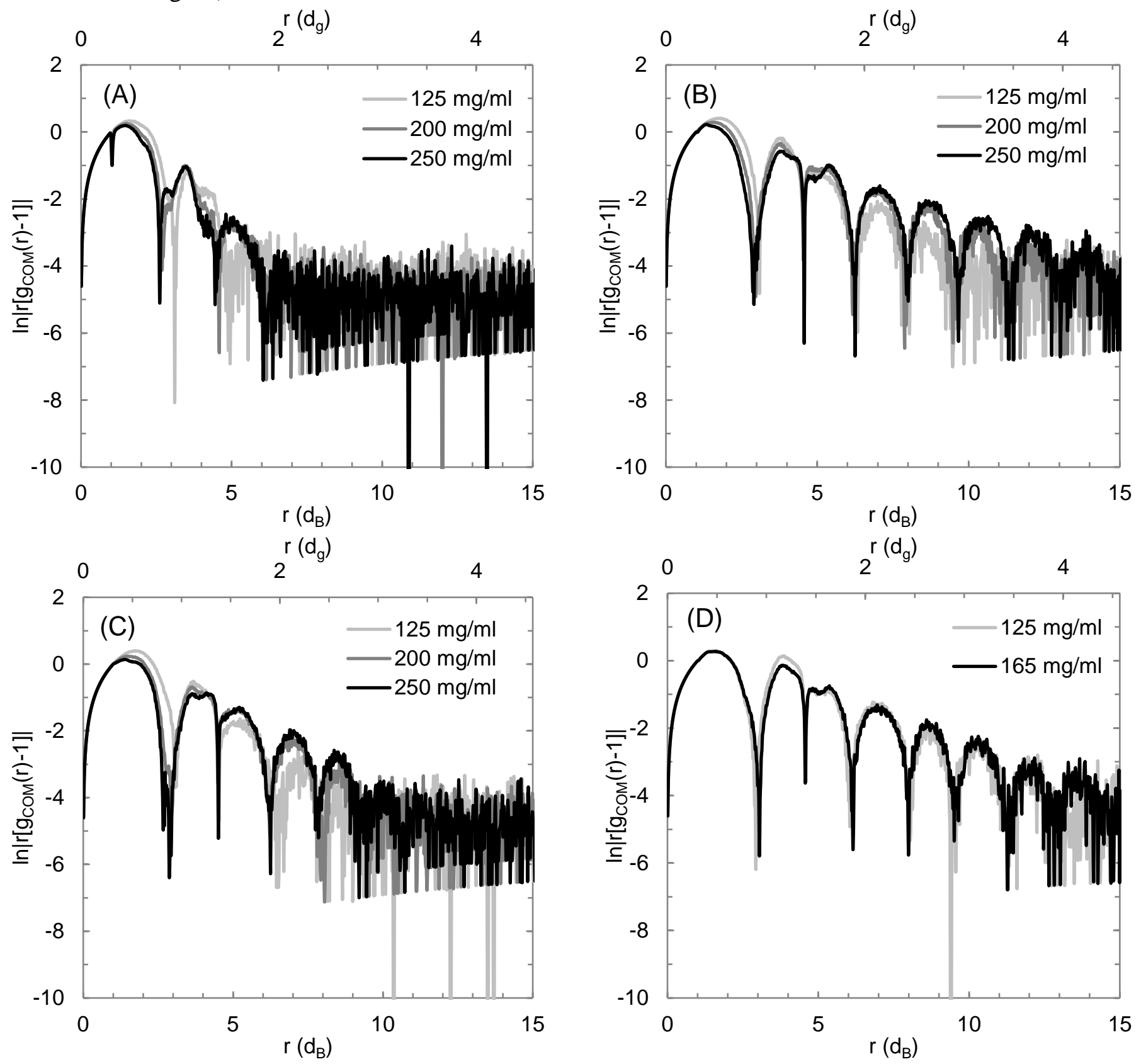

Figure S12.9. Transformed $\mathrm{g}_{\text {Сом }}(\mathrm{r}), \ln \left|\mathrm{r}\left[\mathrm{g}_{\mathrm{COM}}(\mathrm{r})-1\right]\right|$ to emphasize long range oscillations in $\mathrm{g}_{\mathrm{COM}}(\mathrm{r})^{20}$ for each best fit simulation in Fig. 7 across the concentrations measured for the best fit data. (A) All4 K=0.7, which fit mAb2: Arg, (B) All1 K=3.2, which fit mAb2: Arg, (C) FabFab1: K=3.5, which fit mAb2: Arg, and (D) All1 $\mathrm{K}=3.6$ at $125 \mathrm{mg} / \mathrm{ml}$ and $\mathrm{All1} \mathrm{K}=3.5$ at $165 \mathrm{mg} / \mathrm{ml}$, which fit $\mathrm{mAb} 4: \mathrm{NaCl}$. Oscillations at long range ( $\mathrm{r}>5$ ) increase with $\mathrm{mAb}$ concentration for all systems signifying increased order in long range structure. 


\section{SECTION S13: SUMmaRY TABLES OF SimUlations}

The $\mathrm{S}(0)$, slope of $\mathrm{S}_{\text {eff }}\left(\mathrm{q}<0.015 \mathrm{~A}^{-1}\right)$, average aggregation number $\langle n\rangle$, and the average number of nearest neighbors $\left\langle n_{\text {neigh }}\right\rangle$ for every simulation tested are included in this section.

Table S13.1. S(0) of each simulation tested

\begin{tabular}{|c|c|c|c|c|c|c|}
\hline \multirow{2}{*}{ Model } & \multirow{2}{*}{$\mathbf{K}$} & \multirow{2}{*}{$B_{22} / B_{22, S t}$} & \multicolumn{4}{|c|}{$S(0)$} \\
\hline & & & $125 \mathrm{mg} / \mathrm{ml}$ & $165 \mathrm{mg} / \mathrm{ml}$ & $200 \mathrm{mg} / \mathrm{ml}$ & $250 \mathrm{mg} / \mathrm{ml}$ \\
\hline Steric & 0 & 1.00 & 0.19 & 0.10 & 0.07 & 0.04 \\
\hline All4 & 0.7 & 0.75 & 0.31 & 0.20 & 0.13 & 0.08 \\
\hline All4 & 0.9 & 0.61 & 0.46 & --- & --- & --- \\
\hline All4 & 1 & 0.53 & 0.62 & 0.55 & 0.47 & 0.30 \\
\hline All4 & 1.2 & 0.28 & 2.17 & 2.08 & 1.59 & 1.07 \\
\hline All1 & 2.7 & 0.74 & 0.24 & 0.13 & 0.08 & 0.04 \\
\hline All1 & 2.9 & 0.69 & 0.25 & --- & --- & --- \\
\hline All1 & 3 & 0.67 & 0.29 & --- & --- & --- \\
\hline All1 & 3.2 & 0.60 & 0.37 & 0.21 & 0.14 & 0.07 \\
\hline All1 & 3.3 & 0.57 & 0.44 & --- & --- & --- \\
\hline All1 & 3.4 & 0.53 & 0.48 & 0.32 & 0.17 & 0.06 \\
\hline All1 & 3.5 & 0.49 & 0.70 & 0.41 & 0.19 & 0.07 \\
\hline All1 & 3.6 & 0.44 & 0.90 & 0.53 & 0.29 & 0.08 \\
\hline All1 & 3.9 & 0.27 & 2.42 & 1.25 & 0.27 & 0.08 \\
\hline FabFab1 & 3 & 0.87 & 0.24 & --- & --- & --- \\
\hline FabFab1 & 3.5 & 0.79 & 0.31 & 0.21 & 0.13 & 0.08 \\
\hline FabFab1 & 3.7 & 0.76 & 0.40 & 0.29 & 0.17 & 0.08 \\
\hline FabFab1 & 3.9 & 0.71 & 0.58 & --- & --- & --- \\
\hline FabFab1 & 4.2 & 0.62 & 0.83 & --- & --- & --- \\
\hline FabFab1 & 4.5 & 0.50 & 1.08 & 0.53 & 0.25 & 0.08 \\
\hline FabFab1 & 4.9 & 0.26 & 1.23 & 0.58 & 0.28 & 0.13 \\
\hline
\end{tabular}


Table S13.2. Slope of $S_{\text {eff }}(q)$ at $q<0.015$ of each simulation tested

\begin{tabular}{|c|c|c|c|c|c|c|}
\hline \multirow{2}{*}{ Model } & \multirow{2}{*}{$K$} & \multirow{2}{*}{$\mathrm{B}_{22} / \mathrm{B}_{22, \mathrm{st}}$} & \multicolumn{4}{|c|}{ Slope $(A) S\left(q<0.015 A^{-1}\right)$} \\
\hline & & & $125 \mathrm{mg} / \mathrm{ml}$ & $165 \mathrm{mg} / \mathrm{ml}$ & $200 \mathrm{mg} / \mathrm{ml}$ & $250 \mathrm{mg} / \mathrm{ml}$ \\
\hline Steric & 0 & 1.00 & 4.7 & 2.9 & 1.7 & 1.1 \\
\hline All4 & 0.7 & 0.75 & 6.1 & 3.2 & 2.9 & 1.9 \\
\hline All4 & 0.9 & 0.61 & 4.3 & --- & --- & --- \\
\hline All4 & 1 & 0.53 & 4.3 & 5.0 & 3.3 & 3.5 \\
\hline All4 & 1.2 & 0.28 & -87 & -105 & -77 & -24 \\
\hline All1 & 2.7 & 0.74 & 3.9 & 2.2 & 2.1 & 0.7 \\
\hline All1 & 2.9 & 0.69 & 2.4 & --- & --- & --- \\
\hline All1 & 3 & 0.67 & 1.4 & --- & --- & --- \\
\hline All1 & 3.2 & 0.60 & -1.3 & 0.83 & 0.86 & 0.40 \\
\hline All1 & 3.3 & 0.57 & -3.8 & --- & --- & --- \\
\hline All1 & 3.4 & 0.53 & -9.6 & -5.5 & -2.8 & 1.7 \\
\hline All1 & 3.5 & 0.49 & -20 & -9.4 & -3.4 & 1.5 \\
\hline All1 & 3.6 & 0.44 & -48 & -17 & -4.1 & 2.0 \\
\hline All1 & 3.9 & 0.27 & -330 & -130 & -4.2 & 3.7 \\
\hline FabFab1 & 3 & 0.87 & 5.1 & --- & --- & --- \\
\hline FabFab1 & 3.5 & 0.79 & 6.7 & 5.4 & 5.0 & 3.3 \\
\hline FabFab1 & 3.7 & 0.76 & 7.9 & 8.6 & 8.0 & 3.8 \\
\hline FabFab1 & 3.9 & 0.71 & 16 & --- & --- & --- \\
\hline FabFab1 & 4.2 & 0.62 & 29 & --- & --- & --- \\
\hline FabFab1 & 4.5 & 0.50 & 35 & 30 & 17 & 4.3 \\
\hline FabFab1 & 4.9 & 0.26 & 40 & 17 & 29 & 19 \\
\hline
\end{tabular}


Table S13.3. Average aggregation number, $\langle n\rangle$, from CSD of each simulation tested

\begin{tabular}{|c|c|c|c|c|c|c|}
\hline \multirow{2}{*}{ Model } & \multirow{2}{*}{$\mathrm{K}$} & \multirow{2}{*}{$B_{22} / B_{22, S t}$} & \multicolumn{4}{|c|}{$\langle n\rangle$} \\
\hline & & & $125 \mathrm{mg} / \mathrm{ml}$ & $165 \mathrm{mg} / \mathrm{ml}$ & $200 \mathrm{mg} / \mathrm{ml}$ & $250 \mathrm{mg} / \mathrm{ml}$ \\
\hline Steric & 0 & 1.00 & 1.07 & 1.13 & 1.21 & 1.36 \\
\hline All4 & 0.7 & 0.75 & 1.37 & 1.71 & 2.29 & 4.14 \\
\hline All4 & 0.9 & 0.61 & 1.81 & --- & --- & --- \\
\hline All4 & 1 & 0.53 & 2.50 & 4.96 & 8.23 & 52.1 \\
\hline All4 & 1.2 & 0.28 & 16.2 & 430 & 1310 & 3390 \\
\hline All1 & 2.7 & 0.74 & 1.87 & 3.62 & 9.95 & 1720 \\
\hline All1 & 2.9 & 0.69 & 2.61 & --- & --- & --- \\
\hline All1 & 3 & 0.67 & 3.51 & --- & --- & --- \\
\hline All1 & 3.2 & 0.60 & 6.35 & 1530 & 3910 & 5460 \\
\hline All1 & 3.3 & 0.57 & 8.85 & --- & --- & --- \\
\hline All1 & 3.4 & 0.53 & 179 & 3850 & 5330 & 5860 \\
\hline All1 & 3.5 & 0.49 & 1050 & 4640 & 5620 & 5890 \\
\hline All1 & 3.6 & 0.44 & 2590 & 5100 & 5680 & 5920 \\
\hline All1 & 3.9 & 0.27 & 5200 & 5810 & 5950 & 5980 \\
\hline FabFab1 & 3 & 0.87 & 1.36 & --- & --- & --- \\
\hline FabFab1 & 3.5 & 0.79 & 2.42 & 4.99 & 22.8 & 2510 \\
\hline FabFab1 & 3.7 & 0.76 & 4.30 & 22.9 & 2130 & 5200 \\
\hline FabFab1 & 3.9 & 0.71 & 9.26 & --- & --- & --- \\
\hline FabFab1 & 4.2 & 0.62 & 214 & --- & --- & --- \\
\hline FabFab1 & 4.5 & 0.50 & 4800 & 5770 & 5910 & 5950 \\
\hline FabFab1 & 4.9 & 0.26 & 5820 & 5960 & 5980 & 5980 \\
\hline
\end{tabular}


Table S13.4. Average number of nearest neighbors, $\left\langle n_{\text {neigh }}\right\rangle$, of each simulation tested

\begin{tabular}{|c|c|c|c|c|c|c|}
\hline \multirow{2}{*}{ Model } & \multirow{2}{*}{$\mathbf{K}$} & \multirow{2}{*}{$\mathrm{B}_{22} / \mathrm{B}_{22, \mathrm{St}}$} & \multicolumn{4}{|c|}{$\left\langle\boldsymbol{n}_{\text {neigh }}\right\rangle$} \\
\hline & & & $125 \mathrm{mg} / \mathrm{ml}$ & $165 \mathrm{mg} / \mathrm{ml}$ & $200 \mathrm{mg} / \mathrm{ml}$ & $250 \mathrm{mg} / \mathrm{ml}$ \\
\hline Steric & 0 & 1.00 & 0.07 & 0.12 & 0.18 & 0.27 \\
\hline All4 & 0.7 & 0.75 & 0.29 & 0.46 & 0.64 & 0.92 \\
\hline All4 & 0.9 & 0.61 & 0.50 & --- & --- & --- \\
\hline All4 & 1 & 0.53 & 0.74 & 1.1 & 1.3 & 1.6 \\
\hline All4 & 1.2 & 0.28 & 1.5 & 1.9 & 2.1 & 2.2 \\
\hline All1 & 2.7 & 0.74 & 0.56 & 0.84 & 1.1 & 1.7 \\
\hline All1 & 2.9 & 0.69 & 0.77 & --- & --- & --- \\
\hline All1 & 3 & 0.67 & 0.83 & --- & --- & --- \\
\hline All1 & 3.2 & 0.60 & 1.0 & 1.7 & 2.2 & 3.2 \\
\hline All1 & 3.3 & 0.57 & 1.2 & --- & --- & --- \\
\hline All1 & 3.4 & 0.53 & 1.6 & 2.2 & 3.1 & 4.2 \\
\hline All1 & 3.5 & 0.49 & 1.8 & 2.6 & 3.5 & 4.3 \\
\hline All1 & 3.6 & 0.44 & 2.1 & 3.0 & 3.7 & 4.5 \\
\hline All1 & 3.9 & 0.27 & 3.7 & 4.4 & 4.9 & 5.3 \\
\hline FabFab1 & 3 & 0.87 & 0.35 & --- & --- & --- \\
\hline FabFab1 & 3.5 & 0.79 & 0.69 & 1.1 & 1.6 & 2.2 \\
\hline FabFab1 & 3.7 & 0.76 & 1.1 & 1.8 & 2.4 & 3.1 \\
\hline FabFab1 & 3.9 & 0.71 & 1.7 & --- & --- & --- \\
\hline FabFab1 & 4.2 & 0.62 & 3.0 & --- & --- & --- \\
\hline FabFab1 & 4.5 & 0.50 & 3.9 & 4.1 & 4.3 & 4.5 \\
\hline FabFab1 & 4.9 & 0.26 & 4.4 & 4.6 & 4.8 & 4.9 \\
\hline
\end{tabular}




\section{SECTION S14: ViscositieS}

\section{Section S14.1: Viscosity Experimental Details}

The mAb2 sample viscosities were measured using both a microfluidic Viscometer/Rheometer-on-Chip (m-VROC, Rheosense Inc. San Ramon, CA) with a C05 chip and with a syringe viscometer (both at $25^{\circ} \mathrm{C}$ ) described in previous work, ${ }^{1-3}$ and as can be seen in Fig. S14.1.1 the two methods agree within error. The mVROC measurements were taken at shear rates of $500 \mathrm{~s}^{-1}$ and $1000 \mathrm{~s}^{-1}$, until the measurement stabilized (at three consecutive runs with measured viscosities within 5\%). The viscosity and standard deviation reported is from the average and standard deviation of the measurements at $1000 \mathrm{~s}^{-1}$ after the measurement had stabilized, though Newtonian behavior was observed for all samples in this shear range.

The mAb4 sample viscosities were measured at the Rheosense facility in San Ramon, CA on a Rheosense VROC Initium, which is an automated version of a Rheosense m-VROC. The viscosities were measured using a B05 chip and all reported viscosities were all measured at shear rates that were automatically selected to achieve $50 \%$ of the chip max pressure capacity of $40 \mathrm{kPa}$ for each measurement. Therefore, the shear rate was lower for more viscous samples and higher for less viscous ones as the pressure is proportional to both shear rate and viscosity. The actual shear rates used for each measurement are shown in Fig. S14.1.2 Solvent viscosities were measured by a Cannon-Fenske viscometer and confirmed by m-VROC using a B05 chip at shear rates ranging from 5000 to $20000 \mathrm{~s}^{-1}$ and are reported in Table S14.1.1. 


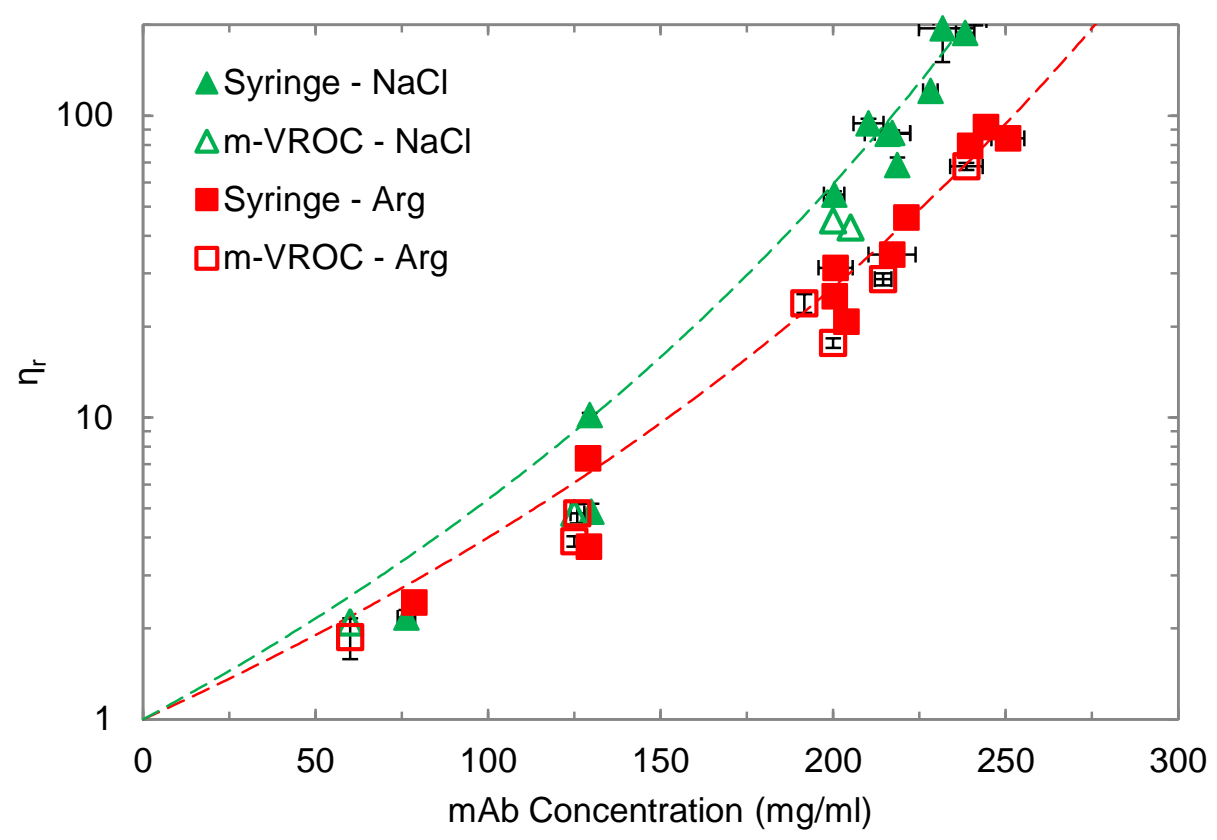

Figure S14.1.1. Comparison of measured viscosity by syringe viscometer and m-VROC for mAb2 with 250 $\mathrm{mM} \operatorname{Arg}(\mathrm{HCl})$ and $250 \mathrm{mM} \mathrm{NaCl}$. The line is fit to the data using the Ross-Minton equation.

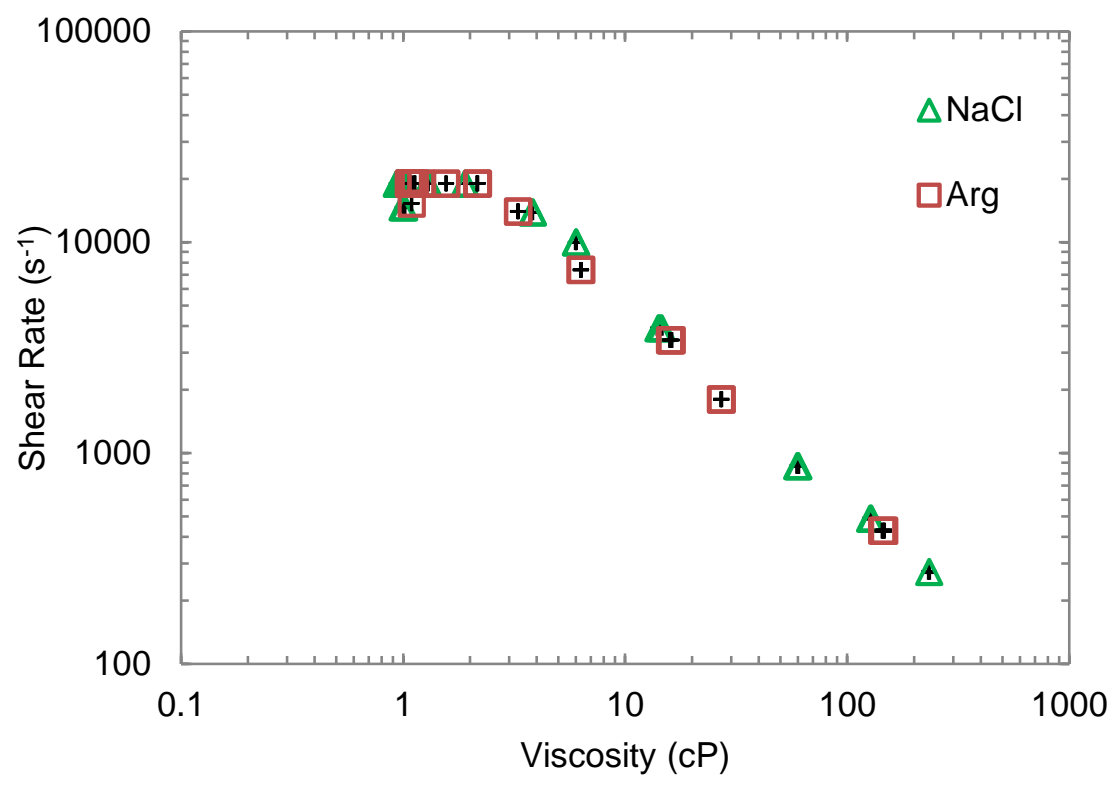

Figure. S14.1.2. Shear rate selected by Rheosense Initium for viscosity measurements of mAb4 samples of various concentrations with $250 \mathrm{mM}$ of listed co-solute versus the measured viscosities of those samples. 
Table S14.1.1. Solvent viscosities

\begin{tabular}{|l|l|c|}
\hline \multicolumn{1}{|c|}{ Background buffer } & \multicolumn{1}{c|}{ Additional Co-solute } & Viscosity (cP) \\
\hline $30 \mathrm{mM}(\mathrm{Na})$ Ace $\mathrm{pH} 5.5$ & None & 0.89 \\
\hline $30 \mathrm{mM}(\mathrm{Na})$ Ace $\mathrm{pH} 5.5$ & $50 \mathrm{mM} \mathrm{NaCl}$ & 0.92 \\
\hline $30 \mathrm{mM}(\mathrm{Na})$ Ace $\mathrm{pH} 5.5$ & $250 \mathrm{mM} \mathrm{NaCl}$ & 0.94 \\
\hline $30 \mathrm{mM}(\mathrm{Na}) \mathrm{Ace}$ pH 5.5 & $250 \mathrm{mM} \mathrm{Arg}(\mathrm{HCl})$ & 1.05 \\
\hline $30 \mathrm{mM} \mathrm{His}(\mathrm{HCl}) \mathrm{pH} 6$ & $250 \mathrm{mM} \mathrm{NaCl}$ & 0.94 \\
\hline $30 \mathrm{mM} \mathrm{His}(\mathrm{HCl}) \mathrm{pH} 6$ & $250 \mathrm{mM} \mathrm{Arg}(\mathrm{HCl})$ & 1.05 \\
\hline
\end{tabular}




\section{Section S14.2 Modeling Viscosities by Ross-Minton Equation}

The Ross-Minton equation is a quasi-spherical hard particle viscosity model that relates relative viscosity, $\eta_{\mathrm{r}}$, to particle features accounting for the volume per mass of the particle through the intrinsic viscosity, $[\eta]$, the max packing fraction which is inversely related to the crowding factor, $\mathrm{k}$, and the particle asymmetry through the Simha shape parameter, ${ }^{22} v$, as shown below where $\mathrm{c}$ is the particle concentration. ${ }^{23}$ $\eta_{r}=\exp \left(\frac{c[\eta]}{1-c[\eta] \frac{k}{v}}\right)$

The Ross-Minton equation is commonly applied to mAb solutions, ${ }^{1-2,24-26}$ and previous work has shown that highly attractive mAbs have downward curvature when plotted as a linearized version of the Ross-Minton curve, while less viscous mAbs remain linear. ${ }^{25}$ This has been shown to apply to multiple different mAbs. ${ }^{1-2,25-}$ ${ }^{26}$ The linearized version of the Ross-Minton equation is shown below

$\eta_{\text {inh }} \equiv \frac{\ln \left(\eta_{r}\right)}{c}=[\eta]+\frac{k}{v}[\eta] c$

If a solution has downward concavity when fit to the linearized Ross-Minton equation, it shows that as the mAb concentration is increased the $y$-intercept and therefore $[\eta]$ increases, which implies that the protein is spreading its mass over volume less efficiently, which is consistent with self-association. (Note, that low concentration values of $[\eta]$ are typically about $6 \mathrm{ml} / \mathrm{g}$ for mAbs). ${ }^{24-25}$ Similarly for downward concavity the slope must be decreasing with concentration, and since $[\eta]$ has already been shown to be increasing $\mathrm{k} / \mathrm{v}$ must be decreasing by more. This can be explained by an increase in $v$ which implies an increase in particle asymmetry which is also consistent with self-association. The viscosities of all tested systems of mAb2 and mAb4 are plotted in Fig. S14.2.1 along with Ross-Minton equation fits across the entire mAb concentration. Linearized versions of the Ross-Minton equation are also fit for the mAb solutions in Fig. S14.2.2 to demonstrate their downward concavity, shown by fitting lines of different slope and y-intercept over different concentration regions, as has been done previously. ${ }^{25}$ The best [ $\left.\eta\right]$ and $\mathrm{k} / v$ to the fits in both S14.2.1 and S14.2.2 are listed in Table S14.2.1, and as can be seen the downward concavity is most pronounced for mAb4: $\mathrm{NaCl}$, then mAb4: Arg and mAb2: $\mathrm{NaCl}$, while mAb2: Arg is the most linear. Additionally, the high concentration intrinsic viscosities from the linearized fits, which can be used to approximate effective molecular volume, ${ }^{26-27}$ follow the same order mAb4: $\mathrm{NaCl}>$ mAb4: Arg > mAb2: $\mathrm{NaCl}>$ mAb2: Arg. 


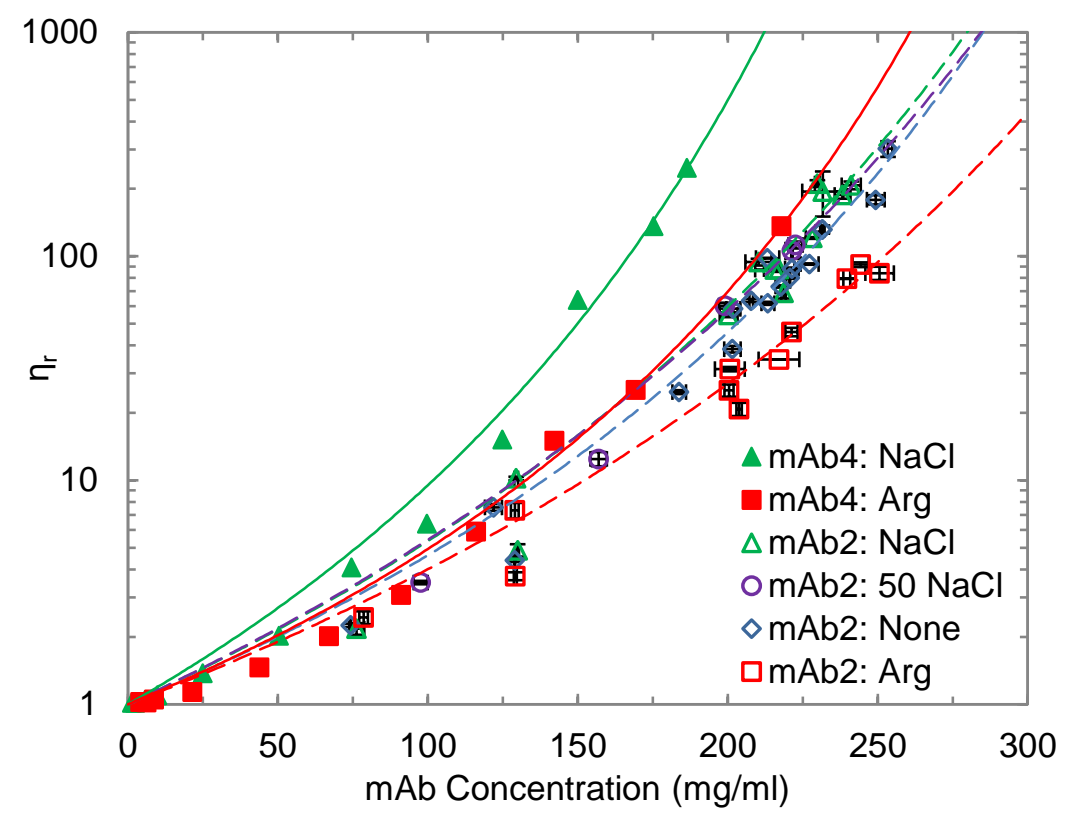

Figure S14.2.1. Viscosity Data for all measured mAb solutions, shown with fits to the Ross-Minton equation (lines). If not listed co-solutes are at $250 \mathrm{mM}$.
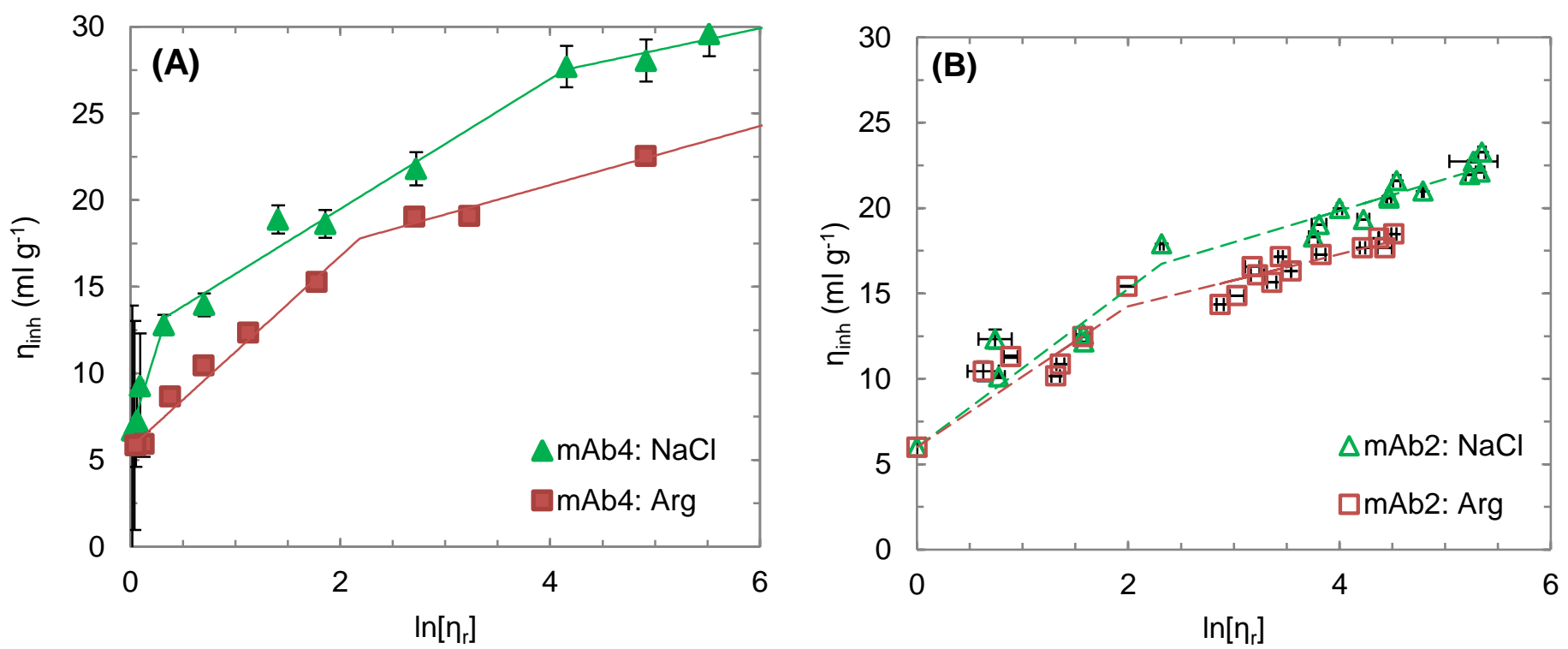

Figure S14.2.2. Viscosity data fit to linearized Ross-Minton equation (lines) for solutions of (A) mAb4, and (B) $\mathrm{mAb} 2$. Listed co-solutes are at $250 \mathrm{mM}$. The $\mathrm{mAb} 2$ solutions have more noise at low concentration $\left(\operatorname{low} \ln \left[\eta_{\mathrm{r}}\right]\right)$ than the mAb4 solutions because they were measured by syringe viscometer which yields noisier low viscosity measurements than the Rheosense Initium. Therefore, the low viscosity y-intercept was set to $6.0 \mathrm{ml} / \mathrm{g}$ for 
mAb2 solutions as this is the average of the fit mAb4 solutions and approximately matches the expected value for mAbs. ${ }^{24-25}$

Table S14.2.1. Best fit parameters to the Ross-Minton equation for mAb systems with $250 \mathrm{mM}$ listed co-solute, (unless otherwise specified) results are plotted in Figure S14.2.1 and S14.2.2.

\begin{tabular}{|c|c|c|c|c|}
\hline $\mathrm{mAb}$ & Co-solutes & $\begin{array}{c}\text { Concentration } \\
\text { Regime of Fit }\end{array}$ & {$[\eta](\mathrm{ml} / \mathrm{g})$} & $\mathrm{k} / \mathrm{v}$ \\
\hline $\mathrm{mAb} 4$ & $\mathrm{NaCl}$ & Full & 17.7 & 0.122 \\
\hline $\mathrm{mAb} 4$ & $\mathrm{Arg}$ & Full & 12.8 & 0.155 \\
\hline $\mathrm{mAb} 2$ & $\mathrm{None}$ & Full & 12.8 & 0.130 \\
\hline $\mathrm{mAb} 2$ & $50 \mathrm{mM} \mathrm{NaCl}$ & Full & 14.5 & 0.097 \\
\hline $\mathrm{mAb} 2$ & $\mathrm{NaCl}$ & Full & 14.2 & 0.106 \\
\hline $\mathrm{mAb} 2$ & $\mathrm{Arg}$ & Full & 12.0 & 0.114 \\
\hline $\mathrm{mAb} 4$ & $\mathrm{NaCl}$ & Low & 6.30 & 3.007 \\
\hline $\mathrm{mAb} 4$ & $\mathrm{NaCl}$ & Intermediate & 12.0 & 0.313 \\
\hline $\mathrm{mAb} 4$ & $\mathrm{NaCl}$ & High & 22.2 & 0.058 \\
\hline $\mathrm{mAb} 4$ & $\mathrm{Arg}$ & Low & 5.71 & 0.968 \\
\hline $\mathrm{mAb} 4$ & $\mathrm{Arg}$ & High & 14.1 & 0.121 \\
\hline $\mathrm{mAb} 2$ & $\mathrm{NaCl}$ & Low & $6.0^{*}$ & 0.773 \\
\hline $\mathrm{mAb} 2$ & $\mathrm{NaCl}$ & High & 12.5 & 0.148 \\
\hline $\mathrm{mAb} 2$ & $\mathrm{Arg}$ & Low & $6.0^{*}$ & 0.690 \\
\hline $\mathrm{mAb} 2$ & $\mathrm{Arg}$ & High & 11.2 & 0.136 \\
\hline
\end{tabular}

*Values were set to $6.0 \mathrm{ml} / \mathrm{g}$ instead of being fit 


\section{Section S14.3 Modeling Viscosities by Entanglement Model}

The entanglement model, developed previously, ${ }^{28}$ assumes that reversible Fab-Fab attractions cause mAbs to linearly associate end-to-end, causing entanglements that elevate viscosity by the following relation.

$\eta_{r}=\frac{A}{\eta_{0}} c^{\frac{3}{3 v-1}}\langle N\rangle^{3}=\frac{A}{\eta_{0}} c^{\frac{3}{3 v-1}}\left[\frac{2 k c}{\sqrt{1+4 k c}-1}\right]^{3}$

Where $\eta_{r}$ is the relative viscosity, defined as the absolute viscosity divided by the solvent viscosity, $\eta_{0}, c$ is the mAb concentration, $v=3 / 5$ is the Flory exponent, $\langle N\rangle$ is the average aggregation number $(\langle N\rangle$ is used to distinguish it from average aggregation from 12 bead model simulations $\langle n\rangle), k$ is the partition function between all possible association states, and $A$ is a constant fit to be $5.4 * 10^{-8} \mathrm{cP}(\mathrm{mg} / \mathrm{ml})^{-3.75}$ by both the original authors ${ }^{28}$ and independently for this work. $A$ was fit to all the data simultaneously, while $k$ was individually fit to each data set. Note that this model is not directly comparable to the FabFab1 simulations as this model only allows for $1 \mathrm{mAb}$ contact per Fab, while FabFab1 allows (and shows) multiple different mAbs interacting simultaneously with a single Fab. The entanglement model, which is fit to the mAb2 and mAb4 data in Fig. S14.3.1A, suggests that the differences in viscosity between the four mAb systems may be interpreted as quantifiable differences in self-association with mAb4: $\mathrm{NaCl}$, having the most association and mAb2: Arg the least, as seen in Fig. S14.3.1B. The best fit $k$ values for each solution are shown in Table S14.3.1, along with $\ln (k)$ which represents the fit Fab-Fab binding strength in $\mathrm{k}_{\mathrm{B}} \mathrm{T}$. Qualitatively $\langle N\rangle$ agrees with the bead model simulations as the self-association of the mAb solutions follows the same order as seen by SAXS, but the predicted aggregation numbers from the entanglement viscosity model are much lower than those from the bead model simulations. This discrepancy likely indicates the limitations applying the entanglement model to proteins, as this model was designed for characterizing entanglements between high molecular weight polymers and is not theoretically applicable to smaller entanglements. ${ }^{28}$ Even though the $\langle N\rangle$ likely does not quantitatively represent the mAb data, the calculated attraction energies, $-\ln (k)$, from this model correspond directly with the solution viscosities and therefore can be interpreted as qualitative measurements of solution attraction from viscosity. Similarly the net attraction $\left(\mathrm{B}_{22} / \mathrm{B}_{22, \mathrm{HS}}\right)$ determined from the isotropic HSY potentials 
fit to the SAXS $S_{\text {eff }}(q)$ can be interpreted as qualitative measurements of attraction from SAXS. Fig. S14.3.2 shows that these measurements of attraction from both SAXS and viscosity directly correlate for the mAb2 and mAb4 solutions tested. This correlation is expected given that HSY potentials were fit to $S_{\text {eff }}(q)$ at low q-values representing large length scale structures, which are a dominant contribution to solution viscosity.
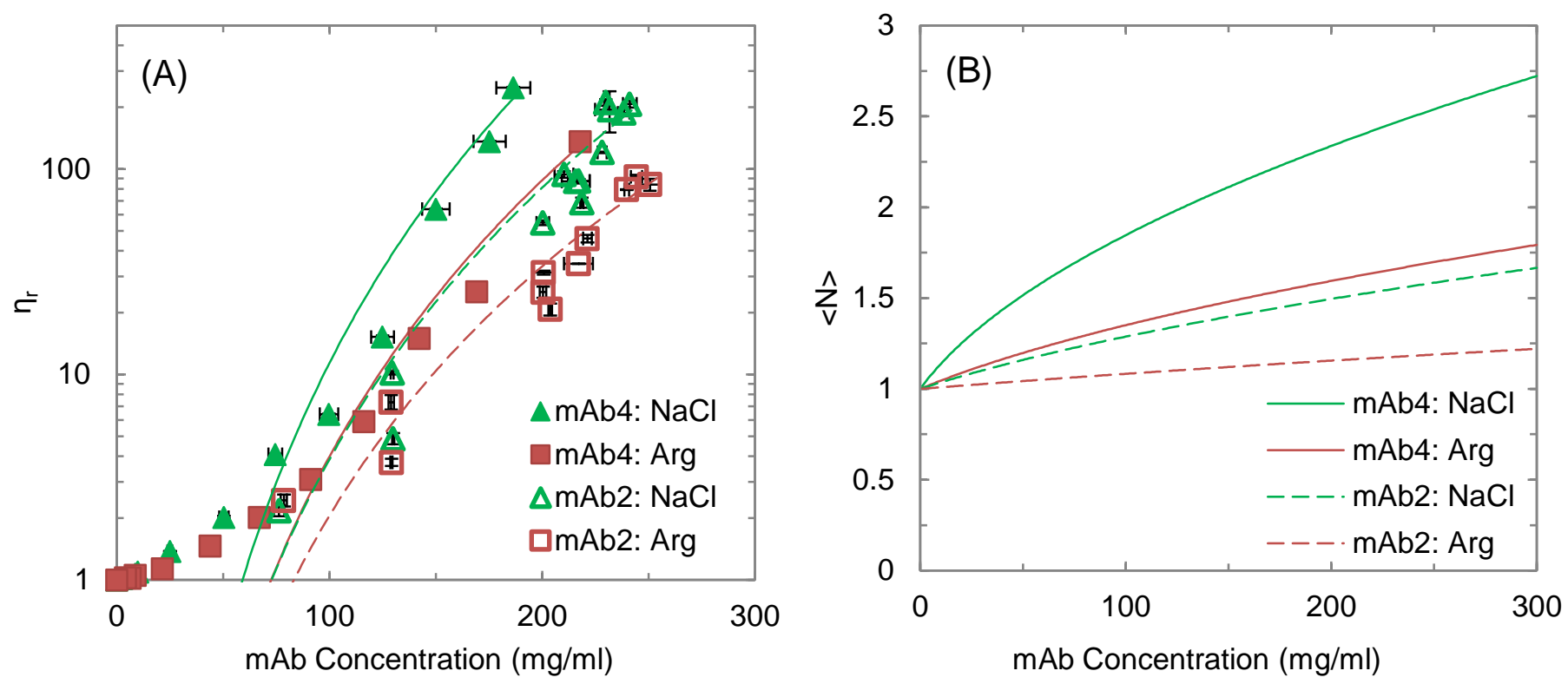

Figure S14.3.1. (A) Relative viscosity versus mAb concentration for mAb2 and mAb4 at pH 6 with $250 \mathrm{mM}$ of listed co-solutes. Lines are fits to the data by the entanglement viscosity model. (B) Average aggregation number, $\langle N\rangle$, from entanglement model fits versus concentration.

Table S14.3.1. Best fit parameters to the Entanglement Viscosity model for each system shown in Figure 13.3.1.

\begin{tabular}{|c|c|c|}
\hline System & $\mathbf{k}$ & $-\mathbf{l n}(\mathbf{k})$ \\
\hline $\mathrm{mAb} 4: \mathrm{NaCl}$ & 2343 & -7.8 \\
\hline $\mathrm{mAb} 4: \mathrm{Arg}$ & 710 & -6.6 \\
\hline $\mathrm{mAb} 2: \mathrm{NaCl}$ & 555 & -6.3 \\
\hline $\mathrm{mAb} 2: \mathrm{Arg}$ & 135 & -4.9 \\
\hline
\end{tabular}




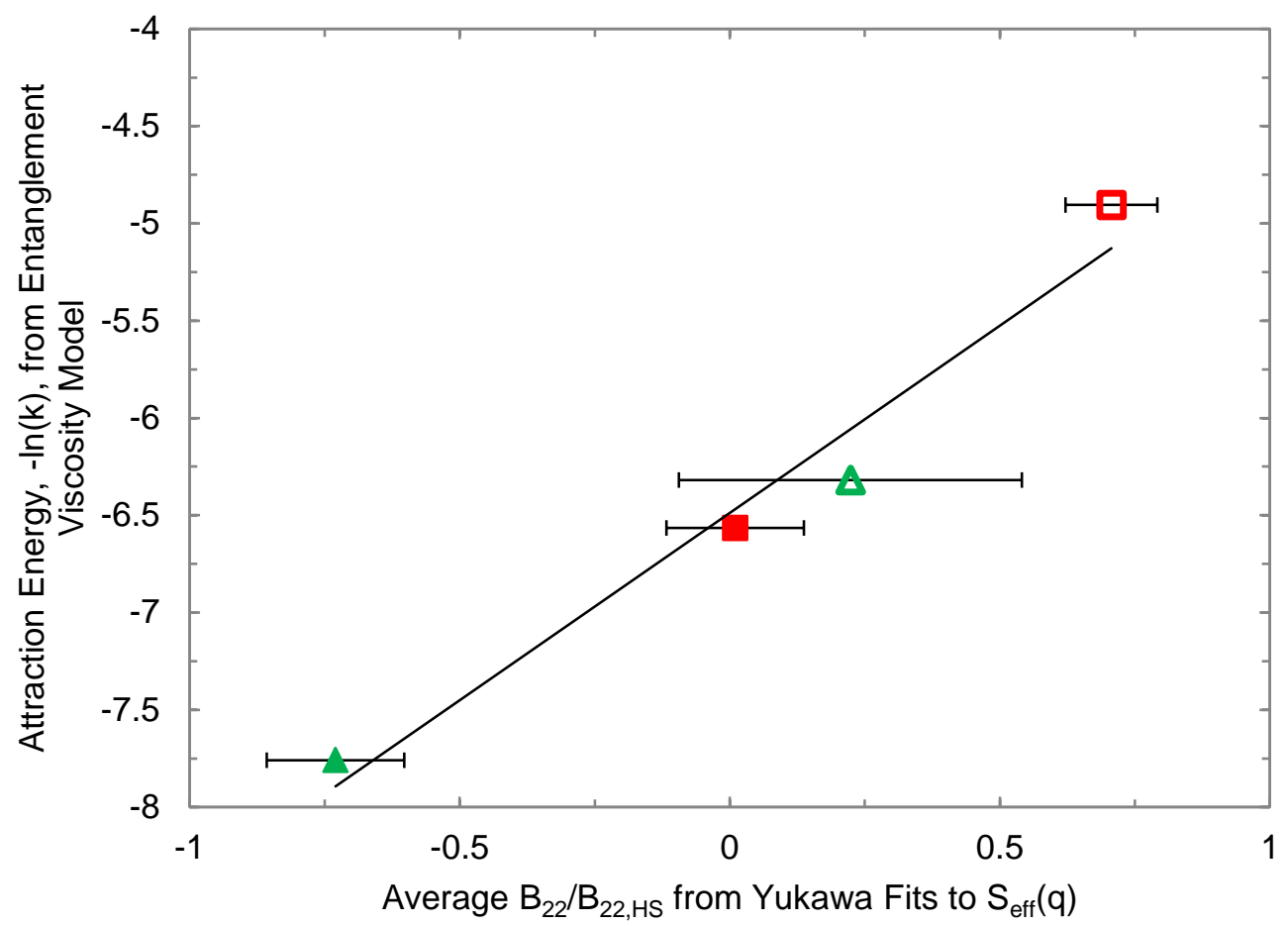

Figure S14.3.2. Correlation of attraction energy from HSY fits to SAXS Seff $(q)$ with attraction energy from viscosity entanglement model. Points include mAb2 (hollow symbols) and mAb4 (filled symbols) each with $250 \mathrm{mM}$ Arg (red squares) and with $250 \mathrm{mM} \mathrm{NaCl}$ (green triangles). The $\mathrm{B}_{22} / \mathrm{B}_{22, \mathrm{HS}}$ used are the average of each concentration of the given formulation with error bars representing the standard deviation. 


\section{Section S14.4 Modelling Viscosities by Kastelic Model}

Since all three models were able to fit the $\mathrm{S}_{\text {eff }}(\mathrm{q})$ of $\mathrm{mAb2}$ : $\operatorname{Arg}(\mathrm{All4} \mathrm{K}=0.7$, All1 K=3.2, FabFab1 K=3.5) the $p(n, c)$ was used for each of these models separately (along with that of All1 $\mathrm{K}=3.6,3.5$ for mAb4: $\mathrm{NaCl}$ ) to eqn 7, to see which models could fit the viscosity as well as the $S_{\text {eff }}(q)$. Since Fig. S14.4.1 and Fig. 8 clearly shows that only All4 $\mathrm{K}=0.7$ can fit the viscosity of $\mathrm{mAb2}$ : Arg, this model was used alongside All1 $\mathrm{K}=3.6,3.5$ for $\mathrm{mAb} 4: \mathrm{NaCl}$ and the All1 K=3.2 to fit mAb4: Arg. As seen in Fig. S14.4.1C the viscosities for all three systems can be successfully fit. $\mathrm{MAb} 2: \mathrm{NaCl}$ is not included, because none of the models fit its $\mathrm{S}_{\text {eff }}(\mathrm{q})$. Table S14.4.1 lists the fit b and d (from eqn 7) for each of these sets as well as the sum of squared errors and root mean squared error for each fit.
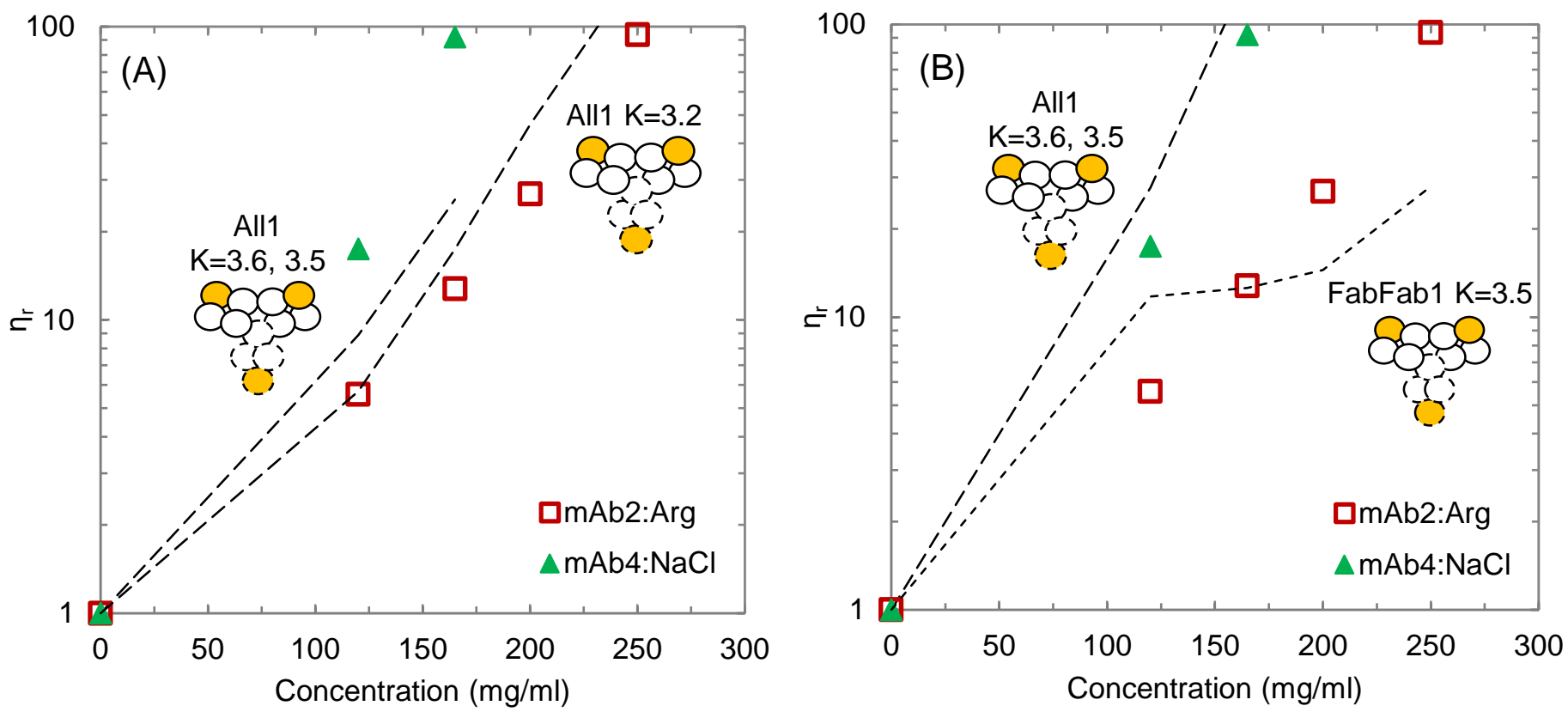


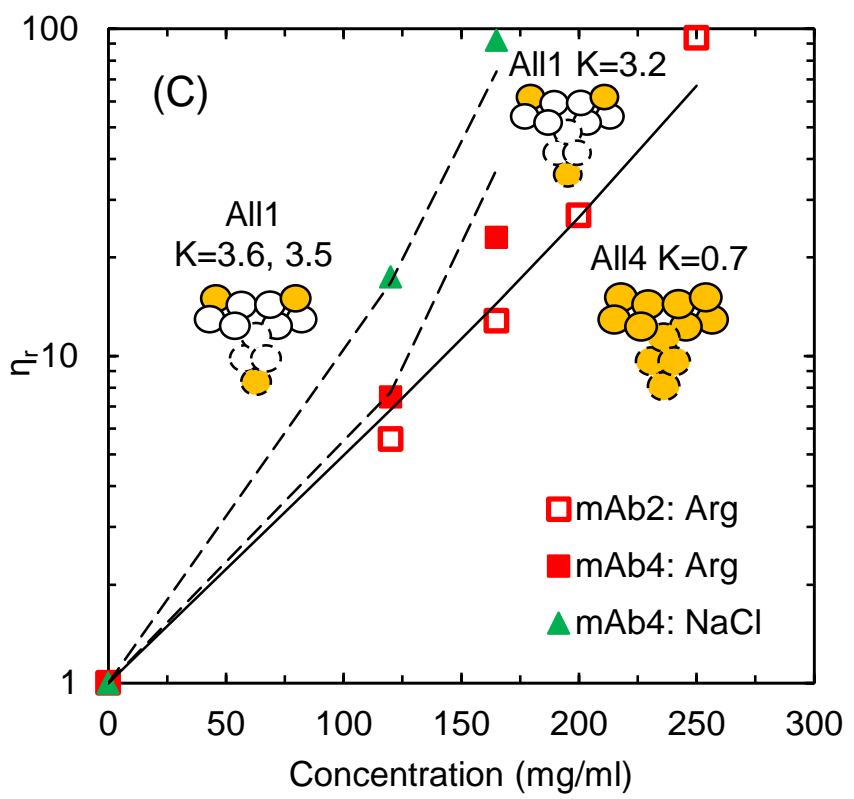

Figure S14.4.1. Relative viscosity versus $\mathrm{mAb}$ concentration for $\mathrm{mAb} 4: \mathrm{NaCl}$ and $\mathrm{mAb} 2$ : $\mathrm{Arg}$ (points) along with fits (lines) from eqn 7 using $p(n, c)$ from 12 bead model simulations of All1 K=3.6 for mAb4: $\mathrm{NaCl}$ at at $125 \mathrm{mg} / \mathrm{ml}$ and All1 K=3.5 for mAb4: $\mathrm{NaCl}$ at $165 \mathrm{mg} / \mathrm{ml}$. The $p(n, c)$ was determined for all mAb2: Arg points using (A) All1 K=3.2, (B) FabFab1 K=3.5, or (C) All4 $K=0.7$. Panel (C) also shows viscosity data for mAb4: Arg fit with All1 K=3.2. The fit $\mathrm{b}$ and d are (A) $13.8 \mathrm{ml} / \mathrm{g}$ and 0.0464, (B) $19.9 \mathrm{ml} / \mathrm{g}$ and 0.0543, and (C) $15.8 \mathrm{ml} / \mathrm{g}$ and 0.450 , respectively.

Table S14.4.1. Summary of fit parameters and corresponding sum of squared error (SSE) and RMS error from fitting Kastelic viscosity model to mAb2: Arg, mAb4: $\mathrm{NaCl}$ and in one case mAb4: Arg with the listed models.

\begin{tabular}{|c|c|c|c|c|c|c|}
\hline $\begin{array}{c}\text { Model 1 } \\
(\mathrm{mAb4}: \mathrm{NaCl})\end{array}$ & $\begin{array}{c}\text { Model 2 } \\
(\mathrm{mAb} 2: \text { Arg })\end{array}$ & $\begin{array}{c}\text { Model 3 } \\
(\mathrm{mAb4}: \text { Arg })\end{array}$ & $\mathrm{b}(\mathrm{mL} / \mathrm{g})$ & $\mathrm{d}$ & $\mathrm{SSE}$ & $\begin{array}{c}\text { RMS } \\
\text { Error }\end{array}$ \\
\hline \multirow{3}{*}{$\begin{array}{c}\text { All1 K=3.6 } \\
3.5\end{array}$} & All4 K=0.7 & None & 16.0 & 0.0687 & 0.158 & 0.162 \\
\cline { 2 - 7 } & All1 K=3.2 & None & 13.8 & 0.0464 & 2.74 & 0.678 \\
\cline { 2 - 7 } & FabFab1 K=3.5 & None & 19.9 & 0.0543 & 2.84 & 0.688 \\
\cline { 2 - 7 } & All4 K=0.7 & All1 K=3.2 & 15.8 & 0.0645 & 0.450 & 0.237 \\
\hline
\end{tabular}




\section{REFERENCES}

1. Dear, B. J.; Hung, J. J.; Truskett, T. M.; Johnston, K. P., Contrasting the Influence of Cationic Amino Acids on the Viscosity and Stability of a Highly Concentrated Monoclonal Antibody. Pharmaceutical Research (New York) 2016.

2. Borwankar, A. U.; Dear, B. J.; Twu, A.; Hung, J. J.; Dinin, A. K.; Wilson, B. K.; Yue, J.; Maynard, J. A.; Truskett, T. M.; Johnston, K. P., Viscosity reduction of a concentrated monoclonal antibody with arginine $\cdot \mathrm{HCl}$ and arginine $\cdot$ glutamate. Ind. Eng. Chem. Res. 2016.

3. Hung, J. J.; Borwankar, A. U.; Dear, B. J.; Truskett, T. M.; Johnston, K. P., High concentration tangential flow ultrafiltration of stable monoclonal antibody solutions with low viscosities. J. Membr. Sci. 2016, $508,113-126$.

4. Hung, J. J.; Dear, B. J.; Karouta, C. A.; Godfrin, P. D.; Bollinger, J. A.; Nieto, M. P.; Wilks, L. R.; Shay, T. Y.; Ramachandran, K.; Sharma, A.; Truskett, T. M.; Johnston, K. P., Protein-Protein Interactions of Highly Concentrated Monoclonal Antibody Solutions via Static Light Scattering and Influence on the Viscosity. J. Phys. Chem. B 2019, 123 (4), 739-755.

5. $\quad$ Castellanos, M. M.; Clark, N. J.; Watson, M. C.; Krueger, S.; McAuley, A.; Curtis, J. E., Role of Molecular Flexibility and Colloidal Descriptions of Proteins in Crowded Environments from Small-Angle Scattering. J. Phys. Chem. B 2016, 120 (49), 12511-12518.

6. $\quad$ Corbett, D.; Hebditch, M.; Keeling, R.; Ke, P.; Ekizoglou, S.; Sarangapani, P.; Pathak, J.; Van Der Walle, C. F.; Uddin, S.; Baldock, C.; Avendano, C.; Curtis, R. A., Coarse-Grained Modeling of Antibodies from Small-Angle Scattering Profiles. J. Phys. Chem. B 2017, 121 (35), 8276-8290.

7. Godfrin, P. D.; Zarzar, J.; Zarraga, I. E.; Porcar, L.; Falus, P.; Wagner, N. J.; Liu, Y., The Effect of Hierarchical Cluster Formation on the Viscosity of Concentrated Monoclonal Antibody Formulations Studied by Neutron Scattering. J. Phys. Chem. B 2015.

8. Inouye, H.; Houde, D.; Temel, D. B.; Makowski, L., Utility of Solution X-Ray Scattering for the Development of Antibody Biopharmaceuticals. J. Pharm. Sci. 2016, 105 (11), 3278-3289.

9. Mosbaek, C. R.; Konarev, P. V.; Svergun, D. I.; Rischel, C.; Vestergaard, B., High concentration formulation studies of an IgG2 antibody using small angle x-ray scattering. Pharm. Res. 2012, 29 (8), 22252235 .

10. Yearley, E. J.; Zarraga, I. E.; Shire, S. J.; Scherer, T. M.; Gokarn, Y.; Wagner, N. J.; Liu, Y., Smallangle neutron scattering characterization of monoclonal antibody conformations and interactions at high concentrations. Biophys. J. 2013, 105 (3), 720-731.

11. Greene, D. G.; Ferraro, D. V.; Lenhoff, A. M.; Wagner, N. J., A critical examination of the decoupling approximation for small-angle scattering from hard ellipsoids of revolution. Journal of Applied Crystallography 2016, 49 (5), 1734-1739.

12. Laue, T., Proximity energies: a framework for understanding concentrated solutions. J. Mol. Recognit. 2012, 25 (3), 165-73.

13. Calero-Rubio, C.; Saluja, A.; Roberts, C. J., Coarse-Grained Antibody Models for "Weak" ProteinProtein Interactions from Low to High Concentrations. J. Phys. Chem. B 2016, 120 (27), 6592-605.

14. Wang, G.; Varga, Z.; Hofmann, J.; Zarraga, I. E.; Swan, J. W., Structure and Relaxation in Solutions of Monoclonal Antibodies. J. Phys. Chem. B 2018, 122 (11), 2867-2880.

15. Kastelic, M.; Dill, K. A.; Kalyuzhnyi, Y. V.; Vlachy, V., Controlling the viscosities of antibody solutions through control of their binding sites. Journal of Molecular Liquids 2017. 
16. Roberts, D.; Keeling, R.; Tracka, M.; van der Walle, C. F.; Uddin, S.; Warwicker, J.; Curtis, R., The Role of Electrostatics in Protein-Protein Interactions of a Monoclonal Antibody. Mol. Pharmaceutics 2014, 11 (7), 2475-2489.

17. Genz, U.; Klein, R., Collective diffusion of charged spheres in the presence of hydrodynamic interaction. Physica A: Statistical Mechanics and its Applications 1991, 171 (1), 26-42.

18. Calero-Rubio, C.; Ghosh, R.; Saluja, A.; Roberts, C. J., Predicting protein-protein interactions of concentrated antibody solutions using dilute solution data and coarse-grained molecular models. J. Pharm. Sci. 2017.

19. Hamaker, H. C., The London-van der Waals attraction between spherical particles. Physica 1937, 4 (10), 1058-1072.

20. Bollinger, J. A.; Truskett, T. M., Fluids with competing interactions. I. Decoding the structure factor to detect and characterize self-limited clustering. The Journal of Chemical Physics 2016, 145 (6), 064902.

21. Godfrin, P. D.; Valadez-Perez, N. E.; Castaneda-Priego, R.; Wagner, N. J.; Liu, Y., Generalized Phase Behavior of Cluster Formation in Colloidal Dispersions with Competing Interactions. Soft Matter 2014, 10 (28), 5061-71.

22. Mehl, J. W.; Oncley, J. L.; Simha, R., VISCOSITY AND THE SHAPE OF PROTEIN MOLECULES. Science (New York, N.Y.) 1940, 92 (2380), 132-3.

23. Ross, P. D.; Minton, A. P., Hard quasi-spherical model for viscosity of hemoglobin solutions. Biochem. Biophys. Res. Commun. 1977, 76 (4), 971-976.

24. Kanai, S.; Liu, J.; Patapoff, T. W.; Shire, S. J., Reversible self-association of a concentrated monoclonal antibody solution mediated by fab-fab interaction that impacts solution viscosity. J Pharm Sci 2008, 97 (10), 4219-4227.

25. Yadav, S.; Shire, S. J.; Kalonia, D. S., Factors affecting the viscosity in high concentration solutions of different monoclonal antibodies. J. Pharm. Sci. 2010, 99 (12), 4812-4829.

26. Lilyestrom, W. G.; Yadav, S.; Shire, S. J.; Scherer, T. M., Monoclonal Antibody Self-Association, Cluster Formation, and Rheology at High Concentrations. J. Phys. Chem. B 2013, 117 (21), 6373-84.

27. Wang, W.; Lilyestrom, W. G.; Hu, Z. Y.; Scherer, T. M., Cluster Size and Quinary Structure Determine the Rheological Effects of Antibody Self-Association at High Concentrations. J. Phys. Chem. B 2018, 122 (7), 2138-2154.

28. Schmit, J. D.; He, F.; Mishra, S.; Ketchem, R. R.; Woods, C. E.; Kerwin, B. A., Entanglement model of antibody viscosity. J. Phys. Chem. B 2014, 118 (19), 5044-9. 